\title{
SARS-CoV-2 Nsp14 mediates the effects of viral infection on the host cell transcriptome
}

Michela Zaffagni ${ }^{1}$, Jenna M Harris ${ }^{1}$, Ines L Patop ${ }^{1}$, Nagarjuna Reddy Pamudurti ${ }^{1}$, Sinead

Nguyen $^{1}$, and Sebastian Kadener ${ }^{1}$

${ }^{1}$ Department of Biology, Brandeis University, Waltham, MA, USA

Key words: SARS-CoV-2, Nsp14, IMPDH2, circRNA, CXCL8, transcription, splicing. 


\section{SUMMARY}

Viral infection involves complex set of events orchestrated by multiple viral proteins. To identify functions of SARS-CoV-2 proteins, we performed transcriptomic analyses of cells expressing individual viral proteins. Expression of Nsp14, a protein involved in viral RNA replication, provoked a dramatic remodeling of the transcriptome that strongly resembled that observed following SARS-CoV-2 infection. Moreover, Nsp14 expression altered the splicing of more than 1,000 genes and resulted in a dramatic increase in the number of circRNAs, which are linked to innate immunity. These effects were independent of the Nsp14 exonuclease activity and required the N7-guanine-methyltransferase domain of the protein. Activation of the NFkB pathway and increased expression of $C X C L 8$ occurred early upon Nsp14 expression. We identified IMPDH2, which catalyzes the rate-limiting step of guanine nucleotides biosynthesis, as a key mediator of these effects. Nsp14 expression caused an increase in GTP cellular levels, and the effect of Nsp14 was strongly decreased in presence of IMPDH2 inhibitors. Together, our data demonstrate an unknown role for Nsp14 with implications for therapy. 


\section{INTRODUCTION}

Severe acute respiratory syndrome coronavirus 2 (SARS-CoV-2) is the virus responsible for the COVID-19 pandemic that began in 2019. As of early February, 2022, COVID-19 has caused 5.7 million deaths worldwide. Coronaviruses are enveloped, relatively small (60-140 nm diameter), positive-stranded RNA viruses belonging to the Coronaviridae family. They derive their name from the crown-like appearance (corona means crown in Latin) that results from the spike glycoproteins in their envelope (V'kovski et al., 2021a). The SARS-CoV-2 RNA genome is 30-kb long and has 14 open reading frames (ORFs) that encode 29 proteins (16 non-structural proteins, 4 structural proteins, and 9 accessory factors, Kim et al., 2020). During the first step of the viral infection, the spike glycoprotein mediates attachment and fusion with the cellular membrane. Once the virus is in the cytoplasm of the host cells, the host ribosome machinery is recruited for the synthesis of viral proteins. Non-structural proteins are required for viral genome replication and are generated by proteolytic cleavage of the polyprotein encoded by ORF1a and ORF1ab. Once the viral genome is replicated, virions are assembled in the host endoplasmic reticulum-Golgi intermediate complex. Finally, new viral particles are incorporated into vesicles and secreted by the host cells (V'kovski et al., 2021a).

Viral infection triggers a variety of pathways in the host cells that ultimately lead to the hijacking of the cellular machineries and escape from immune surveillance. SARS-CoV-2 infection elicits a peculiar gene expression response that first involves activation of interferon pathway (Blanco-Melo et al., 2020; Vanderheiden et al., 2020; Wyler et al., 2021), and then the NFkB pathway (Kircheis et al., 2020; Hariharan et al., 2021; Wyler et al., 2021), as well as expression of specific cytokines such as IL6 and IL8 (Wang et al., 2007; Blanco-Melo et al., 2020; Coperchini et al., 2020; Park and Lee, 2020). 
Recent and intense research on SARS-CoV-2 characterized the role of viral proteins during viral replication, and showed that these functions are often conserved across coronaviruses (V'kovski et al., 2021a). Less is known about the roles of the individual proteins in modulating host cell pathways (Gordon, Hiatt, et al., 2020; Gordon, Jang, et al., 2020). For instance, recent studies have proposed that Nsp16 is a splicing modulator (Banerjee et al., 2020) and that Nsp1 and Nsp14 are translational repressors (Schubert et al., 2020; Hsu et al., 2021).

Nsp14 is a $60-\mathrm{kDa}$ protein conserved among coronaviruses that is involved both in viral replication and immune surveillance escape (Ogando et al., 2020). The N-terminal region of Nsp14 contains an exonuclease domain (ExoN) that excises mismatched nucleotides to ensure accurate replication of the viral genome (Ogando et al., 2020). As a result of this proofreading mechanism, coronaviruses have a lower mutation rate than other RNA viruses (error rate of $10^{6}-10^{7}$ versus $10^{3}$ $10^{5}$ ) (Sanjuán et al., 2010; Robson et al., 2020). Loss of function of the ExoN domain results in increased sensitivity to the RNA mutagen 5-fluorouracil (Eckerle et al., 2010) and attenuated virulence (Graham et al., 2012). Furthermore, the interaction with Nsp10 augments Nsp14 ExoN activity up to 35 fold, and inhibition of the interaction between Nsp10 and Nsp14 leads to reduced replication fidelity (Ma et al., 2015a; Smith et al., 2015). Nsp14 is also involved in assembly the cap at the 5' end of the viral RNA genome, which is crucial for evading immune surveillance. The C-terminal region of Nsp14 functions as an S-adenosyl methionine-dependent guanine-N7 methyl transferase that is independent of the ExoN activity (Chen et al., 2009). Both enzymatic domains are essential for successful viral replication, making Nsp14 an appealing drug target (Otava et al., 2021; Saramago et al., 2021).

Nsp14 is part of the Replication Complex, therefore it interacts with other SARS-CoV-2 proteins. As for other coronaviruses, replication of SARS-CoV-2 genome takes place in replication 
organelles that provide a protective environment for the newly synthesized viral genome(V'kovski et al., 2021b). Notably, these organelles are formed in the cytoplasm and present convoluted double layered membranes that likely exchange material with the cytoplasm through pores (Wolff et al., 2020).

Furthermore, Nsp14 might mediate immune surveillance escape by activating the interferon pathway and activating the pro-inflammatory response through NFkB transcriptional activity and CXCL8 expression (Yuen et al., 2020; Hsu et al., 2021; Li et al., 2021). However, the biological mechanism behind these events has not fully characterized. Furthermore, a global interactome study showed that Nsp14 interacts with the cellular enzyme inosine-monophosphate dehydrogenase 2 (IMPDH2) and that this interaction is conserved also in SARS-CoV-1 and MERS-CoV viruses (Gordon, Hiatt, et al., 2020; Gordon, Jang, et al., 2020). IMPDH2 catalyzes the conversion of inosine-5'-monophosphate (IMP) to xanthine-5'-monophosphate (XMP) (Hedstrom, 2009), which is the rate-limiting step of de novo guanine nucleotides biosynthesis. Guanosine-5'-triphosphate (GTP) is necessary for DNA replication and transcription and is used as energy source for translation and as mediator of signal transduction (Hesketh and Oliver, 2019). How the physical interaction between Nsp14 and IMPDH2 impacts the host pathways is not completely understood (Li et al., 2021).

Interestingly, a recent study has shown that expression of Nsp14 results in global translation inhibition, but it is not clear if this is a direct effect or a downstream consequence of the changes that the expression of this protein provokes to the cellular environment (Hsu et al., 2021). Indeed, no direct interaction between Nsp14 and ribosomes or a known translational modulator has been reported, suggesting that the potential translational inhibition might be a downstream effect. 
Here we undertook transcriptome analyses in cells that express each SARS-CoV-2 protein individually. Nsp14 altered the expression of about 4,000 genes, mostly involved in splicing, RNA metabolism, and cell-cycle control. Importantly, the effect of Nsp14 on cellular gene expression resembled the transcriptional changes that occur upon SARS-CoV-2 infection and included the activation of the NFkB pathway and the expression of CXCL8 (encoding IL8), a marker of acute severe respiratory distress syndrome in COVID-19 patients (Adcock et al., 2015; Blanco-Melo et al., 2020; Kircheis et al., 2020). Intriguingly, we also detected an increase in circRNAs expression upon Nsp14 expression; recent studies indicate that circRNAs can act as modulators of the innate immune response during viral infections (Li et al., 2017; Liu et al., 2019; Chen et al., 2020; Yan and Chen, 2020). Moreover, we showed that the cellular enzyme IMPDH2 mediates the gene expression response induced by Nsp14. We found that IMPDH2 mRNA is downregulated upon Nsp14 expression and that the cellular GTP concentration strongly increases, indicating that Nsp14 might activate IMPDH2 enzymatic activity. In accordance with our hypothesis, we showed that treatment with IMPDH2 inhibitors (Mycophenolic acid and Mizoribine, Seungheon Lee et al., 2020) partially rescued the changes in gene expression induced by Nsp14.

\section{RESULTS}




\section{Expression of individual SARS-CoV-2 proteins specifically remodels the transcriptome}

Infection of cells with SARS-CoV-2 induces strong and specific changes in the transcriptome of host cells and tissues (Blanco-Melo et al., 2020; Wyler et al., 2021). It is assumed that this response results from the hijacking of the cellular systems by the virus as well as from the defense by the host. To identify unknown functions of the individual SARS-CoV-2 proteins and to determine how much each protein contributes to the takeover of cellular systems, we determined how the transcriptome changed when we individually express each viral protein in a human cell line. Specifically, we expressed individual SARS-CoV-2 proteins (Gordon, Jang, et al., 2020) in HEK293T cells, and after 48 hours we purified RNA, generated and sequenced 3' RNA-seq libraries, and identified differentially expressed genes (DEGs; Figure 1A). Extensive cell death or changes in morphology did not occur upon expression of individual proteins, as assessed visually.

Interestingly, expression of most proteins resulted in modest or no changes in the transcriptome of the HEK293T cells. Indeed, we detected less than 300 DEGs upon expression of 17 of the 25 tested proteins (Table 1 and Figure 1B). Expression of seven viral proteins, M, Nsp9, E, ORF9b, ORF3a, Nsp13, and Nsp1, modestly altered the transcriptome (between 300 and 700 DEGs). Interestingly, these DEGs tended to be upregulated rather than downregulated (Figure 1B). Striking, Nsp14 altered the expression of more than 4,000 RNAs (1,862 upregulated and 2,161 downregulated; Figure 1B). The profound impact of Nsp14 expression on the transcriptome of HEK293T cells suggests that this protein has roles beyond its known functions in viral genome proofreading and immune system escape.

To identify cellular pathways affected by the expression of the individual SARS-CoV-2 proteins, we performed Gene Ontology (GO) analysis of the DEGs upon expression of the different viral proteins (Table 2 and Figure 1C). Expression of the viral proteins impacted mRNAs encoding 
proteins related to different aspects of gene expression (regulation of transcription, translation, and RNA metabolism), cell metabolism, cell division, and innate immunity. For example, expression of Nsp7, an accessory protein of the RNA-dependent RNA polymerase (Kirchdoerfer and Ward, 2019; Hillen et al., 2020), deregulated expression of genes encoding proteins involved in DNA and RNA metabolism (Figure 1C). Expression of Nsp9 and Nsp13, known to bind RNA and to regulate RNA metabolism, respectively (Egloff et al., 2004; Shu et al., 2020), resulted in the misregulation of mRNAs encoding proteins involved in RNA metabolism and translation (Figure 1C). Furthermore, expression of the protein ORF3b, known to be an interferon inhibitor (Konno et al., 2020), resulted in alteration of genes involved in cell metabolism and immunity. Indeed, the interferon response is known to impact several metabolic pathways, including carbohydrate catabolism (reviewed in Konno et al., 2020), and genes involved in these pathways are downregulated upon ORF3b expression (Figure 1C). In general, expression of the viral proteins mainly impacted pathways related to RNA metabolism, translation, and cell metabolism that were previously reported to be affected upon viral infection (Blanco-Melo et al., 2020; Gardinassi et al., 2020; Wyler et al., 2021). Nsp14 affected the expression of genes involved in RNA splicing, metabolism, and processing, translation, cell-cycle control, and the cytoskeleton. Nsp14 also impacted the expression of genes involved in general metabolism, especially on genes implicated in nucleotide metabolism (Figure 1C).

\section{Nsp14 expression induces transcriptional changes that resemble SARS-CoV-2 infection}

We decided to focus on Nsp14, as expression of this protein resulted in significantly more DEGs than any other tested protein. To obtain a more comprehensive view of the transcriptome changes provoked by Nsp14, we complemented the 3' RNA-seq data with total RNA-seq data 
generated from cells transfected with Nsp14. The new dataset strongly resembled the one obtained by 3' RNA-seq (Figure 2A, Table 3, and Figure 2 - figure supplement 1A) but also contained information about the full-length RNAs, non-poly-adenylated RNAs, and pre-mRNAs.

To gain further insights into the mechanism and pathways altered by Nsp14, we performed Gene Set Enrichment Analysis (GSEA) of the total RNA-seq data from Nsp14-expressing cells. Strikingly, we found that for genes upregulated upon expression of Nsp14, three of the four most highly enriched GSEA datasets were those of cells infected with SARS-CoV-2 (Blanco-Melo et al., 2020) (Figure 2B, 2C, and Figure 2 - figure supplement 1B). Moreover, we observed a smaller but significant enrichment of genes upregulated upon infection with MERS, a related virus (Blanco-Melo et al., 2020). Further, the mRNAs downregulated upon expression of Nsp14 tended to be strongly enriched for those downregulated following SARS-CoV-2 viral infection (Figure 2B). We did not detect enrichment when our dataset were compared to data from cells infected with influenza A virus (IAV) (Blanco-Melo et al., 2020) (Figure 2B). These results demonstrate that expression of a single viral protein can recapitulate a considerable portion of response of a host cell to SARS-CoV-2 infection and highlights the potential importance of Nsp14 in hijacking host gene expression.

\section{Nsp14 alters gene expression mostly at the transcriptional level}

To evaluate whether the transcriptome changes were due to alterations at the transcriptional or post-transcriptional level or a combination of both, we utilized intronic signals from the total RNA-seq experiment as a proxy for transcriptional activity (Stuart Lee et al., 2020). For each DEG in the 3' RNA-seq dataset, we determined whether the intronic signal in the total RNA-seq dataset was altered in the same direction. We observed a strong correlation $\left(\mathrm{R}=0.73\right.$ and $\mathrm{p}$-value $\left.=2.2 \mathrm{e}^{-16}\right)$ 
between these two measures (Figure 2D), indicating that a large part of the response is transcriptional. For example, of the 1,862 genes that were upregulated upon Nsp14 expression, 1,006 also had higher intronic signal (at least 20\% signal increase), whereas only 57 of the showed decreased intronic signal. Similarly, of the 2,161 genes downregulated upon Nsp14 expression, 1,242 displayed lower intronic signal (at least 20\% signal decrease), whereas only 109 showed higher intronic signal (Table 4). We then performed a similar analysis using the exonic signal of DEGs in the same total RNA-seq dataset. We obtained an even stronger correlation between the changes in exonic signal and total RNA signal for each gene $\left(\mathrm{R}=0.87\right.$ and $\mathrm{p}$-value $=2.2 \mathrm{e}^{-16}$, Figure 2E). In sum, we observed that more than $50 \%$ of the changes in the transcriptome upon Nsp14 expression are transcriptional. Notably, this might be an underestimation, as changes in intronic signal could be lower than the steady-state RNA levels or some introns could be very efficiently and quickly removed, so that splicing intermediates are not detected. To further confirm the transcriptional effect, we determined the levels of a subset of DE genes from chromatin-bound nascent RNA from cells transfected with a control or a Nsp14-expressing plasmid. As expected a pre-mRNA (pre-TBP), was enriched in the chromatin bound fraction, U6 was abundant in the nuclear compartment (nucleoplasm and chromatin bound), whereas $18 S$ rRNA and a circRNA (circVKR1) were more abundant in the cytoplasm (Figure 2 - figure supplement 2A). Then, we checked the expression of some genes that were up or down regulated upon Nsp14 expression in our dataset in the chromatin bound fraction. Genes upregulated upon Nsp14 expression (FGF-18 and $C X C L 8$ ) were also upregulated in the chromatin bound fraction, while the downregulated ones (SH2D2A and COL13A) were downregulated indicating that at least those mRNAs are regulated at the transcriptional level by Nsp14. These results verify the genomic observations and strongly suggest that the gene expression changes observed upon Nsp14 are mainly transcriptional (Figure 
2F). Interestingly, we also observed that there are more than 1,000 genes that display higher intronic signals with no changes in gene expression, indicating that, in addition to the transcriptional effects, Nsp14 might also affect splicing (Table 5).

\section{Nsp14 expression provokes changes in alternative splicing and circRNAs production}

Genes upregulated upon Nsp14 expression are enriched in genes encoding proteins with GO terms related to RNA metabolism and, more specifically, splicing (Figure 1C). Moreover, for more than 1,000 genes, there were significant increases in intron signal upon expression of Nsp14 without changes in mRNA levels, suggesting that Nsp14 alters the splicing of these pre-mRNAs (Table 5). Indeed, we found that expression of Nsp14 strongly altered the inclusion patterns of almost 2,300 exons, with more than 2,000 exons displaying lower inclusion in the mature mRNA and 238 showing higher levels of inclusion when we expressed Nsp14 (Figure 3A, Table 5, and Figure 3 - figure supplement 1A). Furthermore, we also identified genes which used alternative acceptor or donor splice sites upon expression of Nsp14 (Figure 3A and Table 5). Moreover, we observed an increase in the retention of more than 2,000 introns following Nsp14 expression (Figure 3A and Figure 3C). Although the effects on exon inclusion and use of alternative splice sites clearly indicate that Nsp14 influences splicing, the increase in intron retention could be secondary to changes in transcription. However, as most of the introns with increased retention are within genes that were not differentially expressed (Figure 3B and Figure 3 - figure supplement 1B), we reasoned that expression of Nsp14 leads to changes in splicing in this subset of genes as well. Moreover, the effect of Nsp14 on alternative splicing appears to be specific to particular introns and exons in each gene, as the majority $(\sim 62 \%)$ of identified genes had a single spicing event altered (Figure 3D and Table 5). Notably, most genes with altered splicing do not show 
expression changes upon Nsp14 expression, further indicating that the detected alternative splicing events are independent to transcriptional changes (Figure 3 - figure supplement 1B).

To further characterize the effects of Nsp14 expression on alternative splicing, we looked for genomic features associated with the altered patterns of splicing in the presence of Nsp14. Interestingly, we found that the affected introns tended to be at the 5' end of the transcript and were embedded in genomic regions with higher-than-average GC content (Figure 3 - figure supplement $1 \mathrm{C}$ and Table 6). The GC content may be a confounding factor of the location of these introns, as the GC content is higher at the 5' end of genes and around the transcription start sites (Zhang et al., 2004). Therefore, we concluded that Nsp14 expression has a strong and specific effect on splicing efficiency for a subset of genes.

Furthermore, most of the affected exons are shorter and have higher GC content around their splice sites than a randomized subset of exons not affected by Nsp14 (Figure 3 - figure supplement 1D and Table 6). The higher GC content suggests that stable RNA structures form around the splice sites in these exon, which correlates with alternative splicing propensity (Zhang, Kuo and Chen, 2011; Lin, Taggart and Fairbrother, 2016).

Previous research showed that SARS-CoV-2 infection disrupts splicing, mostly by inducing intron retention (Banerjee et al., 2020). To check whether the effects on splicing induced by Nsp14 were comparable to the ones that happen during SARS-CoV-2 infection, we reanalyzed a published dataset of total RNA sequencing from HEK293T cells expressing human ACE2 and infected with SARS-CoV-2 (Sun et al., 2021). We found that there is a significant overlap ( $\mathrm{p}$-value $<10^{-15}$, see Material and Methods) between the alternative splicing events during the infection and in our model. Specifically, $10 \%$ of the alternative splicing events changing with SARS-CoV-2 infection (Table 7) also change (and in the same direction) when we express Nsp14 
(Table 5). In sum, we showed that expression of Nsp14 partially recapitulates the gene expression changes, as well as some of the alternative splicing events that occur upon SARS-CoV-2 infection.

As circRNAs are generated by back-splicing, a process that competes with linear premRNA splicing (Ashwal-Fluss et al., 2014), we checked whether Nsp14 also alters circRNAs expression. Using the total RNA-seq data, we found that there is a strong increase (more than 2 fold) in the total number of circRNA reads upon Nsp14 expression (Figure 3E). Most of the 246 circRNAs that were differentially expressed upon expression of Nsp14 were upregulated (put the number of upregulated; Figure $3 \mathrm{~F}$ and Table 8). These deregulated circRNAs were contained within 190 loci (some loci host multiple circRNAs). Interestingly, the levels of most of the mRNAs that host these circRNAs were unchanged (Figure 3G and Table 4). Indeed, Nsp14 did not increase the transcription of loci hosting the upregulated circRNAs (we observed increased levels of intronic sequences in only 20 out of the 190 loci with upregulated circRNAs; Figure 3H and Table 4). Together, these results strongly suggest that the increased circRNA levels are caused by increased biosynthesis or stability of the circRNAs. In sum, our data shows that expression of Nsp14 influences alternative splicing and back-splicing on the host cells.

\section{The effect of Nsp14 on gene expression is independent of the exonuclease activity but requires the N7-guanine-methyltransferase domain}

Nsp14 has two separated enzymatic activities: (1) it works as a proofreading exonuclease, and (2) it is a N7-guanine-methyltransferase required for the modification of the viral RNA cap. To determine whether the exonuclease activity is required for the strong effects of Nsp14 on gene expression, we performed two different experiments. First, we tested whether co-expression of Nsp10, which dramatically increases the exonuclease activity of Nsp14 (Bouvet et al., 2012, 2014; 
Ma et al., 2015a), resulted in an enhanced effect of Nsp14. Briefly, we transfected HEK293T cells with plasmids for expressing Nsp14 and/or Nsp10. As a control, we used cells transfected with an empty vector. Co-expression of Nsp14 and Nsp10 did not impact levels of Nsp14 protein (Figure 4A). We then prepared RNA from these samples and quantified the expression of some mRNAs that were altered upon expression of Nsp14 alone. For instance, the levels of FGF-18 increased upon expression of Nsp14 alone, whereas the levels of $S H 2 D 2 A$ were significantly downregulated (Figure 4 - figure supplement 1A). Interestingly, expression of Nsp10 alone or in combination with Nsp14 did not further alter the levels of any of the mRNAs tested (Figure 4 - figure supplement 1A). To determine whether the effect is global, we prepared and sequenced total RNA from these samples. Principal component analysis (PCA) showed that data from samples expressing Nsp14 alone separated from the data from the sample transfected with the empty plasmid, whereas that the ones from the samples expressing only Nsp10 almost overlapped with the control. Coexpression of Nsp14 and Nsp10 resulted in transcriptional changes like the ones induced by expression of only Nsp14 (Figure 4 - figure supplement 1B). Unlike expression of Nsp14, which provoked a strong remodeling of the mRNA and circRNA populations (Figure 1, Figure 2 and Figure 3), expression of Nsp10 did not considerably alter the gene expression profile (only 88 DEGs, Figure 4B, 4C, and Figure 4 - figure supplement 1C). As also suggested by the RT-qPCR experiments (Figure 4 - figure supplement 1A), the gene expression profiles of cells transfected with Nsp14 alone or in combination with Nsp10 are strikingly similar. Indeed, we observed an almost complete overlap between the DEGs resulting from Nsp14 expression and from coexpression of Nsp14 and Nsp10, and there was a very strong correlation between the fold change in DEGs upon Nsp14 expression with and without Nsp10 co-expression (Figure 4B and 4C). Moreover, co-expression of Nsp10 did not result in additional differentially expressed mRNAs 
(Figure 4B and Figure 4C) and did not alter of the number of circRNAs reads (Figure 4D) compared to expression of Nsp14 alone. These data strongly suggests that the Nsp14 exonuclease activity is not responsible for the dramatic effects of Nsp14 expression on the transcriptome.

To definitely test whether the exonuclease activity is related to the remodeling of gene expression upon Nsp14 expression, we determined the effect of Nsp14 ExoN mutants on gene expression. Briefly, we generated plasmids for expression of Nsp14 with mutations in the ExoN domain: the double mutant D90A/G92A and the single mutant D273A (Figure 4E, schematic Figure 4 - figure supplement 2A). These mutations have been previously shown to completely inhibit the exonuclease activity of Nsp14 (Ma et al., 2015a; Ogando et al., 2020). We generated and sequenced 3' RNA-seq libraries from cells that expressed wild-type or ExoN-mutant Nsp14 proteins or eGFP, as a control. PCA indicated that the two mutants have overlapping transcriptomes that differed from the control (Figure 4 - figure supplement 2B). The mutations in the exonuclease domain did not alter the strong effects induced by Nsp14 expression (Figure 4 figure supplement $2 \mathrm{C}$ ) and the fold changes in mRNA expression induced upon expression of the wild-type or mutated Nsp14 were also strikingly similar (Figure 4E). Moreover, we did not detect significant differences in the expression of the three tested circRNAs between samples that expressed the wild-type Nsp14 (Nsp14 WT) and the ExoN mutants (Figure 4 - figure supplement 2D). Taken together, these data indicate that the exonuclease activity of Nsp14 is not required for the observed transcriptome effects.

We also generated a N7-guanine-methyltransferase mutant (Nsp14 D331A), by altering a conserved site previously shown to be essential for the N7-guanine-methyltransferase activity (Jin et al., 2013) (schematic Figure 4 - figure supplement 2A). Then, we checked by RT-qPCR how Nsp14 D331A affects the expression of some mRNAs and circRNAs that are deregulated with 
Nsp14 WT. Interestingly, overexpression of Nsp14 D331A does not alter the expression of the tested targets (Figure $4 \mathrm{G}$ and $4 \mathrm{H}$ ). The lack of effect is not due to low expression or stability of the Nsp14 D331A mutant, as it was expressed at similar levels than Nsp14 WT as assessed by Western Blot (Figure 4 - figure supplement 2E). In summary, our results indicate that the N7guanine-methyltransferase domain of Nsp14 is required for driving the gene expression changes described in this study.

\section{Dissecting the transcriptome changes upon Nsp14 expression}

To gain further insights into the gene expression program orchestrated by Nsp14, we performed a time-course experiment. Briefly, we prepared and sequenced 3' RNA-seq libraries using RNA isolated from cells transfected with the Nsp-14 expressing plasmid 6, 8, 12, 24, and 48 hours after transfection. As a control, we collected data from cells transfected with a control plasmid (eGFP) harvested at the same time points. Importantly, we observed detectable levels of Nsp14 mRNA and protein even early after transfection (Figure 5 - figure supplement 1A and 1B). As expected, the biological triplicates mapped together in the PCA (Figure 5A). Data diverged across time and between control and Nsp14 expressing cells. The effect of Nsp14 expression dramatically increased over time with a gradual increase in the number of DEGs (Figure 5B, Figure 5 - figure supplement 1C, and Table 9), as well as an increase in the number of significantly enriched GO terms (Figure 5C and Table 10). For example, expression of genes related to cell metabolism, RNA metabolism, and cell cycle were altered relative to the control only at 24- and 48-hours post transfection (Figure 5C).

We reasoned that the mRNAs that were differentially expressed at early time points could provide cues regarding the mechanism of action of Nsp14. We observed only 19 DEGs at the 8- 
hour time point and 200 DEGs at the 12-h time point (Figure 5B). Interestingly, CXCL8, which encodes IL8, was the most highly induced mRNA at the 8-hour time point (fold change $=11.5$, pvalue $=1.2 \mathrm{e}^{-5}$, Table 8 ). Furthermore, we found that $C X C L 8$ was induced by more than 12 -fold consistently between 8 and 48 hours post transfection (Figure 5D). It was previously reported that CXCL8 mRNA is significantly upregulated following infection of cells with SARS-CoV-2 and that the levels of IL8 are increased in COVID-19 patients (Blanco-Melo et al., 2020; Coperchini et al., 2020; Del Valle et al., 2020; Gardinassi et al., 2020; Li et al., 2021).

To investigate whether Nsp14 expression induces the transcription of CXCL8, we generated a firefly luciferase reporter under the control of the CXCL8 promoter $(-500$ bp to +80 bp around the transcription start site, Figure 5 - figure supplement 1E). Expression of Nsp14 led to an almost 4-fold increase in the signal from the luciferase reporter (Figure 5E), indicating that Nsp14 expression activates $C X C L 8$ transcription.

CXCL8 expression is controlled by several transcription factors, including NFkB, a master regulator of inflammation (Kunsch and Rosen, 1993). Recent reports have shown that NFkB is activated during infections with SARS-CoV and SARS-CoV-2, although the mechanism and the importance of this activation are not well-established (Liao et al., 2005; Kircheis et al., 2020; Park and Lee, 2020; Hariharan et al., 2021; Hsu et al., 2021; Li et al., 2021). Strikingly, some of the top upregulated RNAs at 8-hours post transfection of Nsp14 were NFKBIA, JUN, and ATF3 (Figure 5 - figure supplement 1D), which encode proteins involved in the activation and modulation of the NFkB pathway (Stein et al., 1993; Baldwin, 1996; Pahl, 1999).

To determine if NFkB activation contributes to the early response of cells following Nsp14 expression, we performed an unbiased analysis for transcription factor binding site enrichment on the promoter regions of the genes with strong upregulation at the 8-hour time point. We found a 
significant enrichment in those promoters for binding sites recognized by components of the NFkB transcription complex and the NFkB regulatory network (Figure 5F, Table 11, and Table 12, Stein et al., 1993; Baldwin, 1996; Pahl, 1999). We next tested whether expression of Nsp14 activates a luciferase reporter containing a minimal promoter and NFkB sites (Wilson et al., 2013). Indeed, we observed that expression of Nsp14 lead to an approximately 1.6-fold increase in the luciferase signal (Figure 5 - figure supplement 1F), demonstrating that this viral protein activates the NFkB pathway.

Then, for the mRNAs strongly upregulated early after Nsp14 transfection, we performed an analysis of their extended promoter regions (1,000 bp upstream of the transcription start site).We found that these regions were enriched for binding sites for factors involved in the interferon response such as EGR2, STAT2, and SP3 (Table 13). Previous work showed that SARSCoV-2 infection modulates both the interferon and the NFkB pathways (Blanco-Melo et al., 2020; Vanderheiden et al., 2020; Wyler et al., 2021) and that Nsp14 affects these pathways (Hsu et al., 2021; Li et al., 2021). Our data indicates that the initial response to Nsp14 expression involves modulation of both the NFkB and the interferon pathways.

\section{IMPDH2 partially mediates the transcriptional changes induced by Nsp14 expression}

Given the strong transcriptional changes we observed upon Nsp14 expression, it is possible that this viral protein acts directly as a transcription factor. However, previous research showed that Nsp14 localizes in the cytoplasm when expressed in HEK293T cells (Gordon, Hiatt, et al., 2020). We then performed subcellular fractionation and chromatin purification, followed by Western Blot at different timepoints after transfection, and we showed that Nsp14 localizes in the 
cytoplasm, and it does not associate with chromatin demonstrating that the transcriptional effect is indirect (Figure 6 - figure supplement 1A).

Recent proteomics studies found that Nsp14 interacts with the host protein IMPDH2 (Gordon, Hiatt, et al., 2020; Gordon, Jang, et al., 2020), which catalyzes the rate-limiting step of guanine biosynthesis, but did not reveal whether this interaction results in any metabolic or cellular change (Li et al., 2021). One possibility is that Nsp14 activates IMPDH2 which then modulates gene expression directly or indirectly. In support of this possibility, expression of Nsp14 changed the levels of genes involved in purine metabolism (Fig 1C). Furthermore, we found IMPDH2 mRNA expression significantly downregulated upon Nsp14 expression (Figure 6A). As GTP levels inversely regulate IMPDH2 expression (Glesne, Collart and Huberman, 1991), we hypothesized that Nsp14 promotes the activation of IMPDH2, leading to higher GTP levels that, in the end, negatively regulate $I M P D H 2$ mRNA. To test whether expression of Nsp14 alters IMPDH2 activity, we performed metabolomic analysis of lysates of cells transfected with a plasmid for expression of Nsp14 or a control plasmid. Consistent with modulation of IMPDH2 activity by Nsp14, we detected an approximately 3-fold increase in the levels of xanthine diphosphate and GTP (Figure 6B and Table 14), the downstream products of XMP. Furthermore, we observed increased concentrations of other nucleotides that directly or indirectly derive from IMP (Figure 6B and Table 14), probably due to activated compensatory pathways.

To determine if IMPDH2 activity mediates the Nsp14-driven changes in gene expression, we compared the gene expression changes upon Nsp14 expression in the presence of an IMPDH2 inhibitor. Briefly, we transfected cells with a Nsp14 or with a control plasmid (eGFP) and 8 hours later treated the cells with Mycophenolic acid (MPA), a non-isoform-selective pan-IMPDH inhibitor, or DMSO. We harvested the cells 40 hours after the treatment. We used a concentration 
of MPA of $0.5 \mu \mathrm{M}$ to avoid cytotoxic effects (Qasim et al., 2011). Although we treated the cells with a low concentration of MPA, MPA treatment could reduce the concentration of cellular GTP, which is the primary energy source for mRNA translation. We confirmed that MPA treatment did not alter Nsp14 or IMPDH2 levels by Western Blot (Figure 6C).

We next performed 3' RNA-seq on the same samples. Interestingly, we observed that MPA treatment diminishes the effects induced by expression of Nsp14 (Figure 6D, Figure 6 - figure supplement 1B, and Figure 6 - figure supplement 2A). We detected only 115 DEGs in cells treated with MPA compared to control cells. In cells expressing Nsp14, we detected 3,761 DEGs. By contrast, there were only 1,245 DEGs in cells expressing Nsp14 that we treated with MPA compared to control cells, demonstrating that about $73 \%$ of the changes depends on the activity of IMPDH2 (Figure 6E). Approximately 1,000 genes were deregulated in cells expressing Nsp14 with or without MPA (Figure 6 - figure supplement 2B). In addition, the effect of those genes still differentially expressed was smaller in presence of MPA. This can be seen by comparing the distribution of fold changes of the DEGs (Figure 6F). When we treated cells expressing Nsp14 with MPA, the distribution of fold change narrowed, indicating that MPA treatment mitigates the effects of Nsp14 even in those mRNAs that are still differentially expressed in the presence of the drug. Moreover, we observed a similar, milder, effect of Nsp14 expression when assaying the levels of a subset of circRNAs (Figure 6 - figure supplement 2C). Furthermore, we corroborated these data using Mizoribine (MZR), another IMPDH2 inhibitor. As for the MPA treatment, MZR treatment did no alter Nsp14 or IMPDH2 protein level (Figure-6 - figure supplement 2D) and partially rescued the expression of the tested mRNAs and circRNAs deregulated by Nsp14 overexpression (Figure 6 - figure supplement $2 \mathrm{E}$ and $2 \mathrm{~F}$ ). Together, the data presented here 
demonstrate that IMPDH2 is a key mediator of the effects of Nsp14 on the transcriptome of the hosting cell.

Finally, we investigated whether IMPDH2 also mediates the effects induced by Nsp14 on alternative splicing. To do so, we treated cells with MPA or MZR and we checked by RT-qPCR the abundance of some of transcripts that displayed intron retention in the total RNA seq data (Figure 3B and Table 5). As expected, we detected increased abundance of retained introns for PAXIP1, SETD1A, and ZNF507 upon Nsp14 expression, and both MPA and MZR treatment partially rescued this effect, indicating that IMPDH2 mediates the observed splicing changes (Figure 6G and Figure 6 - figure supplement 2G).

In summary, these results indicate that IMPDH2 mediates both the gene expression changes, and the alternative splicing effects induced by Nsp14. 


\section{DISCUSSION}

Viral infection leads to a complex set of events orchestrated by multiple viral proteins. In the last two years, new studies shed light in some unexpected functions of diverse SARS-CoV-2 proteins. For instance, protein interactome experiments defined the interaction map of SARS-CoV2 proteins with host cellular proteins (Gordon, Hiatt, et al., 2020; Gordon, Jang, et al., 2020). Moreover, further studies showed that Nsp1 blocks cellular translation, (Schubert et al., 2020) whereas RNA immunoprecipitation experiments indicated that Nsp8 and Nsp19 alter protein trafficking (Banerjee et al., 2020), and that Nsp16 alters splicing (Banerjee et al., 2020).

Here we used an alternative approach; we performed an expression screen to determine how the individual expression of SARS-CoV-2 proteins influenced host cell gene expression. Nsp14 displayed the most striking effects, deregulating the expression of approximately 4,000 mRNAs and altering splicing. While we acknowledge that the conditions under which we performed our experiments might lead to higher levels of Nsp14 than those observed during infection, we are convinced that our findings are highly relevant. Indeed, both the effects on gene expression and alternative splicing significantly overlap with the ones occurring during SARSCoV-2 infection. Furthermore, during the infection Nsp14 localizes in the replication organelles that are formed in the cytoplasm (V'kovski et al., 2021b), and in our model we also see that Nsp14 localizes in the cytoplasm. Overall, our data indicate that our model, despite some limitations, recapitulates some gene expression changes that occur during SARS-CoV-2 infection.

Regarding the other tested proteins, when expressed individually M, Nsp9, E, ORF9b, ORF3a, Nsp13, and Nsp1 also altered the host cells transcriptome in ways that will require further investigation. Although most of the tested proteins did not dramatically alter gene expression, this does not rule out their roles in remodeling of host cell gene expression. For instance, some may 
require other viral proteins as co-factors. In the future, it will be interesting to test how different combinations of viral proteins that are known to work in complex may affect host cell gene expression.

Our findings unrevealed an unexpected function of the SARS-CoV-2 Nsp14 in regulation of host cell transcription, splicing, and circRNAs expression. Notably, we also showed that IMPDH2 mediates these effects, as pharmacological inhibition of this cellular enzyme partially reverts them.

Our analysis of the transcriptomes of HEK293T cells as a function of time after Nsp14 expression revealed that the transcriptional response is temporarily subdivided into two phases. The early response involves NFkB activation, whereas the later phase includes effects on cellular metabolism, RNA metabolism, and cell-cycle control. Notably, NFkB is one of the first pathways activated upon SARS-CoV-2 infection (Li et al., 2021; Wyler et al., 2021). Furthermore, early after transfection of Nsp14, we detected increased CXCL8 expression, which encodes IL8. IL8 is elevated in plasma of COVID-19 patients (Blanco-Melo et al., 2020; Hariharan et al., 2021; Li et al., 2021) and is a marker of acute severe lung distress (Adcock et al., 2015), an inflammatory condition that can lead to severe complications or death, further confirming the relevance of our model in mimicking the molecular events triggered by SARS-CoV-2 infection. Besides, in accordance with our data, a recent study showed that IMPDH2 mediates the activation of $C X C L 8$ expression and of NFkB transcriptional reporters during Nsp14 expression (Li et al., 2021).

Nevertheless, for a subgroup of genes the response appears to involve alterations of splicing patterns and other post-transcriptional events. Remarkably, splicing is strongly disrupted upon SARS-CoV-2 infection (Banerjee et al., 2020) and we see a significant overlap between the alternative splicing events induced by Nsp14 and the ones occurring during the infection. 
Furthermore, Nsp14 affects the expression of genes encoding proteins with functions in RNA processing and splicing. However, unlike the splicing modulation by Nsp16 which has been proposed to be general (Banerjee et al., 2020), the effect of Nsp14 seems to be specific to certain exons and introns as, in most cases, only one splicing event is modulated per gene. It is likely that Nsp16 and Nsp14 influence alternative splicing through different mechanisms, although we could not compare the effects of the two proteins as the plasmid for Nsp16 expression was not in the collection we utilized in our screening (Gordon, Jang, et al., 2020). In any case, while Nsp16 directly binds to pre-mRNA (Banerjee et al., 2020), Nsp14 may trigger a cascade of events that culminate in altered splicing patterns.

Surprisingly, we also detected increased levels of circRNAs upon Nsp14 expression. Specifically, Nsp14 altered the expression of about $10 \%$ of the cellular circRNAs. The magnitude of this effect is striking, considering that deletion or knock-down of factors involved in circRNAs production generally affects the expression of a smaller percentage of circRNAs (Conn et al., 2015; Errichelli et al., 2017; Knupp et al., 2021). We showed that this increase is not due to enhanced transcription of the hosting RNAs, and our results indicate that Nsp14 influences biosynthesis and/or stability of those circRNAs. Published work showed that circRNAs accumulate in non-proliferating cells (Bachmayr-Heyda et al., 2015). Nsp14 alters the expression of genes regulating cell cycle and proliferation, and this may result in inhibition of pathways related to circRNA degradation or in inhibition of cell division, ultimately leading to circRNAs accumulation. However, this possible explanation will require future investigation.

Interestingly, recent studies indicate that circRNAs modulate some immune factors by repressing their pro-inflammatory activity in normal conditions (Liu et al., 2019). On the contrary, upon viral infection, circRNAs are degraded and these immune factors can orchestrate the 
appropriate response in the cell (Liu et al., 2019). Indeed, circRNA titer dramatically decreases upon viral infection (Liu et al., 2019; Chen et al., 2020). The fact that we detected an increase in levels of certain circRNAs upon Nsp14 expression suggests a possible mechanism for the immune evasion orchestrated by Nsp14.

Nsp14 is conserved among coronaviruses and it participates to viral replication and immune surveillance escape (Ogando et al., 2020). Indeed, on the one end it works as an exonuclease $($ ExoN), important for the correct replication of the viral genome, on the other hand it functions as N7-guanine-methyltransferase for modifying the 5'-cap of the viral genome. Notably, both domains are important for successful viral replication and are considered potential drug targets (Otava et al., 2021; Saramago et al., 2021). Our data indicate that N7-guaninemethyltransferase domain, but not the ExoN one, is necessary for Nsp14 effects on host gene expression.

Nsp14 interacts with the Replication Complex and in proximity with other enzymes, such as Nsp16, involved in the modification of the 5' cap (Romano et al., 2020). Although we excluded the importance of the co-factor Nsp10 (Ma et al., 2015b), we did not test how the combination of Nsp14 with other SARS-CoV-2 proteins modulate gene expression in the host cells. As mentioned above, in the future it would be interesting to co-express Nsp14 and Nsp16, since both are involved in the 5'cap modification (and, as mentioned before, the N7-guanine-methyltransferase domain of Nsp14 is important for the effects on gene expression), and both proteins disrupt splicing of cellular transcripts (Banerjee et al., 2020; Romano et al., 2020).

Finally, we showed that IMPDH2 meditates the effects on cell transcriptome, altered splicing, and circRNAs deregulation induced by Nsp14 expression, as pharmacological inhibition of IMPDH2 activity with MPA and Mizoribine mitigated the effects of Nsp14. Intriguingly, MPA 
is a known immunosuppressant and antiviral agent (Pan et al., 2012; To et al., 2016; Dang et al., 2017), and it inhibits SARS-CoV-2 propagation (Kato et al., 2020).

\section{Ideas and Speculations}

Although our data clearly indicate that IMPDH2 mediates the effects induced by Nsp14, we still do not know the detailed mechanism. We reported altered expression of genes involved in purine synthesis, including a decrease in IMPDH2 mRNA levels, and we also detected elevated cellular GTP concentrations upon Nsp14 expression. Taken together, these data suggest that Nsp14 activates IMPDH2. Besides, previous studies showed that Nsp14 interacts with IMPDH2 (Gordon, Hiatt, et al., 2020; Gordon, Jang, et al., 2020), but we do not know whether the direct interaction between Nsp14 and IMPDH2 is sufficient for triggering the massive gene expression chenges or if this system requires a co-factor.

Notably, IMPDH2 binds nucleic acids (McLean et al., 2004; Mortimer and Hedstrom, 2005) and acts as a transcription factor in Drosophila (Kozhevnikova et al., 2012). However, although IMPDH2 is conserved (Hedstrom, 2009) and can localize in the nucleus of mammalian cells (Ahangari et al., 2021), the transcription factor activity of IMPDH2 has not been demonstrated in mammalian cells. Whether Nsp14 triggers cytoplasmic-nuclear shuffle of IMPDH2 in mammalian cells will require further investigation. Intriguingly, a recent study reported that IMPDH2 can bind a circRNA and that this interaction activates IMPDH2 enzymatic activity (Wang et al., 2021). In the future, it will be interesting to check the circRNA binding capacity of IMPDH2 in our model, where circRNAs expression is highly deregulated. Besides, IMPDH2 can also associate with polyribosomes and modulates the translation of specific mRNAs (Hsu et al., 2021). 
In addition, another recent report indicates that Nsp14 blocks the interferon response, which is upstream of the NFkB pathway, by shutting down global translation 24 hours after Nsp14 transfection (Hsu et al., 2021). However, our data indicate that the transcriptional activation of the NFkB pathway occurs very early after transfection. Furthermore, we confirmed that some effects are transcriptional, and we detected alterations on splicing and circRNAs levels, events which are not necessarily downstream to translational inhibition. Moreover, we showed that the transcriptional effects occur soon after Nsp14 expression, as treatment with MPA or Mizoribine 8 hours after transfection partially recovered the gene expression profile of the cells. This indicates that some of the gene expression changes might precede the global translation shutoff (Hsu et al., 2021). Therefore, we speculate that Nsp14 can alter gene expression by disrupting both the transcriptome and translation. Another possibility is that the transcriptional and the translational effects depend on the levels of Nsp14, that cannot be compared between the two studies (Hsu et al., 2021 and this study).

Although we showed that the N7-guanine-methyltransferase domain of Nsp14 is crucial for mediating the gene expression changes in the host cell, previous studies indicated that this domain is important for mediating Nsp14 translational repression (Jin et al., 2013; Hsu et al., 2021). This leads us to further speculate that Nsp14 may disrupt transcription, alternative splicing, and translation. Interestingly, Nsp14 can methylate free GTP in the cell and convert it to m7GTP, that is known to block cap-dependent translation by competing with mRNA for eIF4E (Jin et al., 2013). Our results indicate that Nsp14 increases cellular GTP concentration by activating IMPDH2. Therefore, a compelling model would be that Nsp14 activates IMPDH2, causing not only to altered transcription and splicing, but also increased cellular GTP, that is then converted to m7GTP by Nsp14, ultimately leading to general translation repression. However, this hypothesis 
will require further investigation and could only explain only a small fraction of the changes observed when expressing Nsp14, as expression of a viral factor that inhibits protein synthesis directly (Nsp1) altered the levels of a much smaller set of genes.

To sum up, we here provided novel insights regarding the function of Nsp14 in altering gene expression of the host cell through the interaction with the cellular enzyme IMPDH2 in the context of SARS-CoV-2 infection.

\section{Material and Methods}

\section{Key resources table}

\begin{tabular}{|l|l|l|l|l|}
\hline $\begin{array}{l}\text { Reagent type } \\
\text { (species) or } \\
\text { resource }\end{array}$ & Designation & $\begin{array}{l}\text { Source or } \\
\text { reference }\end{array}$ & Identifiers & $\begin{array}{l}\text { Additional } \\
\text { information }\end{array}$ \\
\hline $\begin{array}{l}\text { gene } \\
(\text { SARS-CoV-2) }\end{array}$ & Nsp14 & wuhCor1/SARS- & NC_045512v2: \\
CoV-2 & $\begin{array}{l}\text { UCSC } \\
\text { Genome } \\
\text { Browser on } \\
\text { SARS-CoV-2 } \\
\text { Jan. } \\
\text { 2020/NC_045 } \\
\text { 512.2 } \\
\text { Assembly } \\
\text { (wuhCor1) }\end{array}$ \\
\hline $\begin{array}{l}\text { gene } \\
\text { (H. sapiens })\end{array}$ & IMPDH2 & $\begin{array}{l}\text { UCSC Genome } \\
\text { Browser on } \\
\text { Human Feb. 2009 } \\
\text { (GRCh37/hg19) } \\
\text { Assembly }\end{array}$ & NM_000884 & \\
& & & & \\
\hline
\end{tabular}




\begin{tabular}{|c|c|c|c|c|}
\hline $\begin{array}{l}\text { strain, strain } \\
\text { background } \\
\text { (Escherichia coli) }\end{array}$ & DH5alpha & Rosbash Lab & & $\begin{array}{l}\text { Electrocompet } \\
\text { ent cells used } \\
\text { for } \\
\text { transformation } \\
\text { of cloned } \\
\text { plasmids }\end{array}$ \\
\hline $\begin{array}{l}\text { cell line } \\
\text { (H. sapiens) }\end{array}$ & HEK 293T & This paper & & $\begin{array}{l}\text { Cell line } \\
\text { obtained from } \\
\text { Marr Lab } \\
\text { Brandeis } \\
\text { University. } \\
\text { STR } \\
\text { authenticated } \\
\text { by ATCC, and } \\
\text { mycoplasma } \\
\text { tested. }\end{array}$ \\
\hline $\begin{array}{l}\text { transfected } \\
\text { construct (SARS- } \\
\text { CoV-2) }\end{array}$ & $\begin{array}{l}\text { pLXV- } \\
\text { EF1alpha- } \\
\text { 2XStrep- } \\
\text { SARS-CoV2- } \\
\text { nsp14-IRES- } \\
\text { Puro }\end{array}$ & Addgene & $\begin{array}{l}\text { Plasmid } \\
\# 141380\end{array}$ & $\begin{array}{l}\text { human codon } \\
\text { optimized }\end{array}$ \\
\hline $\begin{array}{l}\text { transfected } \\
\text { construct (SARS- } \\
\text { CoV-2) }\end{array}$ & $\begin{array}{l}\text { pLXV- } \\
\text { EF1alpha- } \\
\text { 2XStrep- } \\
\text { SARS-CoV2- } \\
\text { nsp10-IRES- } \\
\text { Puro }\end{array}$ & Addgene & $\begin{array}{l}\text { Plasmid } \\
\# 141376\end{array}$ & $\begin{array}{l}\text { human codon } \\
\text { optimized }\end{array}$ \\
\hline $\begin{array}{l}\text { transfected } \\
\text { construct } \\
\text { (jellyfish) }\end{array}$ & $\begin{array}{l}\text { pLXV- } \\
\text { EF1alpha- } \\
\text { 2XStrep- } \\
\text { eGFP-IRES- } \\
\text { Puro }\end{array}$ & Addgene & $\begin{array}{l}\text { Plasmid } \\
\# 141395\end{array}$ & $\begin{array}{l}\text { human codon } \\
\text { optimized }\end{array}$ \\
\hline $\begin{array}{l}\text { transfected } \\
\text { construct (SARS- } \\
\text { CoV-2) }\end{array}$ & $\begin{array}{l}\text { pLXV- } \\
\text { EF1alpha- } \\
\text { 2XStrep- } \\
\text { SARS-CoV2- } \\
\text { nsp14- } \\
\text { D331A- } \\
\text { IRES-Puro }\end{array}$ & This paper & & $\begin{array}{l}\text { human codon } \\
\text { optimized, } \\
\text { N7-guanine-- } \\
\text { methyltransfer } \\
\text { ase mutant }\end{array}$ \\
\hline
\end{tabular}




\begin{tabular}{|c|c|c|c|c|}
\hline $\begin{array}{l}\text { transfected } \\
\text { construct (SARS- } \\
\text { CoV-2) }\end{array}$ & $\begin{array}{l}\text { pLXV- } \\
\text { EF1alpha- } \\
\text { 2XStrep- } \\
\text { SARS-CoV2- } \\
\text { nsp14- } \\
\text { D273A- } \\
\text { IRES-Puro }\end{array}$ & This paper & & $\begin{array}{l}\text { human codon } \\
\text { optimized, } \\
\text { ExoN mutant }\end{array}$ \\
\hline $\begin{array}{l}\text { transfected } \\
\text { construct (SARS- } \\
\text { CoV-2) }\end{array}$ & $\begin{array}{l}\text { pLXV- } \\
\text { EF1alpha- } \\
\text { 2XStrep- } \\
\text { SARS-CoV2- } \\
\text { nsp14- } \\
\text { D90A/G92A- } \\
\text { IRES-Puro }\end{array}$ & This paper & & $\begin{array}{l}\text { human codon } \\
\text { optimized, } \\
\text { ExoN mutant }\end{array}$ \\
\hline antibody & $\begin{array}{l}\text { anti-Strep } \\
\text { (mouse } \\
\text { monoclonal) }\end{array}$ & Quiagen & Cat\#:34850 & WB $1: 1000$ \\
\hline antibody & $\begin{array}{l}\text { anti-IMPDH2 } \\
\text { (rabbit } \\
\text { polyclonal) }\end{array}$ & Proteintec & $\begin{array}{l}\text { Cat\#: 12948-1- } \\
\text { AP }\end{array}$ & WB 1:1000 \\
\hline antibody & $\begin{array}{l}\text { anti-Actin } \\
\text { (mouse } \\
\text { monoclonal) }\end{array}$ & Cell sign & Cat\#: 3700 & WB 1:1000 \\
\hline antibody & $\begin{array}{l}\text { anti-Nsp14 } \\
\text { (Rabbit } \\
\text { monoclonal) }\end{array}$ & Cell sign & Cat\#: 99098 & WB $1: 1000$ \\
\hline antibody & $\begin{array}{l}\text { anti-Tubulin } \\
\text { (Mouse } \\
\text { monoclonal) }\end{array}$ & SigmaAldrich & Cat\#: T5168 & WB $1: 1000$ \\
\hline
\end{tabular}




\begin{tabular}{|c|c|c|c|c|}
\hline antibody & $\begin{array}{l}\text { anti-Laminin } \\
\text { B1 } \\
\text { (Rabbit } \\
\text { monoclonal) }\end{array}$ & Abcam & Cat\#: ab133741 & WB 1:1000 \\
\hline antibody & $\begin{array}{l}\text { anti-GAPDH } \\
\text { (Rabbit } \\
\text { monoclonal) }\end{array}$ & Cell sign & Cat\#: 2118 & WB 1:1000 \\
\hline antibody & $\begin{array}{l}\text { anti-Tri- } \\
\text { Methyl- } \\
\text { Histone H3 } \\
\text { (Lys27) } \\
\text { (Rabbit } \\
\text { monoclonal) }\end{array}$ & Cell sign & Cat\#: 9733 & WB 1:1000 \\
\hline antibody & $\begin{array}{l}\text { anti-mouse } \\
\text { IgG- HRP } \\
\text { conjugated } \\
\text { (rabbit) }\end{array}$ & Millipore & Cat\#: ap160p & WB 1:10000 \\
\hline antibody & $\begin{array}{l}\text { anti-rabbit } \\
\text { IgG- HRP } \\
\text { conjugated } \\
\text { (mouse) }\end{array}$ & Millipore & Cat\#: AP188P & WB 1:10000 \\
\hline $\begin{array}{l}\text { chemical } \\
\text { compound, drug }\end{array}$ & $\begin{array}{l}\text { Mizoribine } \\
\text { IMPDH } \\
\text { inhibitor }\end{array}$ & Selleckchem & $\begin{array}{l}\text { Cat\#:50924-49- } \\
7\end{array}$ & $\begin{array}{l}\text { Used at } 10 \\
\mu \mathrm{M} \text {, dissolved } \\
\text { in DMSO }\end{array}$ \\
\hline $\begin{array}{l}\text { chemical } \\
\text { compound, drug }\end{array}$ & $\begin{array}{l}\text { Mycophenoli } \\
\text { c acid } \\
\text { (MPA) } \\
\text { IMPDH } \\
\text { inhibitor }\end{array}$ & Sigma Aldrich & Cat\#:M5255 & $\begin{array}{l}\text { Used at } 0.5 \\
\mu \mathrm{M} \text {, dissolved } \\
\text { in DMSO }\end{array}$ \\
\hline software & $\begin{array}{l}\text { GraphPad } \\
\text { Prism } \\
\text { software }\end{array}$ & $\begin{array}{l}\text { GraphPad } \\
\text { Prism } \\
\text { (https://graphpa } \\
\text { d.com) }\end{array}$ & & $\begin{array}{l}\text { RRID:SCR_0 } \\
02798\end{array}$ \\
\hline
\end{tabular}




\begin{tabular}{|l|l|l|l|l|}
\hline software & $\begin{array}{l}\text { R Project for } \\
\text { Statistical } \\
\text { Computing }\end{array}$ & $\begin{array}{l}\text { R Project for } \\
\text { Statistical } \\
\text { Computing } \\
\text { (https://www.r- } \\
\text { project.org/) }\end{array}$ & & RRID:SCR_0 \\
& & & 01905 \\
& & & \\
\hline
\end{tabular}

\section{Experimental procedures}

\section{Cell Culture}

HEK293T cells were a kind gift from Dr. Marr at Brandeis University. HEK293T were authenticated by STR profiling through ATCC. HEK293T were maintained in Dulbecco's Modified Eagle's Medium (Genesee Scientific, 25-500), supplemented with 10\% serum (FetalPlex, Gemini Bio/Fisher, \# 100-602), and 1X Penicillin-Streptomycin (PenicillinStreptomycin 100x, Genesee Scientific, 25-512). Mycoplasma test was performed using Mycoplasma detection kit by Southern Biotech (13100-01), according to manufacturer's instructions.

\section{Transient plasmid transfection}

Plasmids pLVX-EF1alpha-SARS-CoV-2-proteins-2xStrep-IRES-Puro proteins are a gift from Nevan Krogan (Addgene)(Gordon, Jang, et al., 2020) are listed in Table 15 and purified by Midiprep using Invitrogen kit. The day before transfection, $0.35^{*} 10^{6}$ cells per well were plated in 12 well-plates. Then, cells were transfected with PEI (Polyethylenimine 25kD linear from Polysciences, cat\# 23966-2). Briefly, 1500ng of total DNA (1200 ng of pLVX-EF1alpha-SARSCoV-2-proteins-2xStrep-IRES-Pur + 300ng of pLVX-EF1alpha-eGFP-2xStrep-IRES-Puro ) were incubated at RT for 20 min with PEI, with a ratio 3:1=PEI:DNA in 100ul of serum free medium, 
and the mixture was added to the cells. $48 \mathrm{hrs}$ after transfection, the medium was removed, and cells were harvested for following analysis.

\section{IMPDH2 inhibitors treatment}

Mycophenolic acid (MPA) (Sigma Aldrich) was a kind gift from Hedstrom lab at Brandeis University and was reconstituted in DMSO (Sigma-Aldrich) and aliquots were stored at $-20{ }^{\circ} \mathrm{C}$. $8 \mathrm{~h}$ after transfection, MPA wash freshly diluted into cell media and cells were treated with a final concentration of $50 \mu \mathrm{M}$ of MPA, or with an equivalent amount of DMSO.

Mizoribine (MZR) was purchased from Sellechem (50924-49-7), reconstituted in DMSO and aliquots were stored at $-20^{\circ} \mathrm{C}$. $8 \mathrm{~h}$ after transfection, MZR wash freshly diluted into cell media and cells were treated with a final concentration of $10 \mu \mathrm{M}$ of MZR, or with an equivalent amount of DMSO.

\section{RNA extraction and RT-qPCR}

RNA was extracted with TriZol (Invitrogen) reagent following the manufacturer instructions and then treated with DnaseI (NEB). For the RT-qPCRs showed in Figure 2F, Figure 2 - figure supplement 2A, and Figure 4 - figure supplement 1A, cDNA was prepared with 1000ng of DnaseI treated RNA (iScript Select cDNA synthesis Kit, BioRad, following manufacturer's instructions). Random hexamers were used for the nascent RNA experiment showed in Figure 2F and Figure 2 - figure supplement 2A. OligodT primers were used for Figure 4 - figure supplement $1 \mathrm{~A}$. The produced cDNA was utilized as a template for quantitative real-time PCR performed with the C1000 Thermal Cycler Bio-Rad. The PCR mixture contained Taq polymerase (SYBR green BioRad). Cycling parameters were $95^{\circ} \mathrm{C}$ for $3 \mathrm{~min}$, followed by 40 cycles of $95^{\circ} \mathrm{C}$ for $10 \mathrm{~s}, 55^{\circ} \mathrm{C}$ for 
$10 \mathrm{~s}$, and $72^{\circ} \mathrm{C}$ for $30 \mathrm{~s}$. Fluorescence intensities were plotted versus the number of cycles by using an algorithm provided by the manufacturer. For the remaining RT-qPCRs, cDNA was synthetized using 1000ng of RNA as input, 500ng of oligodT (for mRNAs validation) or random hexamers (for circRNAs validation and alternative splicing validation), $50 \mathrm{mM}$ Tris- $\mathrm{HCl} \mathrm{pH} 8.3,50 \mathrm{mM}$ $\mathrm{KCl}, 3 \mathrm{mM} \mathrm{MgCl}$, 10 mM DTT, $400 \mu \mathrm{M}$ dATP, $400 \mu \mathrm{M}$ dCTP, $400 \mu \mathrm{M}$ dGTP, $400 \mu \mathrm{M}$ dTTP, and homemade purified MLV-RT (200 units). The produced cDNA was utilized as a template for quantitative real-time PCR performed with the C1000 Thermal Cycler Bio-Rad. The PCR mixture contained homemade purified Taq polymerase, $20 \mathrm{mM}$ Tris- $\mathrm{HCl} \mathrm{pH} 8.8,10 \mathrm{mM}\left(\mathrm{NH}_{4}\right)_{2} \mathrm{SO}_{4}, 10 \mathrm{mM}$ KCl, 2mM MgSo4, 0.1\% Triton X-100, 1X SYBR, 1.075 M Ethylene glycol. Cycling parameters were $95^{\circ} \mathrm{C}$ for $3 \mathrm{~min}$, followed by 40 cycles of $95^{\circ} \mathrm{C}$ for $10 \mathrm{~s}, 55^{\circ} \mathrm{C}$ for $30 \mathrm{~s}$, and $72^{\circ} \mathrm{C}$ for $30 \mathrm{~s}$. Fluorescence intensities were plotted versus the number of cycles by using an algorithm provided by the manufacturer. All the primers used in this assay are listed in Table 16. Regarding the RTqPCR for detecting retained introns (Figure 6G and Figure 6 - figure supplement 2G, we positioned one primer in the exonic sequence before or after the retained intron, and the other primer in the retained intronic sequence (indicated as exon-intron). In parallel, we also run a reaction using both primers in the exonic regions surrounding the retained intron. We normalized the abundance of the exon-intron and the exon-exon product on a housekeeping gene (TBP mRNA). Finally, we plotted the intronic-exonic ratio, defined as the ratio between the relative abundance of the exon-intron product on the relative abundance of the exon-exon one.

\section{Nascent RNA purification}

Cells were harvested, washed with PBS, and then resuspended in $50 \mu$ of Hypotonic Buffer [20mM Tris- $\mathrm{HCl} \mathrm{pH} 7.4,10 \mathrm{mM} \mathrm{KCl}, 2 \mathrm{mM} \mathrm{MgCl} 2,1 \mathrm{mM}$ EGTA, 0.5mM DTT, Murine RNAse Inhibitor (NEB), Complete Protease Inhibitor (Pierce, PIA32955)]. Cells were incubated on ice 
for $3 \mathrm{~min}$, then NP-40 to a final concentration of $0.1 \%$ was added, the cells were gently flicked, and incubated other $3 \mathrm{~min}$ in ice. Following, cells were centrifuged for $5 \mathrm{~min}$ at $4^{\circ} \mathrm{C}$ at $1000 \mathrm{rcf}$. The supernatant (corresponding to the cytoplasmatic fraction) was collect in a separate tube and RNA was extracted with TriZol (Invitrogen), as indicated above. The nuclei in the pellet were gently resuspended in 250ul of Homogenization buffer [10mM HEPES-KOH pH 7.5, 10mM KCl, 1.5mM $\mathrm{MgCl}_{2}, 0.8 \mathrm{M}$ Sucrose, 0.5mM EDTA, 1mM DTT, 0.5 unit/ $\mu$ l Murine RNase Inhibitor (NEB), protease inhibitor (Pierce, PIA32955) ] were transferred onto $350 \mu 1$ of Sucrose Cushion [10mM HEPES-KOH pH 7.5, 10mM KCl, 1.5mM $\mathrm{MgCl}_{2}, 1 \mathrm{M}$ Sucrose, $10 \%$ Glycerol, 0.5mM

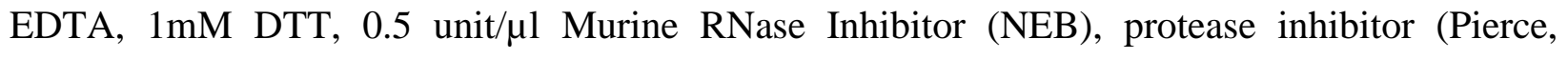
PIA32955)], and centrifuged at $21000 \mathrm{rcf}$ for $10 \mathrm{~min}$ at $4^{\circ} \mathrm{C}$. The supernatant was removed, and the nuclei (pellet) were resuspended in $150 \mu$ l of Nuclear Lysis Buffer [10mM HEPES-KOH pH 7.5, 100mM KCl, 10\% Glycerol, 0.1M EDTA, 0.15mM Spermine, (ThermoFisher), 0.5mM Spermidine, (SigmaAldrich), 1mM NaF, 0.1mM Na $3 \mathrm{VO}_{4}, 0.1 \mathrm{mM} \mathrm{ZnCl} 2,1 \mathrm{mM}$ DTT, 1 unit/ $\mu \mathrm{l}$ Murine RNase Inhibitor (NEB), protease inhibitor (Pierce, PIA32955)]. $150 \mu 1$ of 2X NUN Buffer [mM HEPES-KOH pH 7.5, 300mM NaCl, 1M Urea, 1\% NP-40, 1mM DTT, 1 unit/ $\mu$ l Murine RNase Inhibitor (NEB), protease inhibitor (Pierce, PIA32955)] were added drop by drop, flicking the tube after each addition. Samples were incubated on ice for $20 \mathrm{~min}$ and the centrifuged at 21 $000 \mathrm{rcf}$ for $30 \mathrm{~min}$ at $4^{\circ} \mathrm{C}$. the supernatant (nucleoplasm) was collected, and RNA was extracted with TriZol LS (Thermo-Fisher), according to the manufacturer's protocol. Nascent RNA associated to chromatin (pellet) was extracted by adding $1 \mathrm{ml}$ of TriZol, incubating the sample at $65^{\circ} \mathrm{C}$ for $15 \mathrm{~min}$ and then proceeding with the previously described extraction. All the fractions were treated with DNaseI (NEB), as previously described, before proceeding with RT-cDNA 
synthesis (iScript Select cDNA synthesis Kit, BioRad. Random Priming, following manufacturer's instructions) and RT-qPCR (SYBR green Bio-Rad ), as indicated above.

\section{3' RNA sequencing libraries}

75ng of RNA were used as input for preparing 3' RNA sequencing libraries following CelSeq2 (Hashimshony et al., 2016) protocol, changing the UMI to 6 bases. Sequencing was performed on Illumina NextSeq 500 system.

\section{Total RNA sequencing libraries}

40ng of rRNA depleted RNA was used as a starting material for library preparation. NEBNext rRNA Depletion kit( NEB \#E7405) was used to deplete ribosomal RNA. Libraries were prepared using the NEXTFLEX® Rapid Directional RNA-Seq Kit 2.0 by PerkinElmer, following the manufacturer's instructions. The samples were sequenced by Novogene (Novogene Corporation Inc. 8801 Folsom BLVD, Suite 290, Sacramento, CA 95826) with Hiseq-4000.

\section{Metabolomic analysis}

Cells were transfected as aforementioned, harvested with Trypsin-EDTA $0.25 \%$ IX phenol red, Genesee Scientific (25-510) and washed 3 times with cold PBS. PBS was removed and samples were snap-frozen in liquid nitrogen. Samples were sent to Creative Proteomics 45-1 Ramsey Road, Shirley, NY 11967, USA for metabolomic analysis. Briefly, cell pellet in each sample tube was made into $200 \mu \mathrm{L}$ of $80 \%$ methanol. Cells were lysed on a MM 400 mill mixer with the aid of two metal balls at $30 \mathrm{~Hz}$ for $1 \mathrm{~min}$ three times, followed by sonication for $3 \mathrm{~min}$ in an ice-water bath. The samples were placed at $-20^{\circ} \mathrm{C}$ for 1 hours before centrifugal clarification at $21,000 \mathrm{~g}$ and $5^{\circ} \mathrm{C}$ for $15 \mathrm{~min}$. The clear supernatant was collected for LC-MS and the 
precipitated pellet was used for protein assay using a standardized Bradford procedure. Standard solutions containing all targeted nucleotides were prepared, in a concentration range of 0.0002 to $20 \mathrm{nmol} / \mathrm{mL}$, in an internal standard solution of 13C5-AMP, 13C10-ATP and 13C10- GTP. $20 \mu \mathrm{L}$ of the clear supernatant of each sample was mixed with $180 \mu \mathrm{L}$ of the internal standard solution. $10-\mu \mathrm{L}$ aliquots of resultant sample solutions and standard solutions were injected to a C18 column $(2.1 \times 150 \mathrm{~mm}, 1.7 \mu \mathrm{m})$ to run UPLC-MRM/MS on a Waters Acquity UPLC system coupled to a Sciex QTRAP 6500 Plus mass spectrometer operated in the negative-ion ESI mode. The mobile phase was an acyl amine buffer (A) and acetonitrile/methanol (B) for binary gradient elution (5\% to $65 \% \mathrm{~B}$ in $16 \mathrm{~min})$, at $0.25 \mathrm{~mL} / \mathrm{min}$ and $55^{\circ} \mathrm{C}$. Concentrations of the detected analytes were calculated with internal-standard calibration by interpolating the constructed linear-regression curves of individual compounds, with the analyte-to-internal standard peak ratios measured from sample solutions.

\section{Protein Extraction and Western Blot}

Cells were lysed in RIPA buffer (150mM NaCl, $1 \%$ TritonX-100, 0.5\% SDS, 50mM Tris-HCl pH 8.0) supplemented with EDTA free protease inhibitor (Pierce, PIA32955) and centrifuged at $4^{\circ} \mathrm{C}$ 21.1 x1000 g for 30 min. Lysate was quantified by BCA Assay (ThermoFisher, 23225). Lysates were run on 4-20\% gradient polyAcrylamide gels (BioRad, 4568094) with Tris-Glycine SDS Running buffer. Transfer was performed in a Tris-Glycine buffer supplemented with $20 \%$ Methanol. Membranes were blocked with 3\% BSA in TBS-T Buffer pH 7.6 (Tris base 0.2M, NaCl 1.5 M, 0.1\% Tween-20). Membranes were incubated with the following primary antibodies: mouse anti-Actin (Cell sig, 3700), rabbit anti-IMPDH2 (Proteintec, 12948-1-AP), mouse anti-Strep-tag (Quiagen, 34850). Secondary antibodies: rabbit anti mouse - HRP conjugated (Millipore), mouse anti rabbit- HRP conjugated (Millipore). Detection was performed using ECL (Pierce, 32106). 


\section{Subcellular fractionation and chromatin precipitation}

Cells were harvested, washed with PBS, and then resuspended in Hypotonic Buffer [20mM Tris$\mathrm{HCl} \mathrm{pH} 7.4,10 \mathrm{mM} \mathrm{KCl}, 2 \mathrm{mM} \mathrm{MgCl} 2,1 \mathrm{mM}$ EGTA, 0.5mM DTT, Murine RNAse Inhibitor (NEB), Complete Protease Inhibitor (Pierce, PIA32955)]. Cells were incubated on ice for 3 min, then NP-40 to a final concentration of $0.1 \%$ was added, the cells were gently flicked, and incubated other $3 \mathrm{~min}$ in ice. Following, cells were centrifuged for $5 \mathrm{~min}$ at $4^{\circ} \mathrm{C}$ at $1000 \mathrm{rcf}$. The supernatant (corresponding to the cytoplasmatic fraction) was collect in a separate tube. The nuclei in the pellet were gently washed with PBS and then resuspended in 250ul of Homogenization buffer [10mM HEPES-KOH pH 7.5, 10mM KCl, 1.5mM MgCl $2,0.8 \mathrm{M}$ Sucrose, 0.5mM EDTA, 1mM DTT, 0.5 unit/ $\mu$ l Murine RNase Inhibitor (NEB), protease inhibitor (Pierce, PIA32955) ] were transferred onto $350 \mu \mathrm{l}$ of Sucrose Cushion [10mM HEPES-KOH pH 7.5, 10mM KCl, 1.5mM MgCl $2,1 \mathrm{M}$ Sucrose, 10\% Glycerol, 0.5mM EDTA, 1mM DTT, 0.5 unit/ $\mu$ l Murine RNase Inhibitor (NEB), protease inhibitor (Pierce, PIA32955)], and centrifuged at $21000 \mathrm{rcf}$ for $10 \mathrm{~min}$ at $4^{\circ} \mathrm{C}$. The supernatant was removed, and the nuclei (pellet), were washed in PBS and then resuspended in 20 $\mu \mathrm{l}$ of Nuclear Lysis Buffer [10mM HEPES-KOH pH 7.5, 100mM KCl, 10\% Glycerol, 0.1M EDTA, 0.15mM Spermine, (ThermoFisher), 0.5mM Spermidine, (SigmaAldrich), 1mM NaF, $0.1 \mathrm{mM} \mathrm{Na}_{3} \mathrm{VO}_{4}, 0.1 \mathrm{mM} \mathrm{ZnCl} 2,1 \mathrm{mM}$ DTT, 1 unit/ $\mu$ l Murine RNase Inhibitor (NEB), protease inhibitor (Pierce, PIA32955)]. $20 \mu \mathrm{l}$ of 2X NUN Buffer [mM HEPES-KOH pH 7.5, 300mM NaCl, 1M Urea, 1\% NP-40, 1mM DTT, 1 unit/ $\mu 1$ Murine RNase Inhibitor (NEB), protease inhibitor (Pierce, PIA32955)] were added drop by drop, flicking the tube after each addition. Samples were incubated on ice for $20 \mathrm{~min}$ and the centrifuged at $21000 \mathrm{rcf}$ for $30 \mathrm{~min}$ at $4^{\circ} \mathrm{C}$. The supernatant (nucleoplasm) was collected and transferred to a separate tube. Proteins associated to chromatin 
(pellet) were treated with DNaseI (NEB). Finally, we proceeded with SDS-Page and Western Blot (loaded the entire collected fractions), as described above.

\section{Cloning of Nsp14 ExoN mutants}

\section{pLXV-EIF1 alpha-2xStrep-SARS-CoV-2-nsp14-D90A/G92A-IRES-Puro}

pLXV-EF1alpha-2xStrep-SARS-CoV-2-nsp14-IRES-Puro was opened with BsrGI-HF (NEB) and EcoRI-HF (NEB). The removed cassette was replaced by ligation with a G-block ordered from GenScript (GenScript UAS Inc. Piscataway, NJ), previously amplified with specific primers.

\section{G-block:}

Gaattcgecgccaccatgtggtcccatccgcagtttgagaagggtggtggttcaggcggaggctccgggggegggagctggtctcaccc gcaatttgaaaaaggcgctgcggctgctgaaaatgtaacgggcttgtttaaagactgtagtaaagtgatcacaggactccacccacacaag cacctacccacctttccgtagatacgaagttcaaaacggaaggattgtgtgtggatataccagggataccaaaggatatgacgtaccgaagg ctgatttccatgatgggttttaagatgaattaccaagttaatggctaccccaacatgttcatcaccagggaggaggcaattagacacgtaagag cctggataggcttcGCCgttGCCggttgccatgcaacccgggaagccgtaggcacaaacettccgttgcagcttggcttttccacgggc gtcaacctcgttgccgtaccgactggctatgttgacacgccgaacaacaccgatttctctcgcgtaagtgctaagcetcctccgggagatcaa ttcaagcatcttatacctctcatgtaca

Primers:

D90AG92A_F: cacacgaattcgccgccac

D90AG92A_R: cacactgtacatgagaggtataaga

pLXV-EIF1 alpha-2xStrep-SARS-CoV-2-nsp14-D273A-IRES-Puro 
pLXV-EF1alpha-2xStrep-SARS-CoV-2-nsp14-IRES-Puro was opened with BstBI (NEB) and AfeI (NEB). The removed cassette was replaced by ligation with a G-block ordered from GenScript (GenScript UAS Inc. Piscataway, NJ), previously amplified with specific primers.

\section{G-block:}

ccacacttcgaacttacttctatgaaatactttgtaaaaatcgggccegagcggacatgttgtttgtgcgaccgacgagctacttgttttagcac agcatctgacacctacgcatgctggcaccacagtataggettcgattacgtctacaatccetttatgatagacgtacaacaatggggctttacg ggtaacttgcagagtaatcacgatctttactgccaagttcatgggaacgcacacgtggcctcctgcGCCgcgataatgacgaggtgcttg gccgtgcacgagtgctttgttaagcgggtcgattggactatagagtatcccataatcggtgacgaacttaaaattaatgctgcatgcaggaaa gtgcagcacatggtagtaaaagcagcgct.

Primers:

D273A_F: ccacacttcgaacttacttctatg

D273A_R: cacacagcgctgctttactacc

\section{Cloning of Nsp14 N7-guanine-methyltransferase mutant}

\section{pLXV-EIF1 alpha-2xStrep-SARS-CoV-2-nsp14-D331A-IRES-Puro}

pLXV-EF1alpha-2xStrep-SARS-CoV-2-nsp14-IRES-Puro was opened with NdeI (NEB) and AfeI (NEB). The removed cassette was replaced by ligation with a G-block ordered from GenScript (GenScript UAS Inc. Piscataway, NJ), previously amplified with specific primers.

\section{G-block:}

agcgctcctcgcggataagtttcctgtgctccacGCCatcggcaaccetaaggccattaaatgcgtcccccaagctgatgtagagtggaa attctatgacgctcagccatgtagtgacaaagcatacaagattgaagaattgttttattcatatgcacacc 
Primers:

D331A_F: cacacagcgctcctcgcg

D331A_R: ggtgtgcatatgaataaaacaattc

\section{Cloning of CXCL8-Firefly reporter}

pGL_RSV_RF_BG (a modification of the pGL plasmid) was a kind gift from Dr. Marr at Brandeis University. pGL_RSV_RF_BG was opened with XhoI and NcoI. DNA was extracted from HEK293T cells with DNeasy Blood \& Tissue Kit Quiagen (ID: 69504) according to manufacturer's instructions. The CXCL8 promoter was amplified by PCR with Phusion ${ }^{\circledR}$ High-Fidelity PCR Master Mix with HF Buffer (NEB) according to the manufacturer's instruction with the following primers:

CXCL8_promoter_R:

CACCACCATGGTGGCTAGCAGCTGGTACCCAGCTTGGACCTGGCTCTTGTCCTA GAA

CXCL8_promoter_F: CACCACTCGAGACAGTTCCTAGAAACTCTCTAAAATGCTTAGAA

The purified insert was digested with XhoI and NcoI and inserted into the plasmid by ligation with T7 DNA ligase (NEB) following the manufacturer's instructions to generate the pGL_CXCL8_promoter_Firefly.

\section{Luciferase Assay}

The day before transfection $0.18 * 106$ cells per well were plated into 24 well plates. Cells were transfected as aforementioned using 750ng of total DNA. Cells were transfected with 75ng of 
Firefly reporter, 75ng of Renilla reporter, and 600ng of pLVX-EF1alpha-SARS-CoV-2-Nsp142xStrep-IRES-Puro or 600ng of empty vector. We used the following plasmids as reporters:

pGL_CXCL8_promoter_Firefly, generated as indicated above.

pHAGE NFkB-TA-LUC-UBC-GFP-W was a gift from Darrell Kotton (Addgene plasmid \# 49343 ; http://n2t.net/addgene:49343 ; RRID:Addgene_49343)(Wilson et al., 2013)

7xE-Box::Renilla was a gift from Koen Venken (Addgene plasmid \# 124532 ; http://n2t.net/addgene:124532 ; RRID:Addgene_124532, Sarrion-Perdigones et al., 2020)

48 hours after transfection, cells were lysate in lysis buffer (25 mM Tris-phosphate at pH 7.8, 10\% glycerol, $1 \%$ Triton $\mathrm{X}-100,1 \mathrm{mg} / \mathrm{ml}$ of bovine serum albumin (BSA), $2 \mathrm{mM}$ cyclohexylene diamin tetraacetate, and $2 \mathrm{mM}$ DTT). An aliquot of the lysate was added to Firefly Buffer $1 \mathrm{X}$ (75 mM Tris $\mathrm{pH} 8.0,100 \mu \mathrm{M}$ EDTA, $530 \mu \mathrm{M}$ ATP, $5 \mathrm{mM} \mathrm{MgSO}_{4}$ ) freshly supplemented with $0.1 \mu \mathrm{M}$ Dluciferin (Goldbio.com) and $100 \mu \mathrm{M}$ Coenzyme-A (Fisher, \#BP2510250), and luminescence was measured. Immediately after, an equal amount of Renilla Buffer $1 \mathrm{X}$ supplemented with $10 \mu \mathrm{M}$ Coelenterazine (Goldbio.com) was added to the sample and luminescence was measured again. Non-transfected cell lysate was used to measure the background signal, that was subtracted before calculating the firefly/renilla ratios.

\section{Bioinformatic analyses}

\section{Linear RNA alignment and quantification}

Raw reads were aligned to the human genome (hg38) using STAR (Dobin et al., 2013). Mapped reads in the 3' UTR were quantified using End Sequence Analysis Toolkit (Gohr and Irimia, 2019)for 3' RNA libraries. FeatureCounts (Gohr and Irimia, 2019) was used to quantify mapped 
transcripts from total RNA-seq libraries. DEGs were found using DESeq2 as previously described (Sarrion-Perdigones, Gonzalez and Venken, 2020). DEGs with $\mid$ L2FC $\mid>1$, p-adjusted value $<0.05$ were considered significant and used as input in downstream Gene Ontology (GO) analysis (DAVID, v 6.8). For the analysis of the timepoint 3' RNA-seq experiment, we used $|\mathrm{L} 2 \mathrm{FC}|>0.5$, p-adjusted value $<0.05$. HEK293T cell transcriptome was used as a reference to query for Enriched GO terms from up- and down- regulated DEG lists. Gene set enrichment analysis (GSEA) was performed using the fgsea package in $\mathrm{R}$ (Sergushichev et al., 2016). Gene rank was determined prior to GSEA by calculating -log(p-value)* $\operatorname{sign}(\log 2$ fold change)(Sergushichev et al., 2016). Gene sets used for GSEA were downloaded from Molecular Signatures Database (http://www.msigdb.org). To compare our RNA-seq results with other studies we used a gene set from MSigDB containing DEGs from published RNA-seq data. A curated list of terms from GSEA were plotted to assess the transcriptional response to viral protein expression. Data visualization was carried out using ggplot2 in R. Non-omics statistical analysis and data visualization was completed using Prism.

\section{circRNA detection and differential expression analysis}

Computational analysis of circRNAs was performed on total RNA-seq data. circRNAs were detected by searching unaligned reads for head-to-tail splice junctions as previously described (Memczak et al., 2013). Differentially expressed circRNAs were found by DESeq2 (Love, Huber and Anders, 2014). circRNA reads were normalized using size factors computed by DESeq2 together with all mapped reads.

\section{Intronic reads quantification and analysis}


Reads were aligned with STAR-aligner(Wilson et al., 2013) to the human genome and transcriptome version $\mathrm{Hg} 38$. Intronic reads were extracted and counted using Featurecounts function in $\mathrm{R}$ with an intronic region reference.

\section{Alternative splicing analysis}

Percentage of inclusion (PSI) quantification was done with Vast-Tools (Tapial et al., 2017). Delta PSI was then calculated from the mean of each condition. To determine events changing between Nsp14 and transfection control we chose a minimum of $15 \%$ difference in mean PSI and no overlapping between replicas. Introns and exons feature analysis was done using Matt (Gohr and Irimia, 2019).

With the same approach, we re-analyzed total RNA sequencing from HEK293T-hACE2cells infected with SARS-CoV-2 GSE169158 (Sun et al., 2021). Then, we tested the significance of the overlap between the Alternative Splicing Analysis on our dataset and this dataset by performing a randomization of sets with equal size, evaluating their overlap to generate a null distribution, and calculating the probability of our overlap $\left(10.000\right.$ replicas p-value $\left.<10^{-15}\right)$.For this analysis we used the function enrichment_test from the RVenn package in R.

\section{Motif enrichment analysis}

We extracted the promoters' sequences of upregulated genes with a fold change of at least 1.75 $(\log 2 \mathrm{FC}>0.8$ and adjusted p-value $>0.05)$ using windows of 100, 500 and 1000 bases upstream of each annotated transcription start site for each gene. We then used the MEMEsuite (Bailey et al., 2009) using the tool AME(McLeay and Bailey, 2010) for motif enrichment analysis. We used the motif data base HOmo sapiens COmprehensive MOdel COllection (HOCOMOCO) v11 transcription factor (TF) binding models (binding profiles or binding motifs) for human transcription factors. As control for the input sequences, we used the tool provided for 
scrambled sequences option. Finally, we used MEMEsuit tool FIMO (Grant, Bailey and Noble, 2011) to identify the position of these motifs in the analyzed $100 \mathrm{bp}$ promoters. We extracted the promoters' sequences of upregulated genes with a fold change of at least $1.75(\log 2 \mathrm{FC}>0.8$ and adjusted p-value $>0.05$ ) using windows of 100, 500 and 1000 bases upstream of each annotated transcription start site for each gene. We then used the MEMEsuite tool AME(McLeay and Bailey, 2010) for motif enrichment analysis using. We used the motif data base HOmo sapiens COmprehensive MOdel COllection (HOCOMOCO) v11 transcription factor (TF) binding models (binding profiles or binding motifs) for human transcription factors. As control for the input sequences, we used the tool provided scrambled sequences option. Finally. we used MEMEsuit tool FIMO (Grant, Bailey and Noble, 2011) to identify the position of these motifs in the analyzed 100bp promoters. 


\section{List of the tables}

Table 1: List of DEGs in the screening described in Figure 1. 3' RNA-seq.

Table 2: List of GO terms described in Figure 1. 3' RNA-seq.

Table 3: GSEA analysis described in Figure 2. Total RNA-seq.

Table 4: Differential gene expression results described in Figure 2.

Table 5: Alternative Splicing analysis results described in Figure 3.

Table 6: Feature analysis with MATT for upregulated intron retentions and downregulated exon inclusion events described in Figure 3 - figure supplement 1.

Table 7: Alternative Splicing Analysis on a published total RNA-seq dataset of HEK293T-

hACE2 cells infected with SARS-CoV-2 (Sun et al., 2021).

Table 8: Deregulated circRNAs described in Figure 3.

Table 9: DEG at different time points described in Figure 5. 3' RNA-seq.

Table 10: GO described in Figure 5. 3' RNA-seq.

Table 11: Ame analysis with 100bp of promoter described in Figure 5.

Table 12: Fimo analysis with 100bp promoter described in Figure 5.

Table 13: Ame analysis with 1000bp promoter described in Figure 5.

Table 14: Concentrations of cellular metabolites detected by HPLC/MS.

Table 15: list of plasmids used for SARS-CoV-2 protein expression in the initial screening described in Figure 1.

Table 16: list of primers used for the RT-qPCR assays. 


\section{Figure Legends}

Figure 1: SARS-CoV-2 proteins alter gene expression distinctively. A) Scheme of the experimental approach. DEGs stands for Differentially Expressed Genes and GO for Gene Ontology. B) Heatmap showing the number of DEGs detected in 3' RNA sequencing for each expressed SARS-CoV-2 protein. "Up" stands for upregulated genes, "Down” for downregulated genes. Lfc $<0.5$, corrected p-value $<0.05$. C) Heatmap showing the Gene Ontology analysis (colors represent the significant Normalized Enriched Score).

\section{Figure 2: Expression of Nsp14 induces transcriptional changes like SARS-CoV-2 infection.}

A) MA plot showing the fold change of expression in samples expressing Nsp14 compared to control detected in the Total RNA-seq. In red significantly downregulated genes, in blue upregulated genes, and in grey non significantly deregulated genes. B) Scheme representing the approach to determine the overlap with our Total RNA-seq data and already published dataset (Top). Table reporting the GSEA terms, Up or Down regulation, publication, the Normalized Enriched Score (NES), and adjusted p-value (p-adj) when comparing our Total RNA-seq data with previously published datasets. Significant terms related to SARS-CoV-2 and MERS infection are indicated in blue, non-significant terms related to Influenza A infection are indicated in orange (Bottom). C) Example of GSEA analysis. D) Nsp14 expression vs control Fold Change of intronic signal from total RNA-seq vs 3' RNA-seq signal in logarithmic scale for each detected gene. Colored dots represent significantly changing genes (Fold change $=2$, adjusted $\mathrm{p}$-value $<0.05$, N=3). E) Nsp14 expression vs control Fold Change of intronic signal from total RNA-seq vs exonic signal from total RNA-seq in logarithmic scale for each detected gene. Colored dots represent significantly changing genes (Fold change $=2$, adjusted $p$-value $=<0.05, \mathrm{~N}=3$ ). F) RTqPCR showing the abundance of $F G F-18, C X C L 8, S H 2 D 2 A$, and $C O L 13 A$ in the chromatin bound 
RNA fraction in cells transfected with an empty plasmid (Control) or with Nsp14 (Nsp14). Data represented as mean $\pm \mathrm{SEM}, \mathrm{N}=3$.

Figure 3: Nsp14 expression alters the splicing of a subgroup of genes and increases circRNAs

expression. A) Table summarizing splicing analysis comparison between Nsp14 expression and control. Thresholds used: $\Delta$ PSI $>15 \%$ and a non-overlapping distribution with minimum of $5 \%$ difference $(\mathrm{N}=3)$. B) Fold Change vs Expression in logarithmic scale for the genes with upregulated intron retention. In red genes with increased expression and in blue the ones with downregulated expression. (Foldchange $=2$, adjusted p-value $<0.05, \mathrm{~N}=3$ ). C) Representative IGV alignment tracks of on gene (PAXIP1) with intronic events differentially changing between conditions (Control and Nsp14 expression). The box marks the changing event. On the right, quantification of PSI. D) Pie chart representing number of alternative splicing events deregulated upon Nsp14 expression by gene. 1,772 genes have only one alternative splicing event changing between conditions, 615 has 2 events and 243 genes have 3 alternative splicing events changing. E) Number of circRNAs reads detected in the total RNA-seq experiment. Data represented as mean \pm SEM, N=3, t-test, $* * *$ p-value $<0.0005$. F) Fold Change vs Expression in logarithmic scale for circRNAs in Nsp14 expression vs control. In red upregulated genes and in blue downregulated genes (Foldchange $=2$, adjusted p-value $<0.05, \mathrm{~N}=3$ ). G) Plot of Fold Change vs Expression in logarithmic scale for exonic signal detected in the total RNA-seq dataset in Nsp14 vs control for genes with upregulated circRNA expression. In red genes with increased expression and (Foldchange $=2$, adjusted p-value $<0.05, \mathrm{~N}=3$ ). H) Plot of Fold Change vs Expression in logarithmic scale for intronic signal detected in the total RNA-seq dataset in Nsp14 vs control for genes with upregulated circRNA expression. In red genes with increased expression and in grey non-significant ones (Foldchange $=2$, adjusted $\mathrm{p}$-value $<0.05, \mathrm{~N}=3$ ). 
Figure 4: The N7-guanine-methyltransferase domain but not the exonuclease activity of Nsp14 is required for changing gene expression. A) Western Blot in cells transfected with an empty plasmid (control), Nsp10, Nsp14, or co-expressing Nsp10 and Nsp14 (Nsp10+Nsp14). Nsp10 and Nsp14 were detected through the Strep tag. Actin was used as loading control. See Figure 4 - source data 1. B) MA plots showing the expression fold change in between the indicated conditions in the total RNA-seq dataset. Significantly upregulated genes in blue, downregulated in red, and not significantly deregulated in grey. C) Plot showing the Fold change of deregulated genes in samples co-expressing Nsp10 and Nsp14 vs control (on the y-axis) and Nsp14 vs control (on the X-axis). D) Number of circRNAs reads detected in each indicated condition. Data represented as mean \pm SEM, N=3. E) Plots showing the Fold change of deregulated genes in the indicated condition vs control. G) RT-qPCR showing the expression of $F G F-18, C X C L 8$, and SH2D2A upon the transfection with an empty plasmid (Control), Nsp14 WT, or Nsp14 D331A. Data represented as mean $\pm \mathrm{SEM}, \mathrm{N}=3$. H) RT-qPCR showing the expression of circCDK1, circMARCHF7, and circVKR1 upon the transfection with an empty plasmid (Control), Nsp14 WT, or Nsp14 D331A. Data represented as mean $\pm \mathrm{SEM}, \mathrm{N}=3$.

Figure 5: NFkB pathway is activated soon after Nsp14 transfection. A) Principal component analysis of the 3' RNA-seq of the time course experiment. Arrows indicate how samples separates according to the time point or condition (Nsp14 expression or control). B) Heatmap showing increasing number of up and downregulated genes at different time points after Nsp14 expression. C) Heatmap representing the Gene Ontology Analysis result at the indicated timepoints. D) Expression of CXCL8 across the indicated time points in the 3' RNA-seq data. Data represented as mean $\pm \mathrm{SEM}, \mathrm{N}=3$, t-test, $* *$ p-value $<0.005, *$ p-value $<0.05 \mathbf{E}$ ) Luciferase assay showing that CXCL8 is transcriptionally activated after Nsp14 expression. Firefly expression is controlled by 
CXCL8 promoter, whereas Renilla is under the control of a constitutive promoter. Data represented as mean $\pm \mathrm{SEM}, \mathrm{N}=6$, t-test, ${ }^{* *} \mathrm{p}$-value $\left.<0.005 . \mathrm{F}\right)$ Table showing the enrichment for specific TF binding sites in the promoter (100 bp upstream the transcription starting site of the upregulated genes (lfc >0.8, adjusted p-value $<0.05)$ at 8h after Nsp14 transfection.

Figure 6: Pharmacological inhibition of IMPDH2 partially reverts the transcriptional changes induced by Nsp14. A) Expression of IMPDH2 mRNA is reduced upon Nsp14 expression. Data from the total RNA-seq experiment. Data represented as mean $\pm \mathrm{SEM}, \mathrm{N}=3$, $\mathrm{t}$ test, $* * *$ p-value $<0.0005$. B) In the upper panel, scheme reporting some of the tested metabolites deriving from IMP metabolism. IMPDH2 (highlighted in light blue) catalyzes the conversion of IMP to XMP, precursor of GTP. Significantly upregulated metabolites are highlighted in red. In the lower panel, GTP cellular concentration significantly increases in Nsp14 expressing cells. Data represented as mean $\pm \mathrm{SEM}, \mathrm{N}=3$, t-test, ${ }^{* *} \mathrm{p}$-value<0.005. C) Western Blot showing that MPA treatment does not alter Nsp14 (detected through the Strep-tag) or IMPDH2 expression. Actin used as loading control. See Figure 6 - source data 1. D) Principal component Analysis of the 3' RNAseq library of the indicated samples. E) Table reporting the number of upregulated and downregulated genes in the indicated comparisons. F) Plot showing the distribution of Fold changes of all genes detected in the 3' RNA-seq in the indicated conditions. G) RT-qPCR showing the retention of the first intron for PAXIP1, SETDIA, and ZNF507 in the indicated conditions. Data represented as mean $\pm \mathrm{SEM}, \mathrm{N}=3$.

Figure 2 - figure supplement 1: A) Plot showing the overlap between the 3' RNA-seq dataset and the Total RNA-seq dataset. B) GSEA analysis showing that Nsp14 expression resemble SARS-CoV-2 infection. 
Figure 2 - figure supplement 2: A) representative RT-qPCR showing the abundance of the indicated targets (circVKR1, $18 S$ rRNA, U6, and TBP pre-mRNA) in the indicated subcellular fractions (cytoplasmatic RNA, nucleoplasm RNA, and chromatin bound RNA) from cells transfected with an empty plasmid. Data represented as mean $\pm \mathrm{SEM}, \mathrm{N}=3$.

Figure 3 - figure supplement 1: A) Representative IGV alignment tracks of on gene (HJURP) with multiple exonic events differentially changing between conditions (Control and Nsp14expression). The box marks the changing event. On the right, quantification of PSI. B) Fold Change vs Expression in logarithmic scale for the genes with altered splicing. In red genes with increased expression and in blue the ones with downregulated expression. (Foldchange $=2$, adjusted p-value $<0.05, \mathrm{~N}=3$ ). C) Kernel density plot for 6 intronic features that are significantly changing (Mann Whitney $\mathrm{U}$ test, adjusted p-value $<0.05, \mathrm{~N}=3$ ) in upregulated intron retention upon Nsp14expression. Thresholds used: $\triangle \mathrm{PSI}>15 \%$ and a non-overlapping distribution with minimum of $5 \%$ difference $(\mathrm{N}=3)$. D) Kernel density plot of intron GC content. In grey the distribution for internal introns (never in first position). In blue introns that appear $10 \%$ of the times at first position and in red introns that are in first position in more than $10 \%$ of the transcripts.

Figure 4 - figure supplement 1: A) RT-qPCR showing the expression of $F G F-18$ and $S H 2 D 2 A$ in the indicated conditions. Data represented as mean \pm SEM, N=3. B) PCA for the 3' RNA-seq of the indicated samples. C) Plot showing the Fold change of deregulated genes in samples expressing Nsp10 vs control (on the y-axis) and Nsp14 vs control (on the x-axis).

Figure 4 - figure supplement 2: A) Scheme of the Nsp14 mutants generated in this study. B) PCA for the 3' RNA-seq of the indicated samples. C) MA plots showing the expression fold change in between the indicated conditions in 3' RNA-seq. Significantly upregulated genes in blue, downregulated in red, and not significantly deregulated in grey. D) RT-qPCR showing the 
expression of circCDK1, circMARCHF7, and circVKR1 in the indicated conditions. Data represented as mean $\pm \mathrm{SEM}, \mathrm{N}=3$. E) Western Blot showing the expression of Nsp14 WT and Nsp14 D331A, detected through the Strep tag. Actin was used as loading control. See Figure 4 figure supplement 2 - source data 1.

Figure 5 - figure supplement 1: A) Plot showing the normalized number of Nsp14 reads from the 3' RNA-seq experiment, at the indicated timepoints, in cells transfect with a control plasmid (Control), or the Nsp14 plasmid (Nsp14). B) Western Blot showing increasing amount of Nsp14 at the indicated timepoints in cells transfected with the Nsp14 plasmid. Nsp14 was detected through the Strep tag. Actin was used as loading control. See Figure 5 - figure supplement 1 source data 1. C) MA plots showing the expression fold change in between the indicated conditions in 3' RNA-seq. Significantly upregulated genes in blue, downregulated in red, and not significantly deregulated in grey. D) Expression of selected genes across the indicated time points from the 3' RNA-seq dataset. Data represented as mean \pm SEM, N=3. E) Scheme of the CXCL8 promoter region used for the firefly reporter. F) Luciferase assay showing NFkB activation. Firefly expression is controlled by a minimal transcriptional activator recognized by NFkB, whereas Renilla is under the control of a ubiquitous promoter. Data represented as mean $\pm S E M, N=6$, $t$ test, $* *$ p-value $<0.005$.

Figure 6 - figure supplement 1: A) Western Blots of the subcellular fractionation and chromatin precipitation at the indicated timepoints post transfection (12h, 24h, and $48 \mathrm{~h}$ ) in cells transfected with an empty plasmid (Control), or Nsp14 (Nsp14). Nsp14 was detected through the Strep tag. GAPDH is used as cytoplasmatic marker, and H3K27me3 as a chromatin bound marker. See Figure 6 - figure supplement 1 - source data 1. B) MA plots relative to the 3' RNA-seq experiment of cells transfected with a control plasmid (Control) or Nsp14 (Nsp14) and treated with the vehicle 
(DMSO) or MPA (MPA). Significantly upregulated genes in blue, downregulated in red, and not significantly deregulated in grey.

Figure 6 - figure supplement 2: A) Expression of $I M P D H 2, F G F-18, S H 2 D 2 A$, and $C X C L 8$ in the 3' RNA-seq dataset in the indicated conditions. B) Venn diagram showing the common genes upregulated (left) or downregulated (right) in samples expressing Nsp14 and treated with or without MPA. C) RT-qPCR showing the expression of circCDK1, circMARCHF7, and circVKR1 in the indicated conditions. Data represented as mean $\pm \mathrm{SEM}, \mathrm{N}=3$. D) Western Blot showing that MZR treatment does not alter Nsp14 or IMPDH2 expression. Actin used as loading control. See Figure 6 - figure supplement 2 - source data 1. E) RT-qPCR showing the expression of $F G F-18$, $C X C L 8$, and $S H 2 D 2 A$, in the indicated conditions. Data represented as mean $\pm \mathrm{SEM}, \mathrm{N}=3$. F) RTqPCR showing the expression of circCDK1, circMARCHF7, and circVKR1 in the indicated conditions. Data represented as mean $\pm \mathrm{SEM}, \mathrm{N}=3$. G) RT-qPCR showing the retention of the first intron for PAXIP1, SETD1A, and ZNF507 in the indicated conditions. Data represented as mean \pm SEM, N=3. 


\section{List of Source Data Files}

Figure 4 - source data 1: Western Blot data for Figure 4A

Figure 4 - figure supplement 2 - source data 1: Western Blot data for Figure 4 - figure supplement $2 \mathrm{E}$

Figure 5 - figure supplement 1 - source data 1: Western Blot data for Figure 5 - figure supplement $1 \mathrm{~B}$

Figure 6 - source data 1: Western Blot data for Figure 6C

Figure 6 - figure supplement 1 - source data 1: Western Blot data for Figure 6 - figure supplement $1 \mathrm{~A}$

Figure 6 - figure supplement 2 - source data 1: Western Blot data for Figure 6 - figure supplement 2D 


\section{Competing interests}

The authors declare no competing interests.

\section{Founding}

This work was supported by the NIH R01 Grant R01AG057700 to SK and NIH NIGMS P41

GM132087 to NP. NP is an investigator of HHMI.

\section{Acknowledgments}

We thank the Hedstrom Lab, the Marr lab, and the Rosbash Lab at Brandeis University for sharing reagents, instruments, and for helpful discussion. Thanks Dr. tenOever at Icahn School of Medicine at Mount Sinai for critical discussion of the data. Thanks to Dr. Aarti Jajoo for the initial steps of the screening data analysis, and to Claire Martel for helping with plasmids purification. Special appreciation to Valentina Tacconi for preparing the Potential Striking Image. We warmly thank all the members of Kadener lab for helpful and critical discussion.

\section{Authors' contribution}

M.Z. performed most of the experiments, designed the experiments, and wrote the manuscript. J.M.H. and I.L.P. performed the bioinformatic analysis. I.L.P. helped drafting the manuscript. N.R.P. performed most of the RNA extractions, part of the RT-qPCRs and prepared the total RNA

libraries. S.N. prepared most of the 3' RNA libraries. S.K. wrote the manuscript, designed the experiments, and supervised the project. 


\section{References}

Adcock, I. M. et al. (2015) 'Severity of acute respiratory distress syndrome resulting from tuberculosis correlates with bronchoalveolar lavage CXCL-8 expression', International Journal of Mycobacteriology, 4, p. 71. doi: https://doi.org/10.1016/j.ijmyco.2014.11.039. Ahangari, N. et al. (2021) 'Nuclear IMPDH Filaments in Human Gliomas.', Journal of neuropathology and experimental neurology, 80(10), pp. 944-954. doi: 10.1093/jnen/nlab090. Ashwal-Fluss, R. et al. (2014) 'circRNA Biogenesis Competes with Pre-mRNA Splicing', Molecular Cell, 56(1), pp. 55-66. doi: https://doi.org/10.1016/j.molcel.2014.08.019. Bachmayr-Heyda, A. et al. (2015) 'Correlation of circular RNA abundance with proliferation exemplified with colorectal and ovarian cancer, idiopathic lung fibrosis and normal human tissues', Scientific Reports, 5(1), p. 8057. doi: 10.1038/srep08057.

Bailey, T. L. et al. (2009) 'MEME SUITE: tools for motif discovery and searching.', Nucleic acids research, 37(Web Server issue), pp. W202-8. doi: 10.1093/nar/gkp335.

Baldwin, A. S. J. (1996) 'The NF-kappa B and I kappa B proteins: new discoveries and insights.', Annual review of immunology, 14, pp. 649-683. doi:

10.1146/annurev.immunol.14.1.649.

Banerjee, A. K. et al. (2020) 'SARS-CoV-2 Disrupts Splicing, Translation, and Protein Trafficking to Suppress Host Defenses', Cell, 183(5), pp. 1325-1339.e21. doi: https://doi.org/10.1016/j.cell.2020.10.004.

Blanco-Melo, D. et al. (2020) 'Imbalanced Host Response to SARS-CoV-2 Drives Development of COVID-19.', Cell, 181(5), pp. 1036-1045.e9. doi: 10.1016/j.cell.2020.04.026.

Bouvet, M. et al. (2012) 'RNA 3'-end mismatch excision by the severe acute respiratory syndrome coronavirus nonstructural protein nsp10/nsp14 exoribonuclease complex.', Proceedings of the National Academy of Sciences of the United States of America, 109(24), pp. 9372-9377. doi: 10.1073/pnas.1201130109.

Bouvet, M. et al. (2014) 'Coronavirus Nsp10, a critical co-factor for activation of multiple replicative enzymes.', The Journal of biological chemistry, 289(37), pp. 25783-25796. doi: 10.1074/jbc.M114.577353.

Chen, T.-C. et al. (2020) 'Host-derived circular RNAs display proviral activities in Hepatitis C virus-infected cells.', PLoS pathogens, 16(8), p. e1008346. doi: 10.1371/journal.ppat.1008346. Chen, Y. et al. (2009) 'Functional screen reveals SARS coronavirus nonstructural protein nsp14 as a novel cap N7 methyltransferase', Proceedings of the National Academy of Sciences, 106(9), pp. 3484 LP - 3489. doi: 10.1073/pnas.0808790106.

Conn, S. J. et al. (2015) 'The RNA binding protein quaking regulates formation of circRNAs', Cell, 160(6), pp. 1125-1134. doi: 10.1016/j.cell.2015.02.014.

Coperchini, F. et al. (2020) 'The cytokine storm in COVID-19: An overview of the involvement of the chemokine/chemokine-receptor system.', Cytokine \& growth factor reviews, 53, pp. 2532. doi: 10.1016/j.cytogfr.2020.05.003.

Dang, W. et al. (2017) 'Inhibition of Calcineurin or IMP Dehydrogenase Exerts Moderate to Potent Antiviral Activity against Norovirus Replication.', Antimicrobial agents and chemotherapy, 61(11). doi: 10.1128/AAC.01095-17.

Dobin, A. et al. (2013) 'STAR: ultrafast universal RNA-seq aligner.', Bioinformatics (Oxford, England), 29(1), pp. 15-21. doi: 10.1093/bioinformatics/bts635.

Eckerle, L. D. et al. (2010) 'Infidelity of SARS-CoV Nsp14-exonuclease mutant virus replication is revealed by complete genome sequencing.', PLoS pathogens, 6(5), p. e1000896. doi: 10.1371/journal.ppat.1000896. 
Egloff, M.-P. et al. (2004) 'The severe acute respiratory syndrome-coronavirus replicative protein nsp9 is a single-stranded RNA-binding subunit unique in the RNA virus world', Proceedings of the National Academy of Sciences of the United States of America, 101(11), pp. 3792 LP - 3796. doi: 10.1073/pnas.0307877101.

Errichelli, L. et al. (2017) 'FUS affects circular RNA expression in murine embryonic stem cellderived motor neurons', Nature Communications, 8, pp. 1-11. doi: 10.1038/ncomms14741. Gardinassi, L. G. et al. (2020) 'Immune and Metabolic Signatures of COVID-19 Revealed by Transcriptomics Data Reuse', Frontiers in Immunology, 11, p. 1636. doi: 10.3389/fimmu.2020.01636.

Glesne, D. A., Collart, F. R. and Huberman, E. (1991) 'Regulation of IMP dehydrogenase gene expression by its end products, guanine nucleotides', Molecular and Cellular Biology, 11(11), pp. 5417-5425. doi: 10.1128/mcb.11.11.5417-5425.1991.

Gohr, A. and Irimia, M. (2019) 'Matt: Unix tools for alternative splicing analysis.', Bioinformatics (Oxford, England), 35(1), pp. 130-132. doi: 10.1093/bioinformatics/bty606. Gordon, D. E., Jang, G. M., et al. (2020) 'A SARS-CoV-2 protein interaction map reveals targets for drug repurposing.', Nature, 583(7816), pp. 459-468. doi: 10.1038/s41586-020-2286-9.

Gordon, D. E., Hiatt, J., et al. (2020) 'Comparative host-coronavirus protein interaction networks reveal pan-viral disease mechanisms', Science, 370(6521), p. eabe9403. doi:

10.1126/science.abe9403.

Graham, R. L. et al. (2012) 'A live, impaired-fidelity coronavirus vaccine protects in an aged, immunocompromised mouse model of lethal disease.', Nature medicine, 18(12), pp. 1820-1826. doi: 10.1038/nm.2972.

Grant, C. E., Bailey, T. L. and Noble, W. S. (2011) 'FIMO: scanning for occurrences of a given motif.', Bioinformatics (Oxford, England), 27(7), pp. 1017-1018. doi:

10.1093/bioinformatics/btr064.

Hariharan, A. et al. (2021) 'The Role and Therapeutic Potential of NF-kappa-B Pathway in Severe COVID-19 Patients.', Inflammopharmacology, 29(1), pp. 91-100. doi: 10.1007/s10787020-00773-9.

Hashimshony, T. et al. (2016) 'CEL-Seq2: sensitive highly-multiplexed single-cell RNA-Seq', Genome Biology, 17(1), p. 77. doi: 10.1186/s13059-016-0938-8.

Hedstrom, L. (2009) 'IMP dehydrogenase: structure, mechanism, and inhibition.', Chemical reviews, 109(7), pp. 2903-2928. doi: 10.1021/cr900021w.

Hesketh, A. and Oliver, S. G. (2019) 'High-energy guanine nucleotides as a signal capable of linking growth to cellular energy status via the control of gene transcription', Current Genetics, 65(4), pp. 893-897. doi: 10.1007/s00294-019-00963-1.

Hillen, H. S. et al. (2020) 'Structure of replicating SARS-CoV-2 polymerase', Nature, 584(7819), pp. 154-156. doi: 10.1038/s41586-020-2368-8.

Hsu, J. C.-C. et al. (2021) 'Translational shutdown and evasion of the innate immune response by SARS-CoV-2 NSP14 protein', Proceedings of the National Academy of Sciences, 118(24), p. e2101161118. doi: 10.1073/pnas.2101161118.

Jin, X. et al. (2013) 'Characterization of the guanine-N7 methyltransferase activity of coronavirus nsp14 on nucleotide GTP', Virus Res, 176(1)(Sep), pp. 45-52.

Kato, F. et al. (2020) 'Antiviral activities of mycophenolic acid and IMD-0354 against SARSCoV-2', Microbiology and Immunology, 64(9), pp. 635-639. doi: https://doi.org/10.1111/13480421.12828.

Kim, D. et al. (2020) 'The Architecture of SARS-CoV-2 Transcriptome.', Cell, 181(4), pp. 914- 
921.e10. doi: 10.1016/j.cell.2020.04.011.

Kirchdoerfer, R. N. and Ward, A. B. (2019) 'Structure of the SARS-CoV nsp12 polymerase bound to nsp7 and nsp8 co-factors', Nature Communications, 10(1), p. 2342. doi:

10.1038/s41467-019-10280-3.

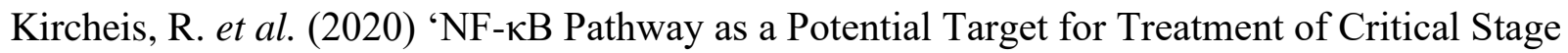
COVID-19 Patients', Frontiers in Immunology, 11, p. 3446. doi: 10.3389/fimmu.2020.598444.

Knupp, D. et al. (2021) 'NOVA2 regulates neural circRNA biogenesis', Nucleic Acids Research, 49(12), pp. 6849-6862. doi: 10.1093/nar/gkab523.

Konno, Y. et al. (2020) 'SARS-CoV-2 ORF3b Is a Potent Interferon Antagonist Whose Activity Is Increased by a Naturally Occurring Elongation Variant', Cell Reports, 32(12), p. 108185. doi: https://doi.org/10.1016/j.celrep.2020.108185.

Kozhevnikova, E. N. et al. (2012) 'Metabolic enzyme IMPDH is also a transcription factor regulated by cellular state.', Molecular cell, 47(1), pp. 133-139. doi:

10.1016/j.molcel.2012.04.030.

Kunsch, C. and Rosen, C. A. (1993) 'NF-kappa B subunit-specific regulation of the interleukin-8 promoter.', Molecular and cellular biology, 13(10), pp. 6137-6146. doi:

10.1128/mcb.13.10.6137-6146.1993.

Lee, Stuart et al. (2020) 'Covering all your bases: incorporating intron signal from RNA-seq data', NAR Genomics and Bioinformatics, 2(3). doi: 10.1093/nargab/lqaa073.

Lee, Seungheon et al. (2020) 'Mycophenolic anilides as broad specificity inosine-5'-

monophosphate dehydrogenase (IMPDH) inhibitors.', Bioorganic \& medicinal chemistry letters, 30(24), p. 127543. doi: 10.1016/j.bmcl.2020.127543.

Li, T. et al. (2021) 'SARS-CoV-2 Nsp14 activates NF- $\kappa \mathrm{B}$ signaling and induces IL-8 upregulation', bioRxiv. doi: 10.1101/2021.05.26.445787.

Li, X. et al. (2017) 'Coordinated circRNA Biogenesis and Function with NF90/NF110 in Viral Infection.', Molecular cell, 67(2), pp. 214-227.e7. doi: 10.1016/j.molcel.2017.05.023.

Liao, Q.-J. et al. (2005) 'Activation of NF-kappaB by the full-length nucleocapsid protein of the SARS coronavirus.', Acta biochimica et biophysica Sinica, 37(9), pp. 607-612. doi:

10.1111/j.1745-7270.2005.00082.x.

Lin, C.-L., Taggart, A. J. and Fairbrother, W. G. (2016) 'RNA structure in splicing: An evolutionary perspective.', RNA biology, 13(9), pp. 766-771. doi:

10.1080/15476286.2016.1208893.

Liu, C.-X. et al. (2019) 'Structure and Degradation of Circular RNAs Regulate PKR Activation in Innate Immunity', Cell, 177(4), pp. 865-880.e21. doi:

https://doi.org/10.1016/j.cell.2019.03.046.

Love, M. I., Huber, W. and Anders, S. (2014) 'Moderated estimation of fold change and dispersion for RNA-seq data with DESeq2.', Genome biology, 15(12), p. 550. doi:

10.1186/s13059-014-0550-8.

Ma, Y. et al. (2015a) 'Structural basis and functional analysis of the SARS coronavirus nsp14nsp10 complex.', Proceedings of the National Academy of Sciences of the United States of America, 112(30), pp. 9436-9441. doi: 10.1073/pnas.1508686112.

Ma, Y. et al. (2015b) 'Structural basis and functional analysis of the SARS coronavirus nsp14 Insp10 complex', Proceedings of the National Academy of Sciences, 112(30), pp. 94369441. doi: 10.1073/pnas.1508686112.

McLean, J. E. et al. (2004) 'Inosine 5'-monophosphate dehydrogenase binds nucleic acids in vitro and in vivo.', The Biochemical journal, 379(Pt 2), pp. 243-251. doi: 10.1042/BJ20031585. 
McLeay, R. C. and Bailey, T. L. (2010) 'Motif Enrichment Analysis: a unified framework and an evaluation on ChIP data.', BMC bioinformatics, 11, p. 165. doi: 10.1186/1471-2105-11-165.

Memczak, S. et al. (2013) 'Circular RNAs are a large class of animal RNAs with regulatory potency.', Nature, 495(7441), pp. 333-338. doi: 10.1038/nature11928.

Mortimer, S. E. and Hedstrom, L. (2005) 'Autosomal dominant retinitis pigmentosa mutations in inosine 5'-monophosphate dehydrogenase type I disrupt nucleic acid binding.', The Biochemical journal, 390(Pt 1), pp. 41-47. doi: 10.1042/BJ20042051.

Ogando, N. S. et al. (2020) 'The Enzymatic Activity of the nsp14 Exoribonuclease Is Critical for Replication of MERS-CoV and SARS-CoV-2.', Journal of virology, 94(23). doi:

10.1128/JVI.01246-20.

Otava, T. et al. (2021) 'The Structure-Based Design of SARS-CoV-2 nsp14 Methyltransferase

Ligands Yields Nanomolar Inhibitors', ACS Infectious Diseases, 7(8), pp. 2214-2220. doi:

10.1021/acsinfecdis.1c00131.

Pahl, H. L. (1999) 'Activators and target genes of Rel/NF-kappaB transcription factors.', Oncogene, 18(49), pp. 6853-6866. doi: 10.1038/sj.onc.1203239.

Pan, Q. et al. (2012) 'Mycophenolic acid augments interferon-stimulated gene expression and inhibits hepatitis C Virus infection in vitro and in vivo.', Hepatology (Baltimore, Md.), 55(6), pp. 1673-1683. doi: 10.1002/hep.25562.

Park, J. H. and Lee, H. K. (2020) 'Re-analysis of Single Cell Transcriptome Reveals That the NR3C1-CXCL8-Neutrophil Axis Determines the Severity of COVID-19', Frontiers in Immunology, 11, p. 2145. doi: 10.3389/fimmu.2020.02145.

Robson, F. et al. (2020) 'Coronavirus RNA Proofreading: Molecular Basis and Therapeutic Targeting’, Molecular Cell, 79(5), pp. 710-727. doi:

https://doi.org/10.1016/j.molcel.2020.07.027.

Romano, M. et al. (2020) 'A Structural View of SARS-CoV-2 RNA Replication Machinery: RNA Synthesis, Proofreading and Final Capping', Cells, 9(5). doi: 10.3390/cells9051267.

Sanjuán, R. et al. (2010) 'Viral Mutation Rates', Journal of Virology, 84(19), pp. 9733-9748. doi: 10.1128/JVI.00694-10.

Saramago, M. et al. (2021) 'New targets for drug design: importance of nsp14/nsp10 complex formation for the 3'-5' exoribonucleolytic activity on SARS-CoV-2', FEBS Journal, 288(17), pp. 5130-5147. doi: 10.1111/febs.15815.

Sarrion-Perdigones, A., Gonzalez, Y. and Venken, K. J. T. (2020) 'Rapid and Efficient Synthetic Assembly of Multiplex Luciferase Reporter Plasmids for the Simultaneous Monitoring of Up to Six Cellular Signaling Pathways.', Current protocols in molecular biology, 131(1), p. e121. doi: 10.1002/cpmb. 121.

Schubert, K. et al. (2020) 'SARS-CoV-2 Nsp1 binds the ribosomal mRNA channel to inhibit translation', Nature Structural \& Molecular Biology, 27(10), pp. 959-966. doi: 10.1038/s41594020-0511-8.

Sergushichev, A. A. et al. (2016) 'GAM: a web-service for integrated transcriptional and metabolic network analysis.', Nucleic acids research, 44(W1), pp. W194-200. doi:

10.1093/nar/gkw266.

Shu, T. et al. (2020) 'SARS-Coronavirus-2 Nsp13 Possesses NTPase and RNA Helicase Activities That Can Be Inhibited by Bismuth Salts.', Virologica Sinica, 35(3), pp. 321-329. doi: 10.1007/s12250-020-00242-1.

Smith, E. C. et al. (2015) 'Mutations in Coronavirus Nonstructural Protein 10 Decrease Virus Replication Fidelity', Journal of Virology, 89(12), pp. 6418-6426. doi: 10.1128/JVI.00110-15. 
Stein, B. et al. (1993) 'Cross-coupling of the NF-kappa B p65 and Fos/Jun transcription factors produces potentiated biological function.', The EMBO journal, 12(10), pp. 3879-3891.

Sun, G. et al. (2021) 'Comparative transcriptomic analysis of SARS-CoV-2 infected cell model systems reveals differential innate immune responses', Scientific Reports, 11(1), pp. 1-12. doi: 10.1038/s41598-021-96462-w.

Tapial, J. et al. (2017) 'An atlas of alternative splicing profiles and functional associations reveals new regulatory programs and genes that simultaneously express multiple major isoforms.', Genome research, 27(10), pp. 1759-1768. doi: 10.1101/gr.220962.117.

To, K. K. W. et al. (2016) 'Mycophenolic acid, an immunomodulator, has potent and broadspectrum in vitro antiviral activity against pandemic, seasonal and avian influenza viruses affecting humans', Journal of General Virology, 97(8), pp. 1807-1817. doi:

https://doi.org/10.1099/jgv.0.000512.

V'kovski, P. et al. (2021a) 'Coronavirus biology and replication: implications for SARS-CoV-2', Nature Reviews Microbiology, 19(3), pp. 155-170. doi: 10.1038/s41579-020-00468-6.

V'kovski, P. et al. (2021b) 'Coronavirus biology and replication: implications for SARS-CoV2', Nature Reviews Microbiology, 19(3), pp. 155-170. doi: 10.1038/s41579-020-00468-6.

Del Valle, D. M. et al. (2020) 'An inflammatory cytokine signature predicts COVID-19 severity and survival.', Nature medicine, 26(10), pp. 1636-1643. doi: 10.1038/s41591-020-1051-9. Vanderheiden, A. et al. (2020) 'Type I and Type III Interferons Restrict SARS-CoV-2 Infection of Human Airway Epithelial Cultures.', Journal of virology, 94(19). doi: 10.1128/JVI.00985-20. Wang, S. et al. (2021) 'Circular RNA circPFKP promotes cell proliferation by activating IMPDH2 in prostate cancer', Cancer Letters, 524(May), pp. 109-120. doi:

10.1016/j.canlet.2021.10.021.

Wang, W. et al. (2007) 'Up-regulation of IL-6 and TNF-alpha induced by SARS-coronavirus spike protein in murine macrophages via NF-kappaB pathway.', Virus research, 128(1-2), pp. 1-8. doi: 10.1016/j.virusres.2007.02.007.

Wilson, A. A. et al. (2013) 'Lentiviral delivery of RNAi for in vivo lineage-specific modulation of gene expression in mouse lung macrophages.', Molecular therapy: the journal of the American Society of Gene Therapy, 21(4), pp. 825-833. doi: 10.1038/mt.2013.19.

Wolff, G. et al. (2020) 'A molecular pore spans the double membrane of the coronavirus replication organelle', Science, 369(6509), pp. 1395-1398. doi: 10.1126/SCIENCE.ABD3629. Wyler, E. et al. (2021) 'Transcriptomic profiling of SARS-CoV-2 infected human cell lines identifies HSP90 as target for COVID-19 therapy.', iScience, 24(3), p. 102151. doi: 10.1016/j.isci.2021.102151.

Yan, L. and Chen, Y. G. (2020) 'Circular RNAs in Immune Response and Viral Infection', Trends in Biochemical Sciences, 45(12), pp. 1022-1034. doi:

https://doi.org/10.1016/j.tibs.2020.08.006.

Yuen, C.-K. et al. (2020) 'SARS-CoV-2 nsp13, nsp14, nsp15 and orf6 function as potent interferon antagonists.', Emerging microbes \& infections, 9(1), pp. 1418-1428. doi: 10.1080/22221751.2020.1780953.

Zhang, J., Kuo, C. C. J. and Chen, L. (2011) 'GC content around splice sites affects splicing through pre-mRNA secondary structures.', BMC genomics, 12, p. 90. doi: 10.1186/1471-216412-90.

Zhang, L. et al. (2004) 'GC/AT-content spikes as genomic punctuation marks.', Proceedings of the National Academy of Sciences of the United States of America, 101(48), pp. 16855-16860. doi: 10.1073/pnas.0407821101. 
bioRxiv preprint doi: https://doi.org/10.1101/2021.07.02.450964; this version posted February 16,2022 . The copyright holder for this preprint (which was not certified by peer review) is the author/funder. All rights reserved. No reuse allowed without permission. 
bioRxiv preprint doi: https://doi.org/10.1101/2021.07.02.450964; this version posted February 16,2022 . The copyright holder for this preprint (which was not certified by peer review) is the author/funder. All rights reserved. No reuse allowed without permission.

A.

$B$.

\section{Expression of 26 SARS-CoV-2 proteins} in HEK-293T

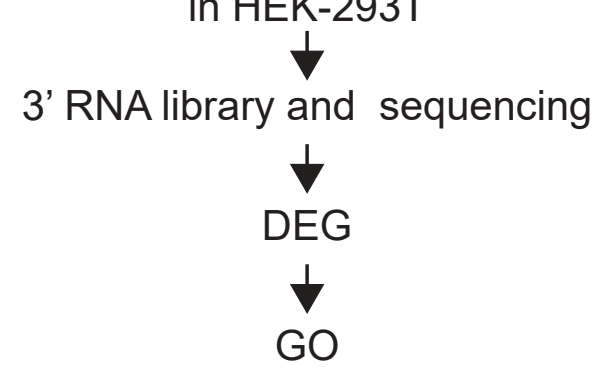

significant

C. Normalized Enriched Score

$\begin{array}{lllllll}3 & 2 & 1 & 0 & -1 & -2 & -3\end{array}$
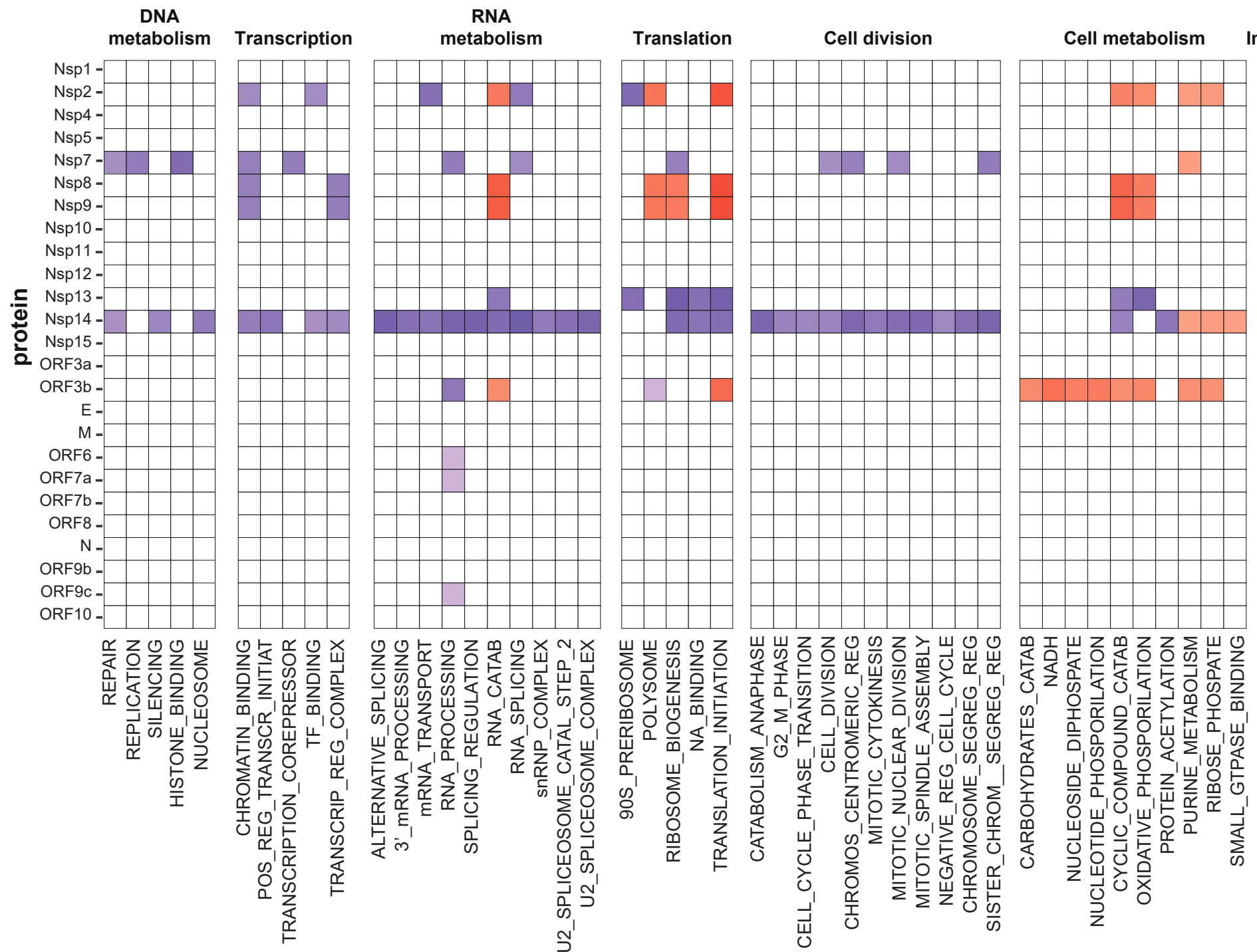

Immunity

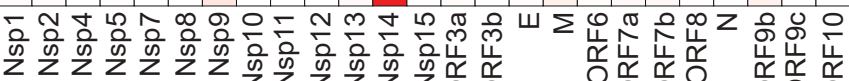

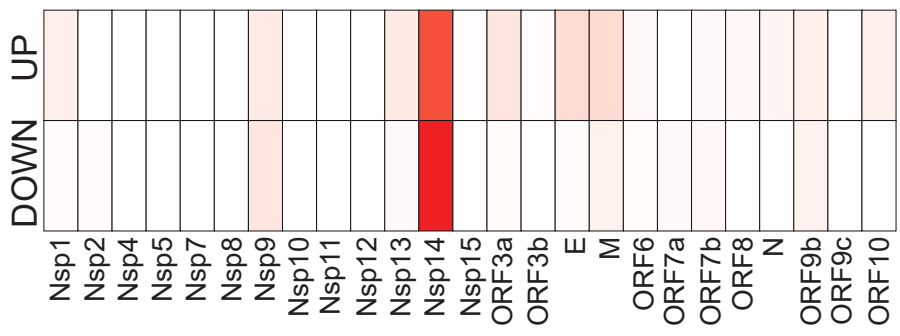

count

$-1500$

1000

500 
bioRxiv preprint doi: https://doi.org/10.1101/2021.07.02.450964; this version posted February 16, 2022. The copyright holder for this preprint (which was not certified by peer review) is the author/funder. All rights reserved. No reuse allowed without permission.

A.

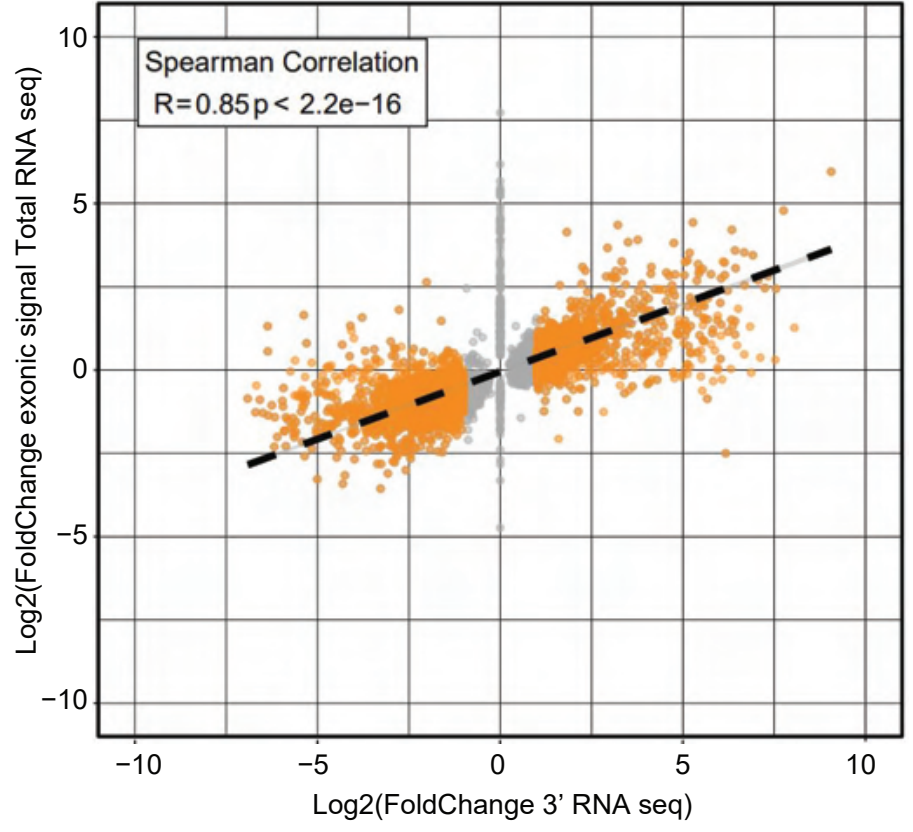

\section{Dataset}

BLANCO_MELO_COVID19_SARS_COV_2 INFECTION_A594_ACE2_EXPRESSING_CĒELLS RUXXLITINIB_UP

BLANCO MELO COVID19 SARS COV 2 INFECTION_A594_AC̄E2_EXPRESSING_CELLS'UP

CHEN_HOXA5_TARGETS_9HR_UP
BLANCO_MELO_COVID19_SARS_COV_2_ LOW MOI INFECTION A594_ACE2_EXPRESSING_CELLS_UP

BLANCO_MELO_MERS_COV INFECTION_MCR5_CELLS_UP

BLANCO_MELO_COVID19_SARS_COV_2 INFECTION_A594_ACEE2_EXPRESSING_CELLS_DN

BLANCO_MELO_INFLUENZA_A
INFECTION A594_CELLS_UP

BLANCO_MELO_INFLUENZA_A INFECTION_A5944_CELLS_DN
Gene ranks

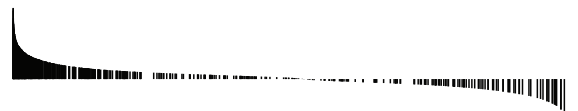

2.36

$2.7 e-04$

$4.7 e-03$

2.32

$2.8 e-04$

$4.8 e-03$

2.34

$2.4 e-04$

$4.4 e-03$

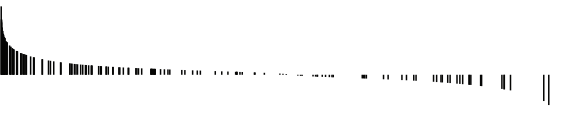

2.15

$2.4 e-04$

$4.4 e-03$

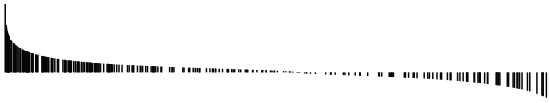

1.92

$2.5 e-04$

$4.5 e-03$

|| ||I || ।

$1.3 e-01$

$2.7 e-01$

\section{Figure 2 - figure supplement 1}


A.

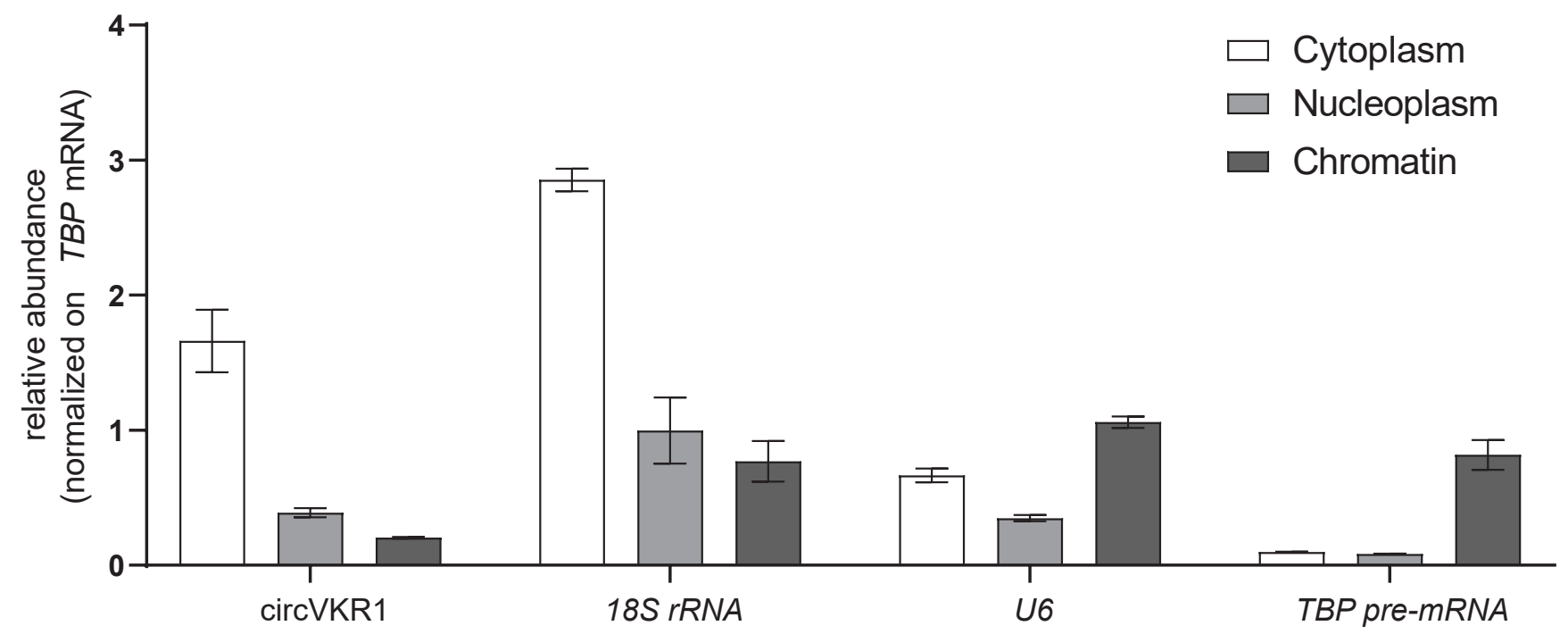

Figure 2 - figure supplement 2 
bioRxiv preprint doi: https://doi.org/10.1101/2021.07.02.450964; this version posted February 16,2022 . The copyright holder for this preprint

\section{All rights reserved. No reuse allowed without permission.

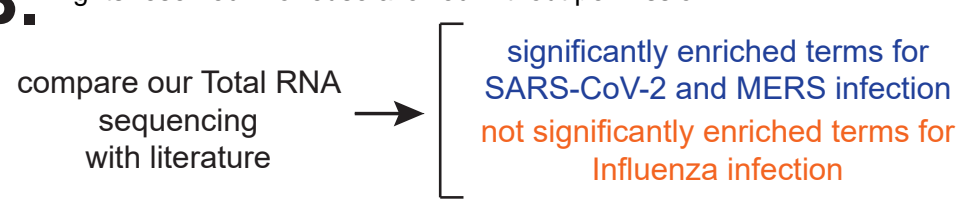

10

Nsp14 vs Control $\quad \begin{gathered}\text { Differentially } \\ \text { expressed }\end{gathered} \mid \begin{aligned} & \bullet \text { Down } \\ & \bullet \text { NS } \\ & \text { Unp }\end{aligned}$

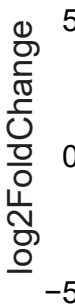

$-10$
$1 e+03$ BaseMean
A549:ACE2 infected with SARS-CoV-2, Up, Blanco Melo et al., 2020

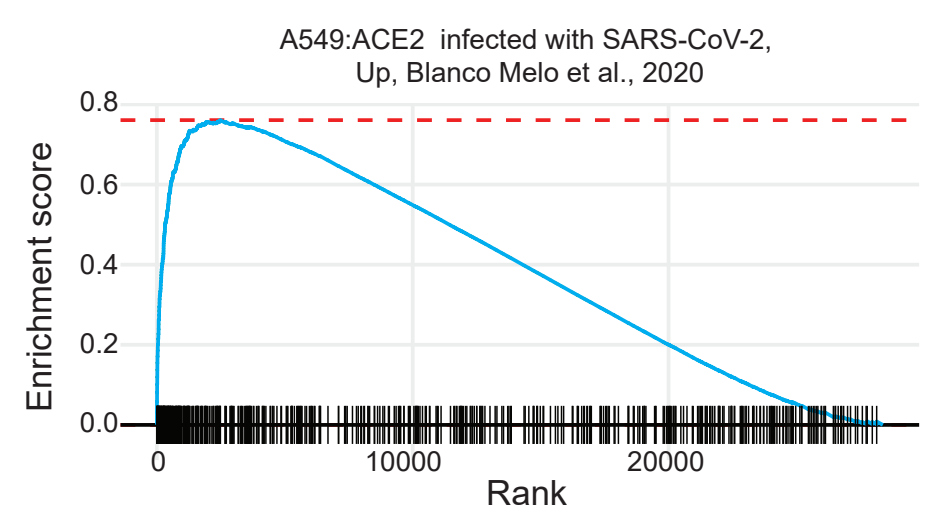

E.

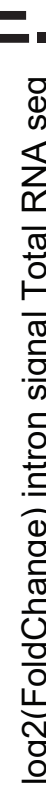

\section{ODE ONA}

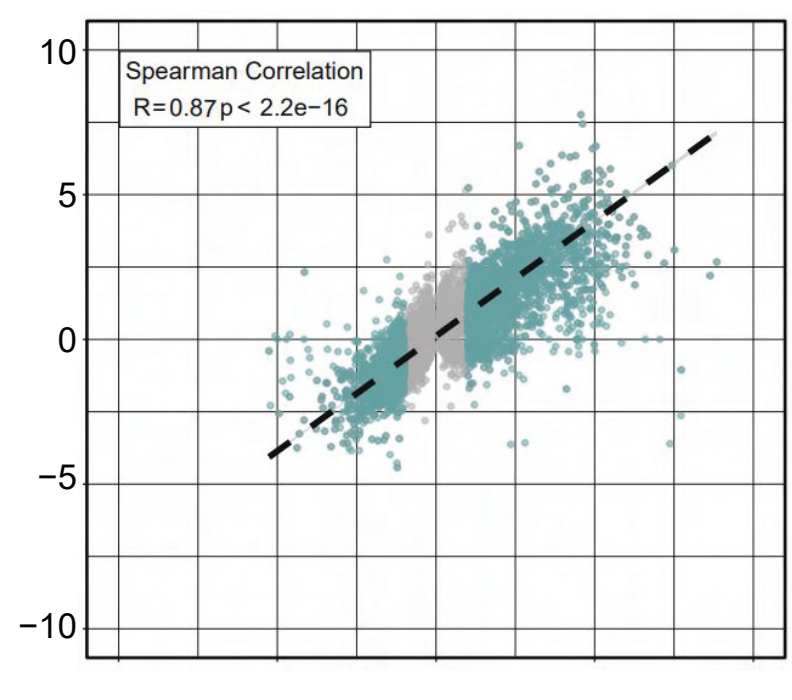

log2(FoldChange) exon signal Total RNA seq
C.
D.

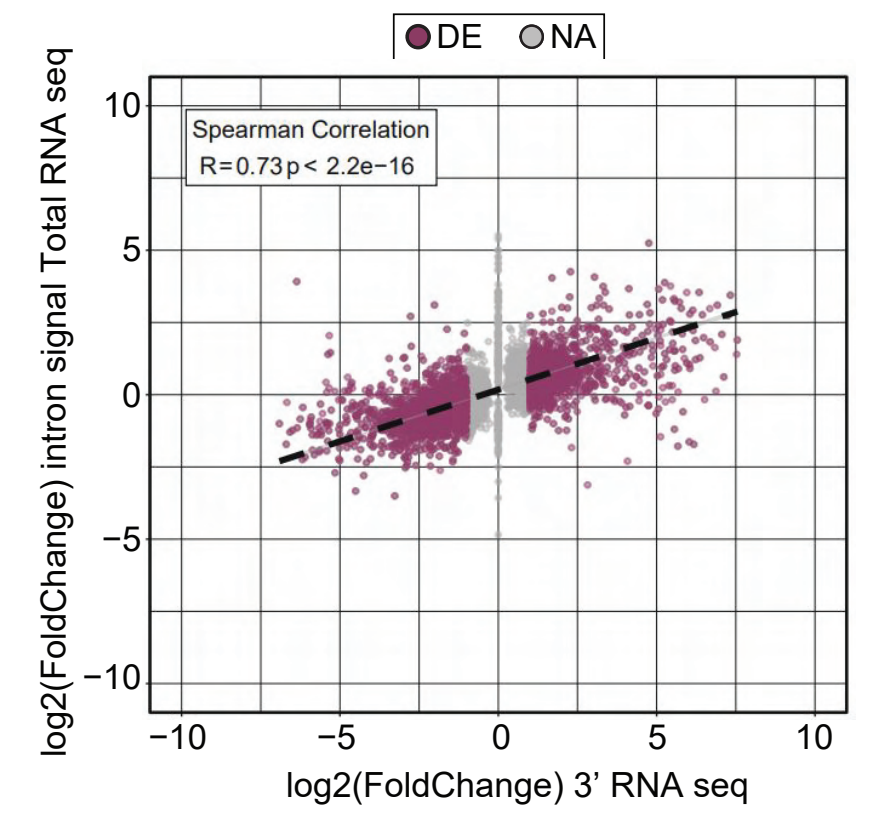

$\mathbf{F}$.

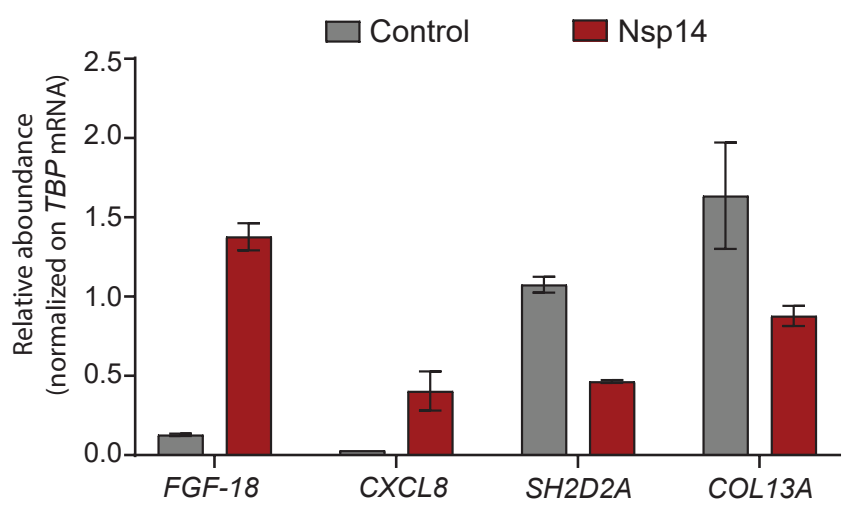

\begin{tabular}{|ccccc|}
\hline GSEA term & Up/ Down regulated & Publication & NES & p-adj \\
\hline $\begin{array}{c}\text { A549:ACE2 infected with } \\
\text { SARS-CoV-2(RUX treatment) }\end{array}$ & Up & Blanco Melo et al., 2020 & 2.36 & 0.0047 \\
$\begin{array}{c}\text { A549:ACE2 infected with } \\
\text { SARS-CoV-2 }\end{array}$ & Up & Blanco Melo et al., 2020 & 2.32 & 0.0048 \\
$\begin{array}{c}\text { HOXA5 targets 9h after induction } \\
\text { A549:ACE2 infected } \\
\text { with SARS-CoV-2Low MOI }\end{array}$ & Up & Chen et al., 2005 & 2.31 & 0.0044 \\
$\begin{array}{c}\text { MCR5 cells infected with MERS } \\
\text { A549:ACE2 infected with } \\
\text { SARS-CoV-2 }\end{array}$ & Up & Blanco Melo et al., 2020 & 2.15 & 0.0044 \\
$\begin{array}{c}\text { A549:ACE2 infected with } \\
\text { Influenza A }\end{array}$ & Down & Blanco Melo et al., 2020 & 1.92 & 0.0045 \\
$\begin{array}{c}\text { A549:ACE2 infected with } \\
\text { Influenza A }\end{array}$ & Blanco Melo et al., 2020 & -1.75 & 0.0071 \\
\hline
\end{tabular}


bioRxiv preprint doi: https://doi.org/10.1101/2021.07.02.450964; this version posted February 16, 2022. The copyright holder for this preprint (which was not certified by peer review) is the author/funder. All rights reserved. No reuse allowed without permission.

A.
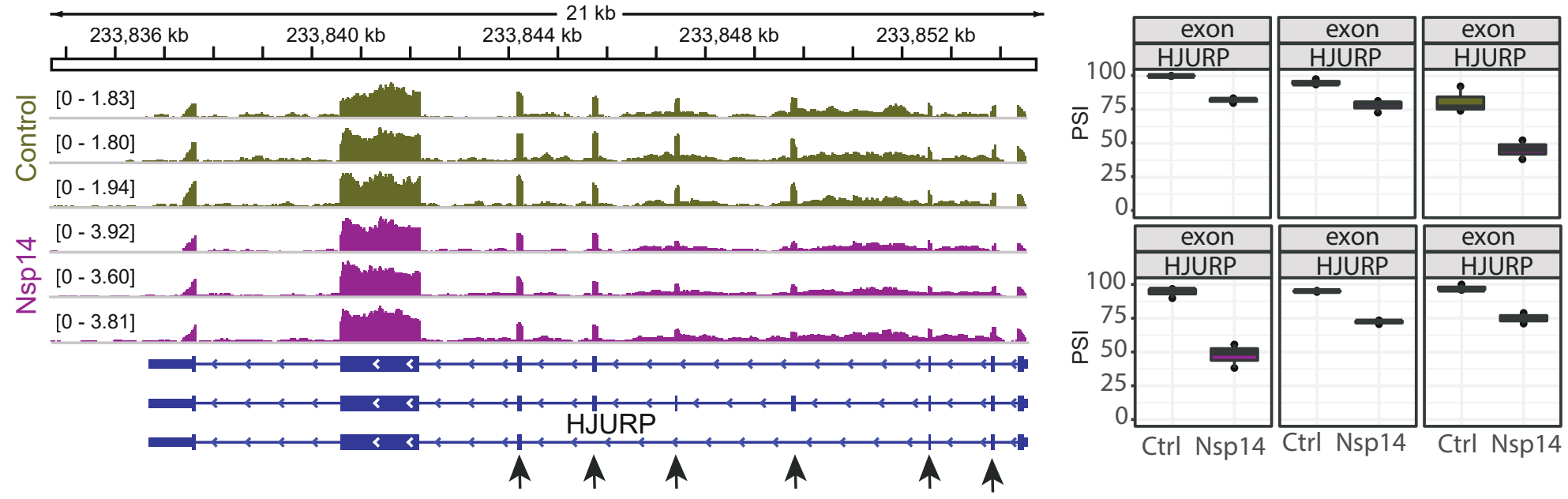

B.

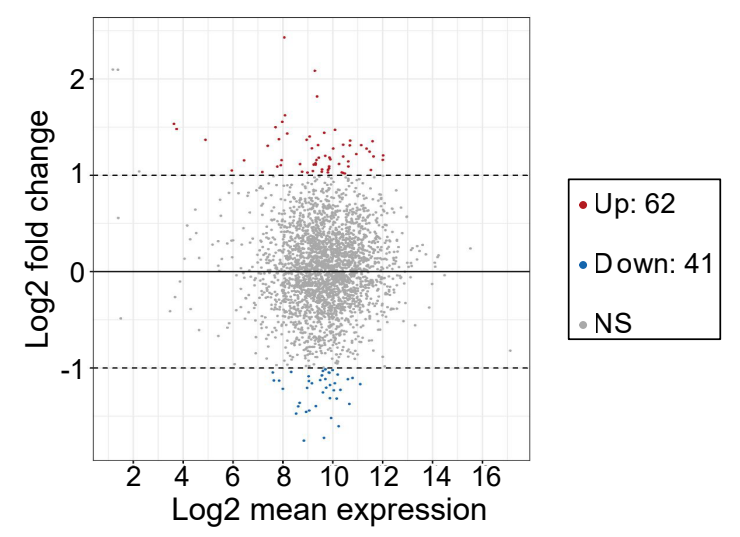

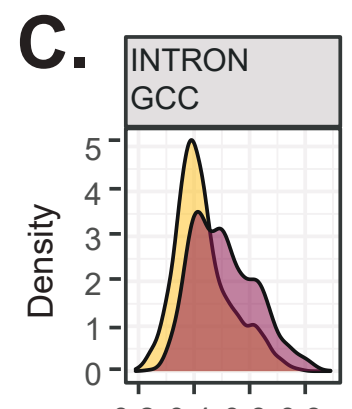

0.20 .40 .60 .8

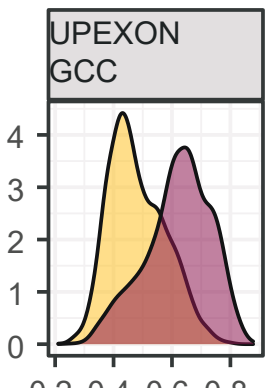

$0.20 .40 .6 \quad 0.8$

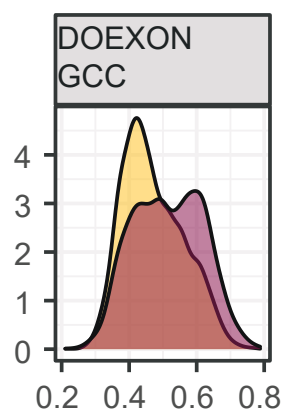

$\begin{array}{llll}0.2 & 0.4 & 0.6 & 0.8\end{array}$

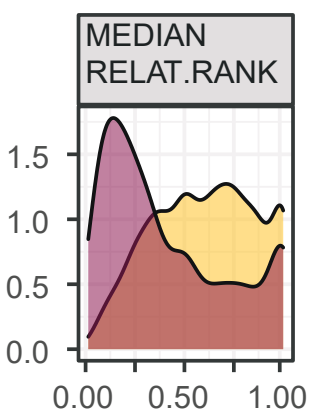

$0.00 \quad 0.50 \quad 1.00$

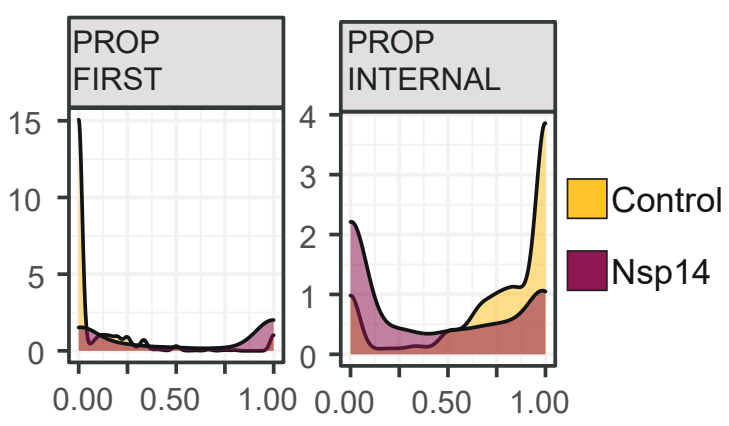

D. $\square$ Control $\square$ Nsp14
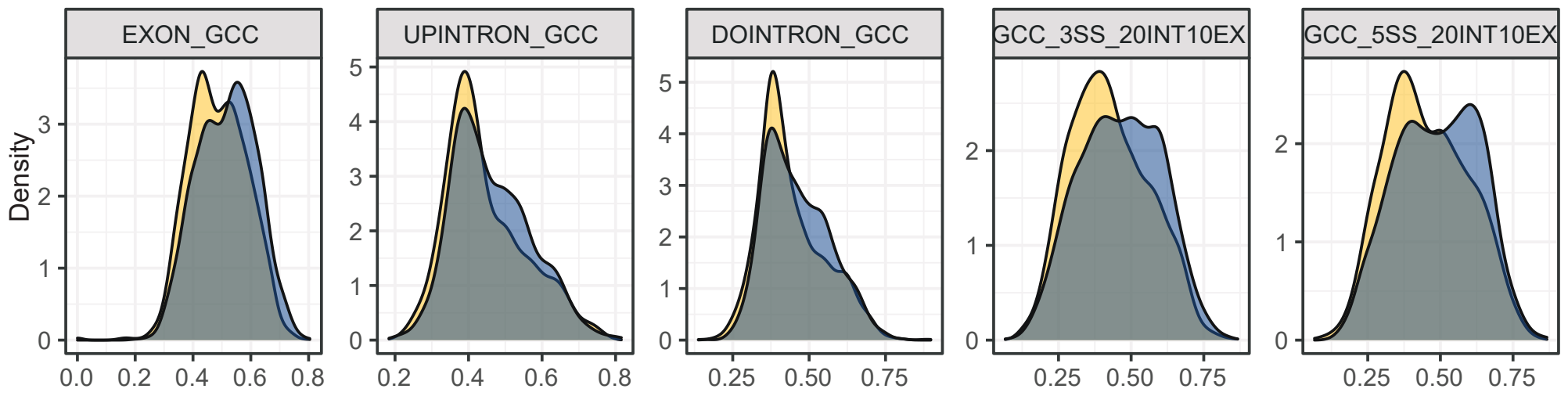

Figure 3 - figure supplement 1 
bioRxiv preprint doi: https://doi.org/10.1101/2021.07.02.450964; this version posted February 16, 2022. The copyright holder for this preprint

A. (which was not certified by peer review) is the author/funder. All rights reserved. No reuse allowed without permission.

\begin{tabular}{|r|c|c|}
\hline exon inclusion & UP & DOWN \\
\hline intron retention & 2139 & 2053 \\
\hline ALT Acceptor & 65 & 98 \\
\hline ALT Donor & 112 & 130 \\
\hline
\end{tabular}

B.

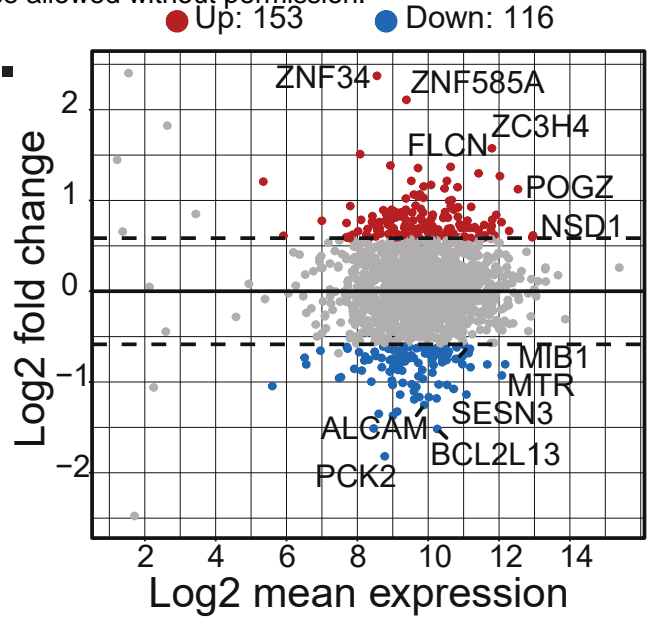

C.

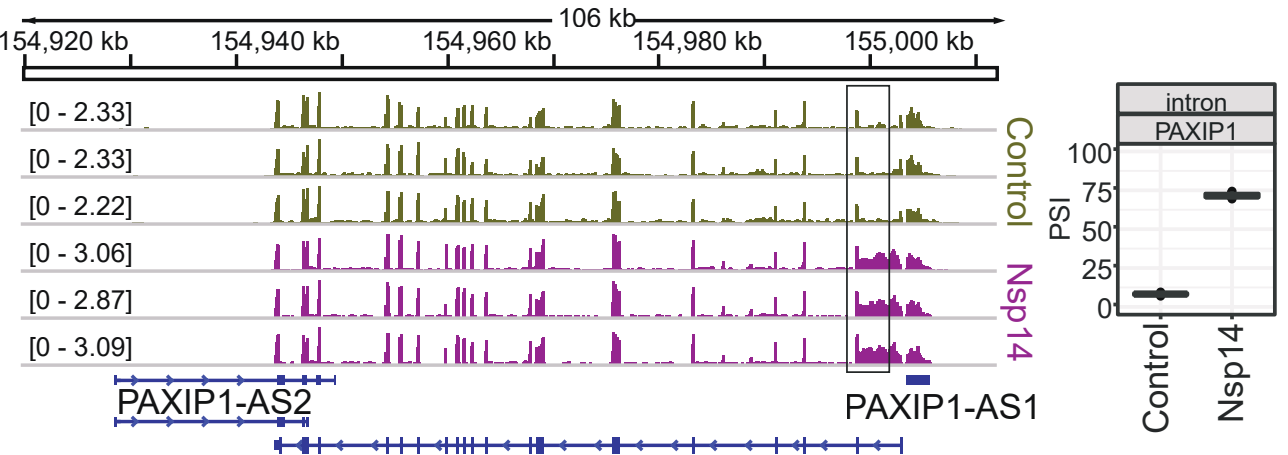

Log2 mean expression

D.

E.
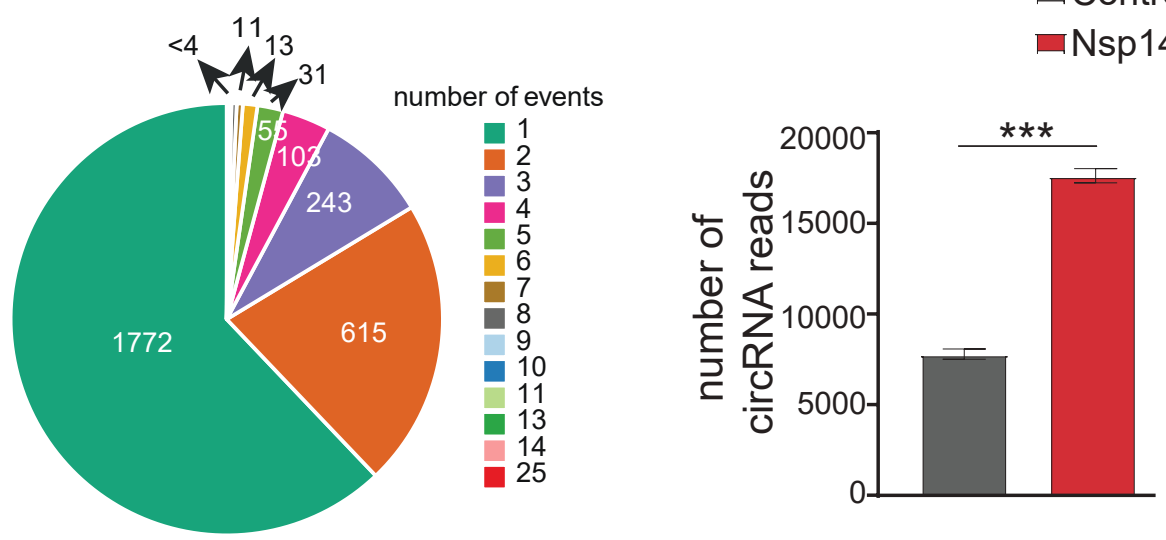

G.

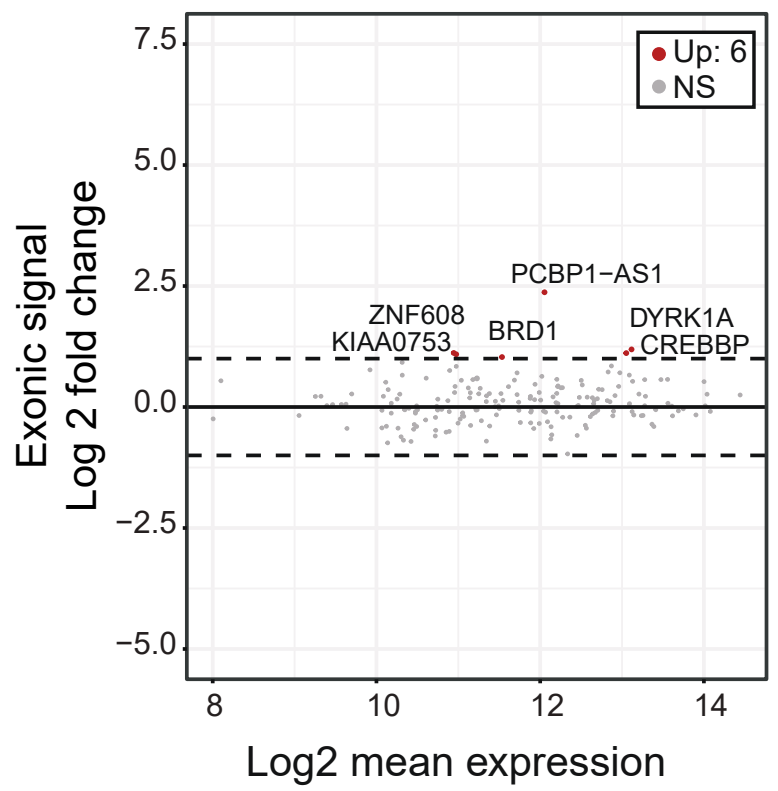

H.
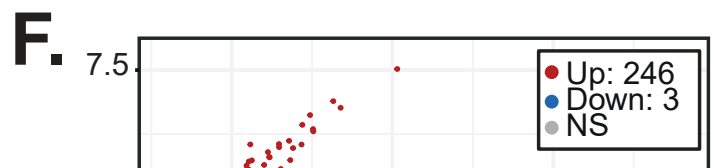

- Control

Nsp14

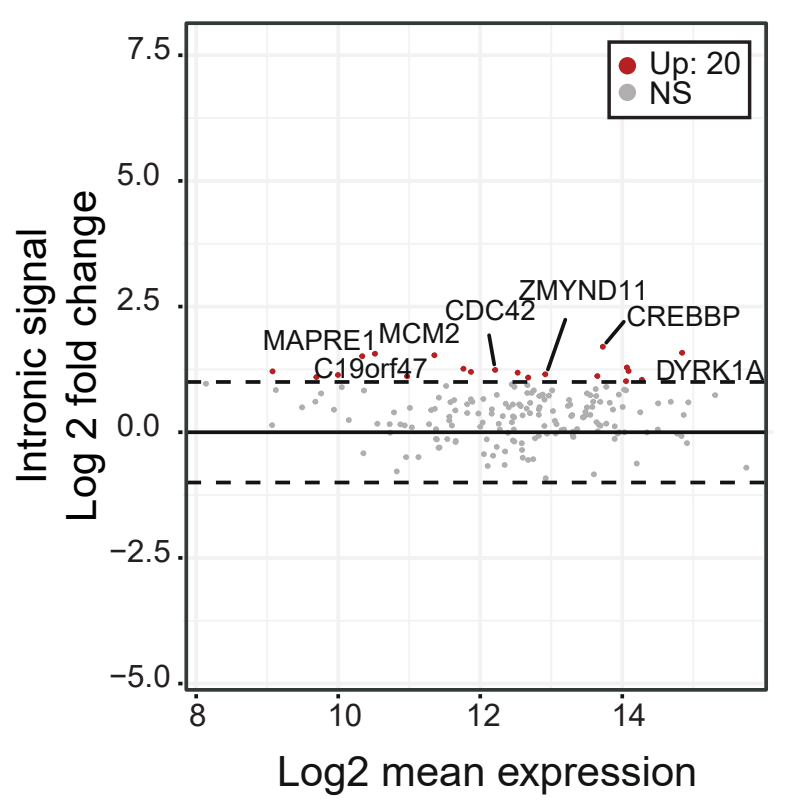


bioRxiv preprint doi: https://doi.org/10.1101/2021.07.02.450964; this version posted February 16, 2022. The copyright holder for this preprint (which was not certified by peer review) is the author/funder. All rights reserved. No reuse allowed without permission.

A.

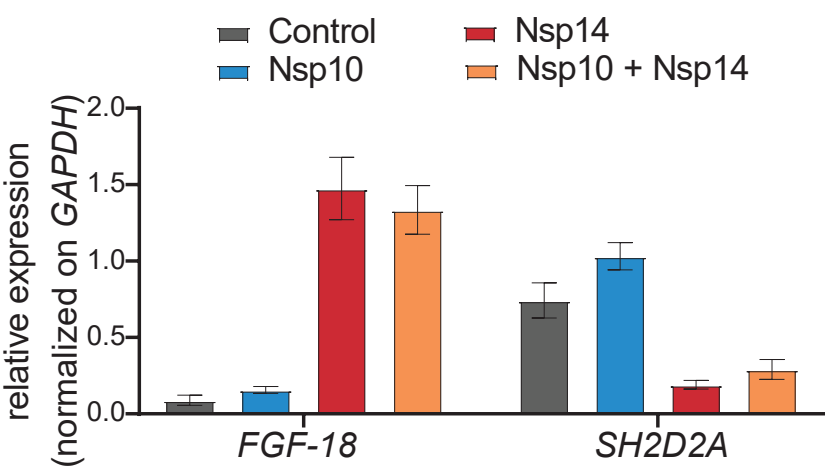

B. oControl ONsp10 ONsp14 ONsp10+Nsp14

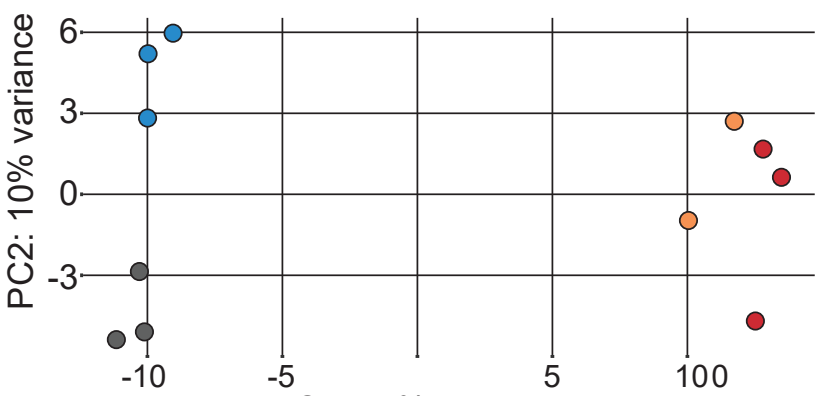

PC1: $81 \%$ variance

C.

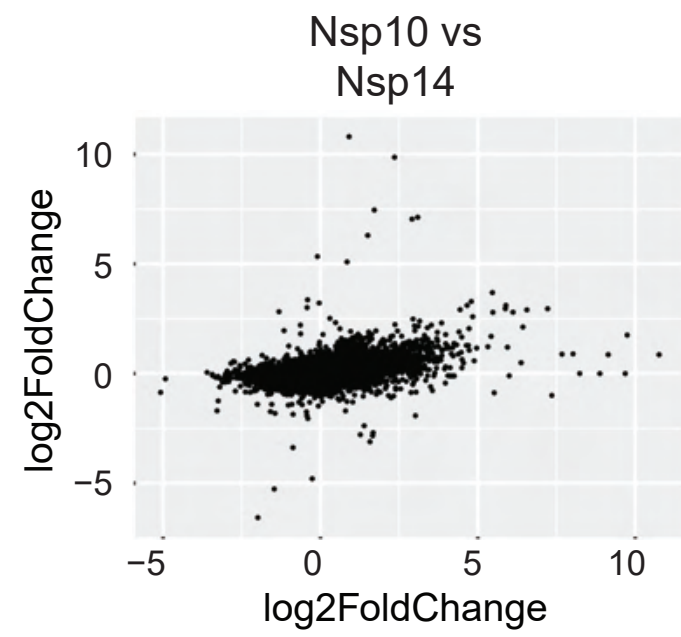


A.

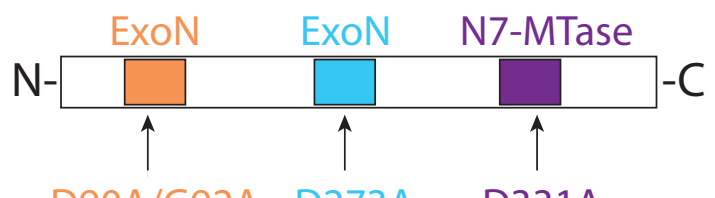

D90A/G92A D273A D331A

C.

D.

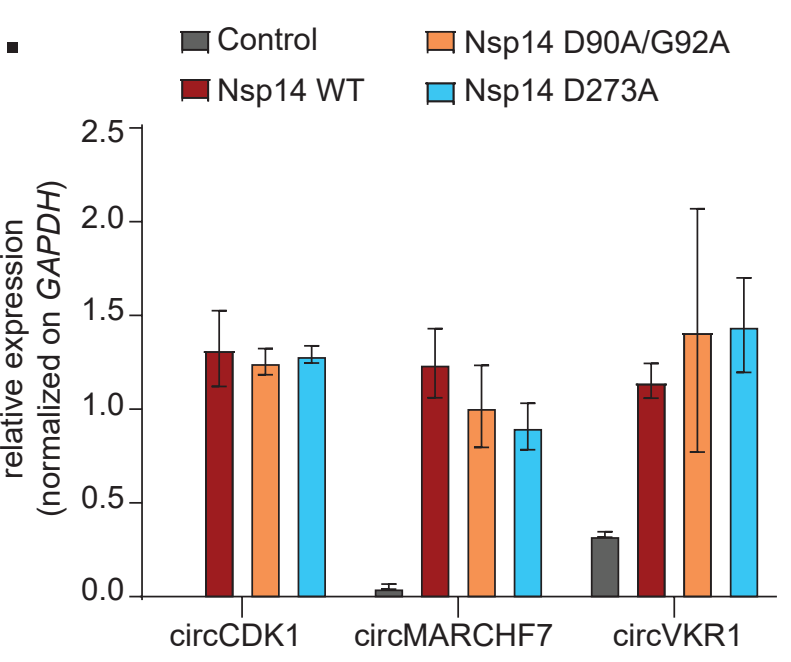

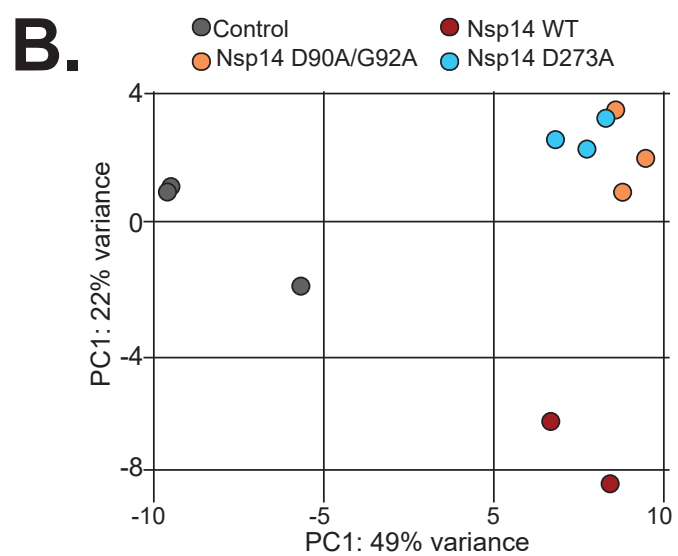

Nsp14 D273A vs Nsp14 WT

10

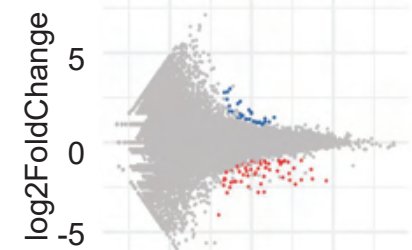

$-10$

110010000

BaseMean
Nsp14 D90A/G92A
vs Control

10

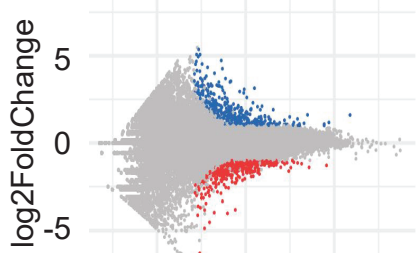

$-10$

110010000

BaseMean
Nsp14 D273A

vs Control

10

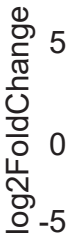

$-10$

110010000

BaseMean

E.

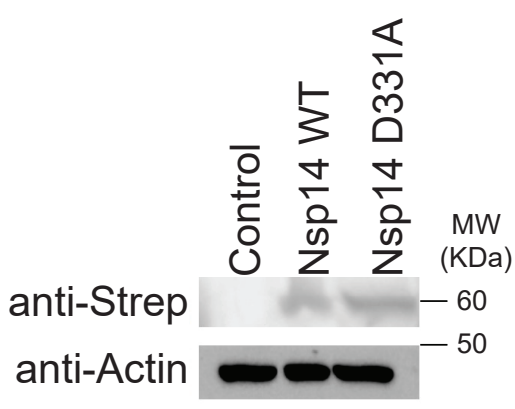


bioRxiv preprint doi: https://doi.org/10.1101/2021.07.02.450964; this version posted February 16,2022 . The copyright holder for this preprint (which was not certified by peer review) is the author/funder. All rights reserved. No reuse allowed without permission.

A.

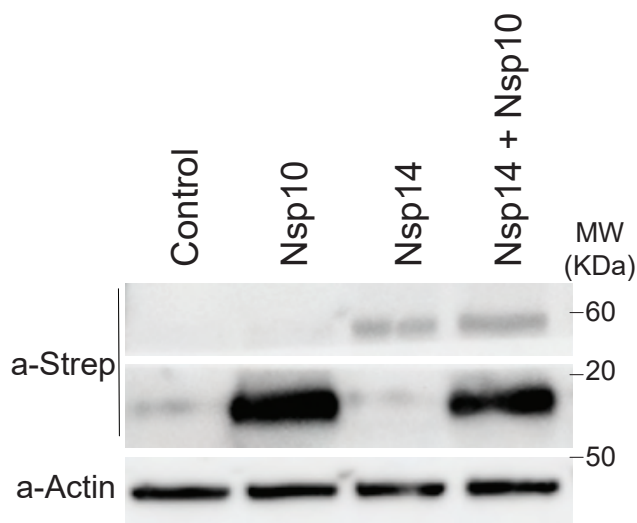

C.

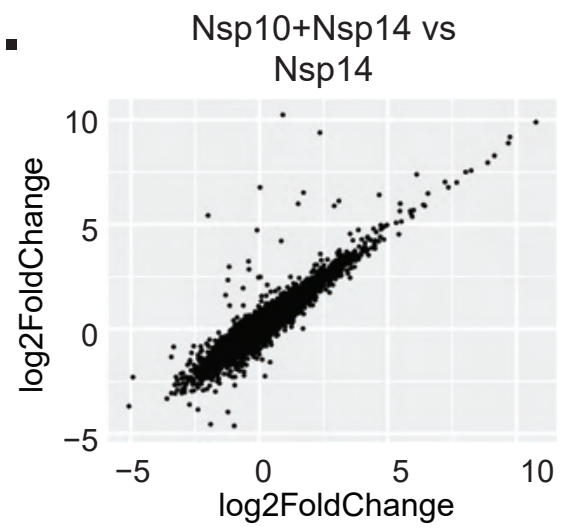

E. Nsp14 D90A/G92A vs
Nsp14 WT

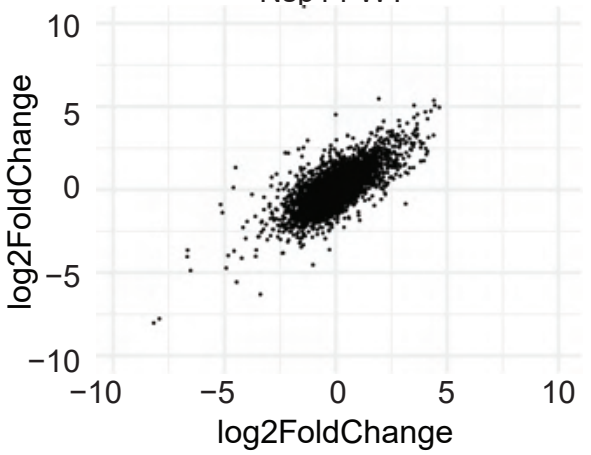

G.

$\square$ Control $\square$ Nsp14 WT

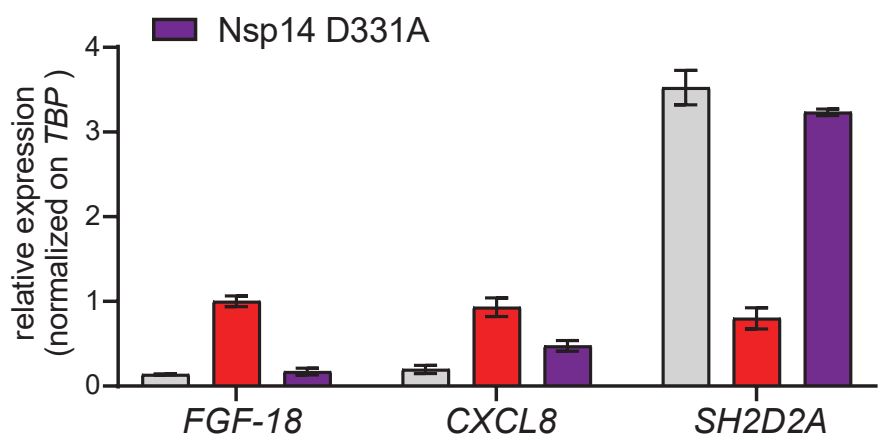

B.

D.
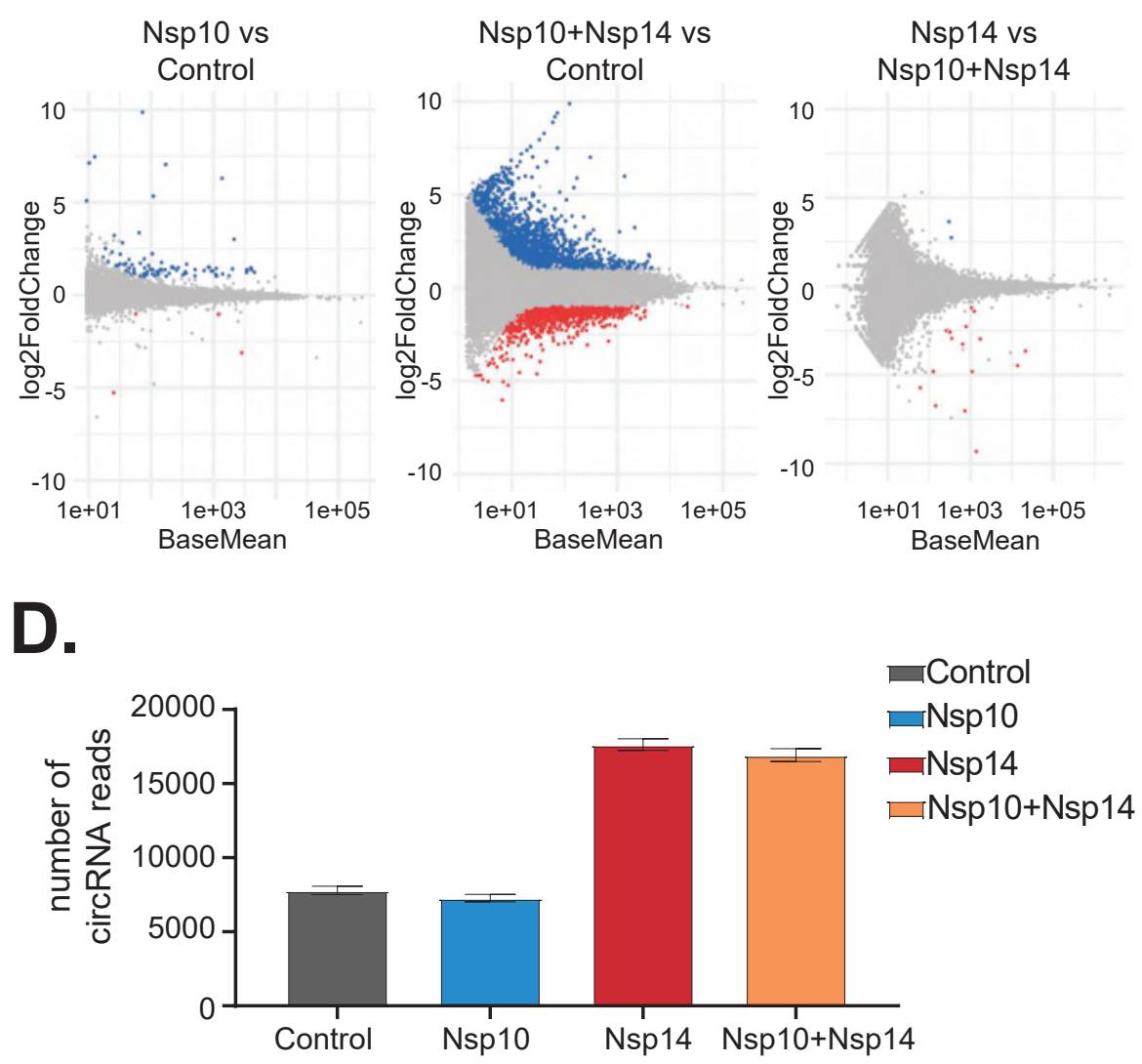

Nsp14 D273A vs

Nsp14 WT

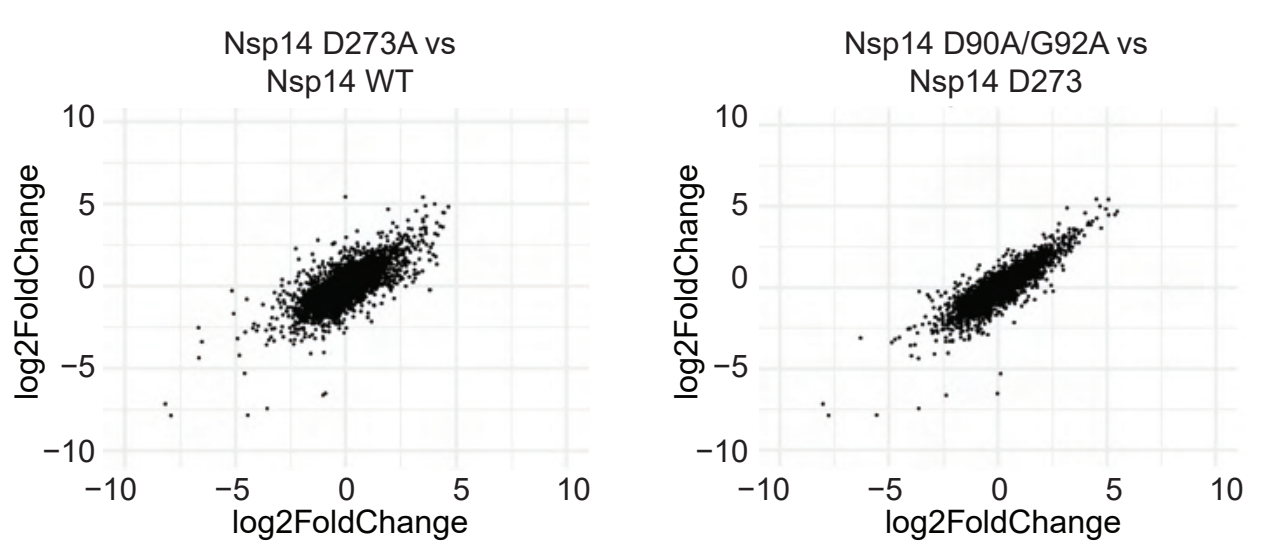

Nsp14 vs

Nsp10+Nsp14

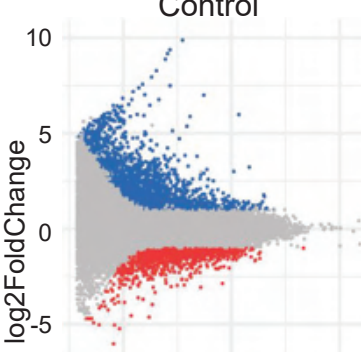

10

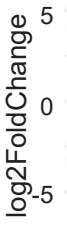

$-10$

$1 \mathrm{e}+01 \quad 1 \mathrm{e}+03 \quad 1 \mathrm{e}+05$ BaseMean

$1 \mathrm{e}+01 \quad 1 \mathrm{e}+03 \quad 1 \mathrm{e}+05$ BaseMean

\section{H.}

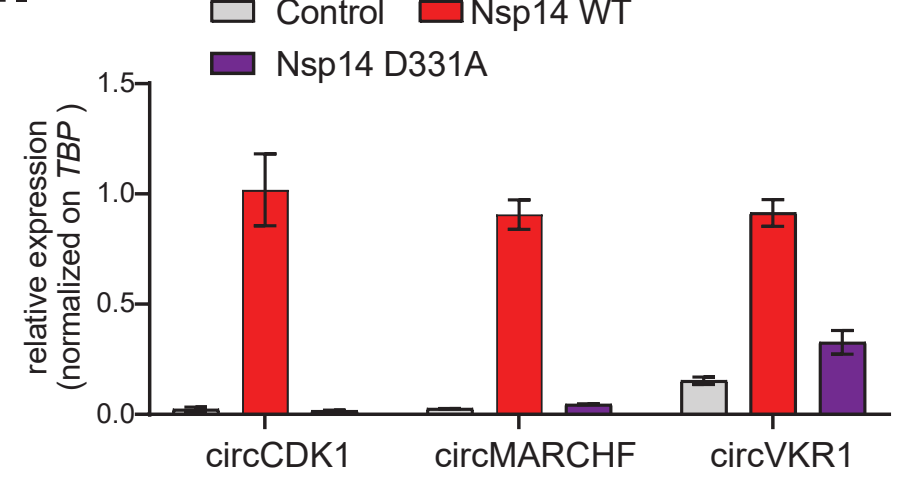


bioRxiv preprint doi: https://doi.org/10.1101/2021.07.02.450964; this version posted February 16,2022 . The copyright holder for this preprint (which was not certified by peer review) is the author/funder. All rights reserved. No reuse allowed without permission.

A.

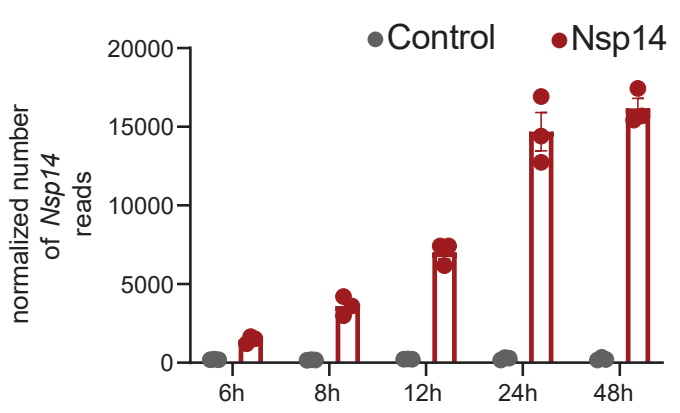

B.

C.
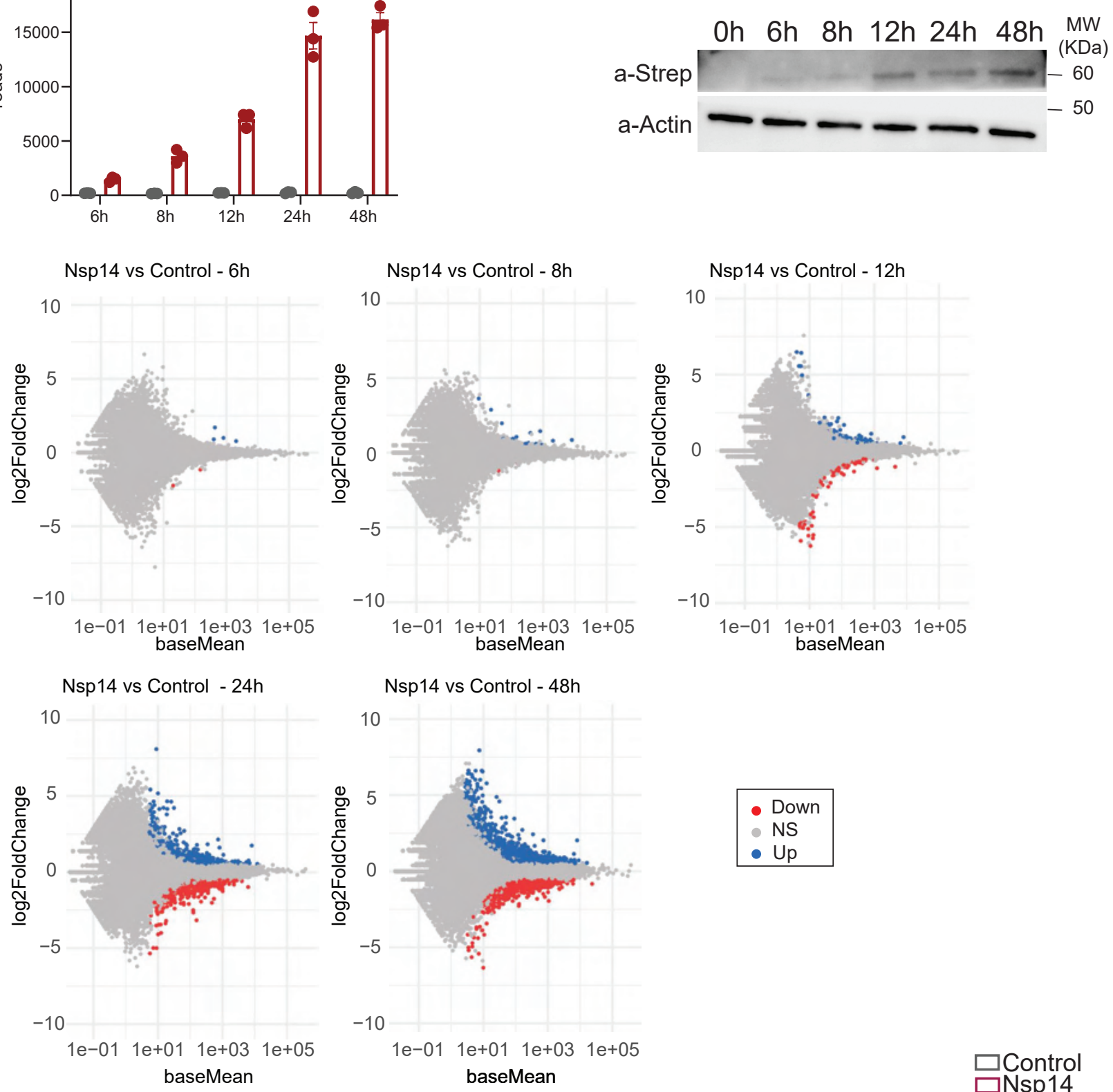

D.

baseMean
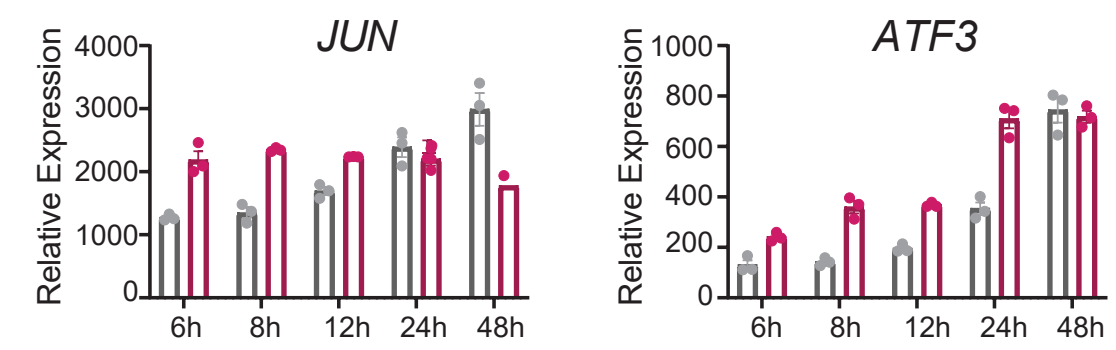

E.
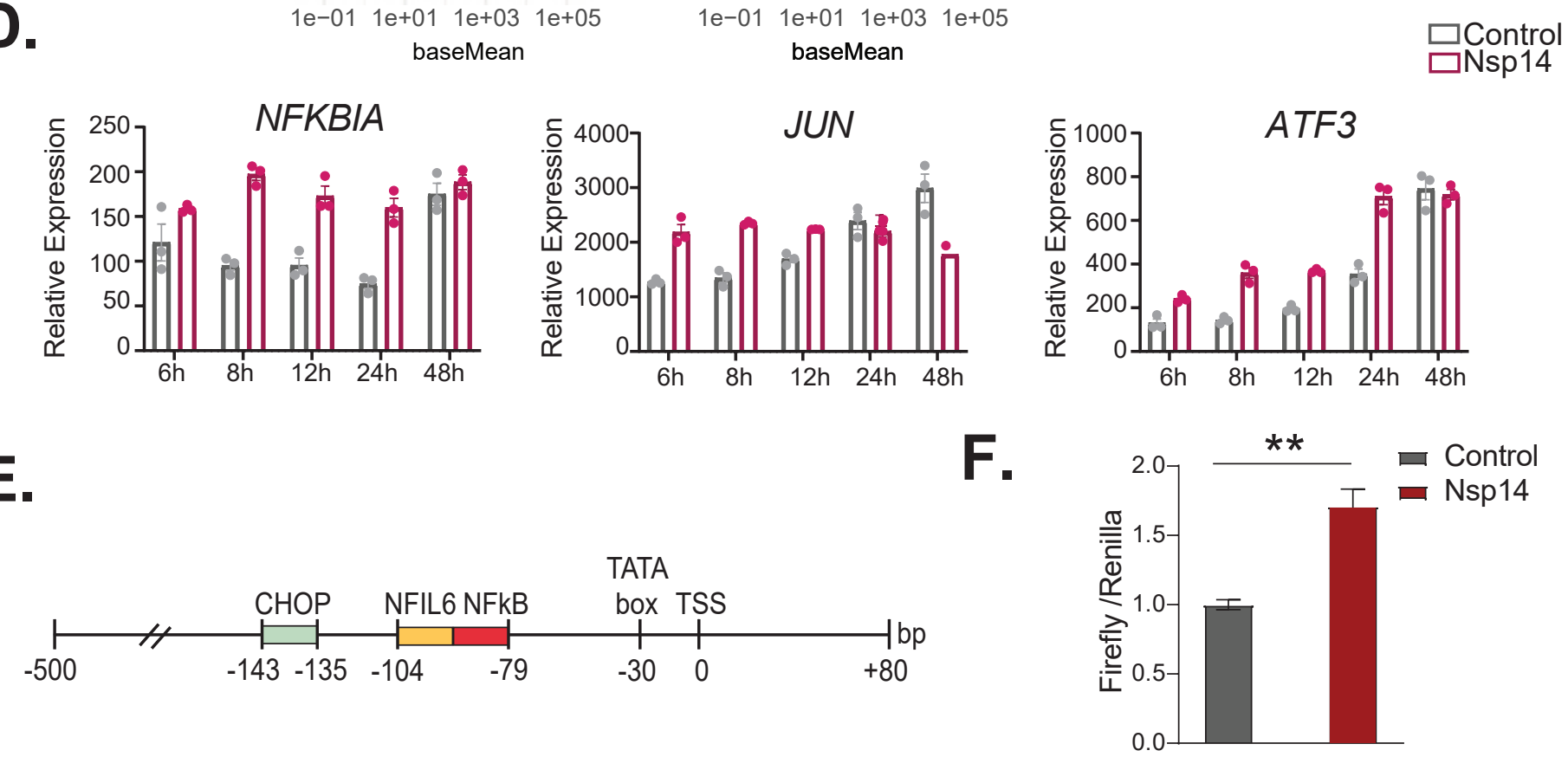
bioRxiv preprint doi: https://doi.org/10.1101/2021.07.02.450964; this version posted February 16,2022 . The copyright holder for this preprint (which was not certified by peer review) is the author/funder. All rights reserved. No reuse allowed without permission.

A.

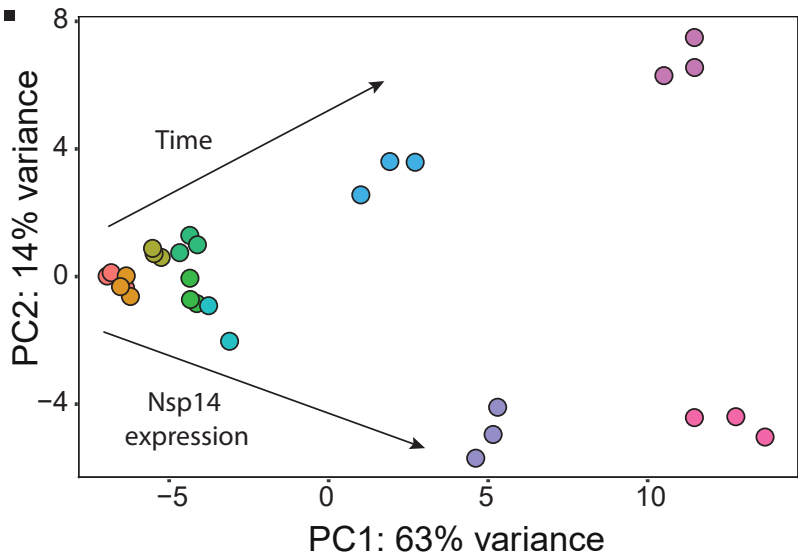

B.
Control 6 h O Nsp14 6h

- Control 8h

O Nsp14 8h

- Control $12 \mathrm{~h}$

- Control $24 \mathrm{~h}$

O Nsp14 24h

o Control 48h

O Nsp14 48h
O Nsp14 12h

c.

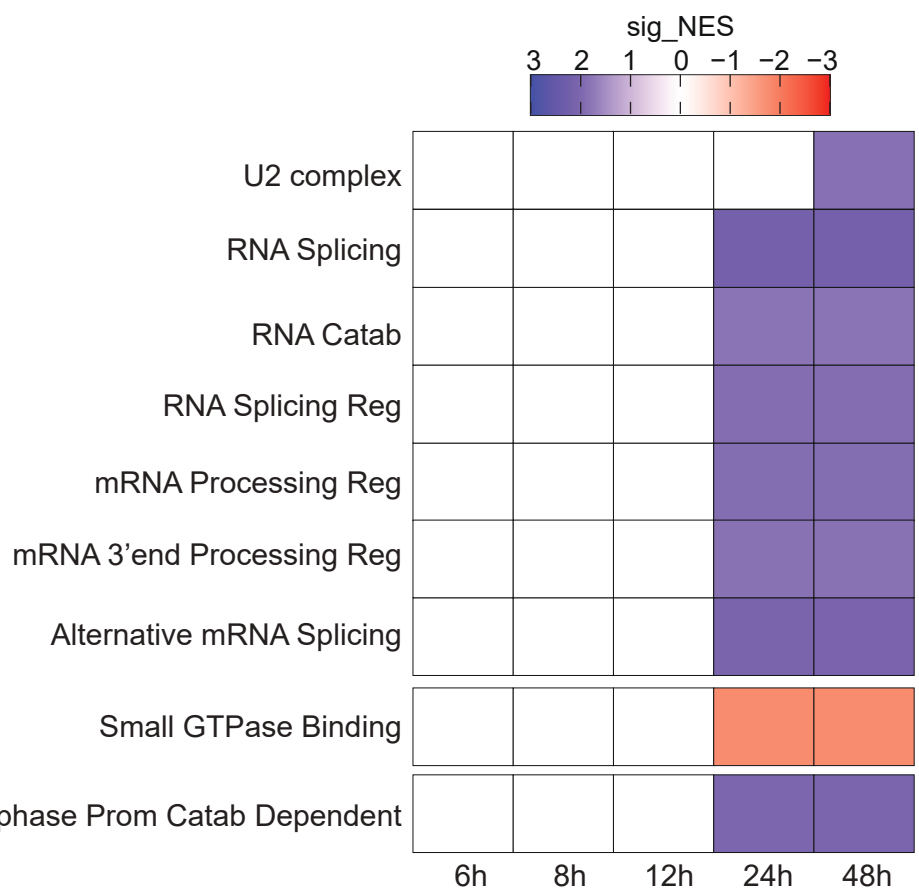

D.
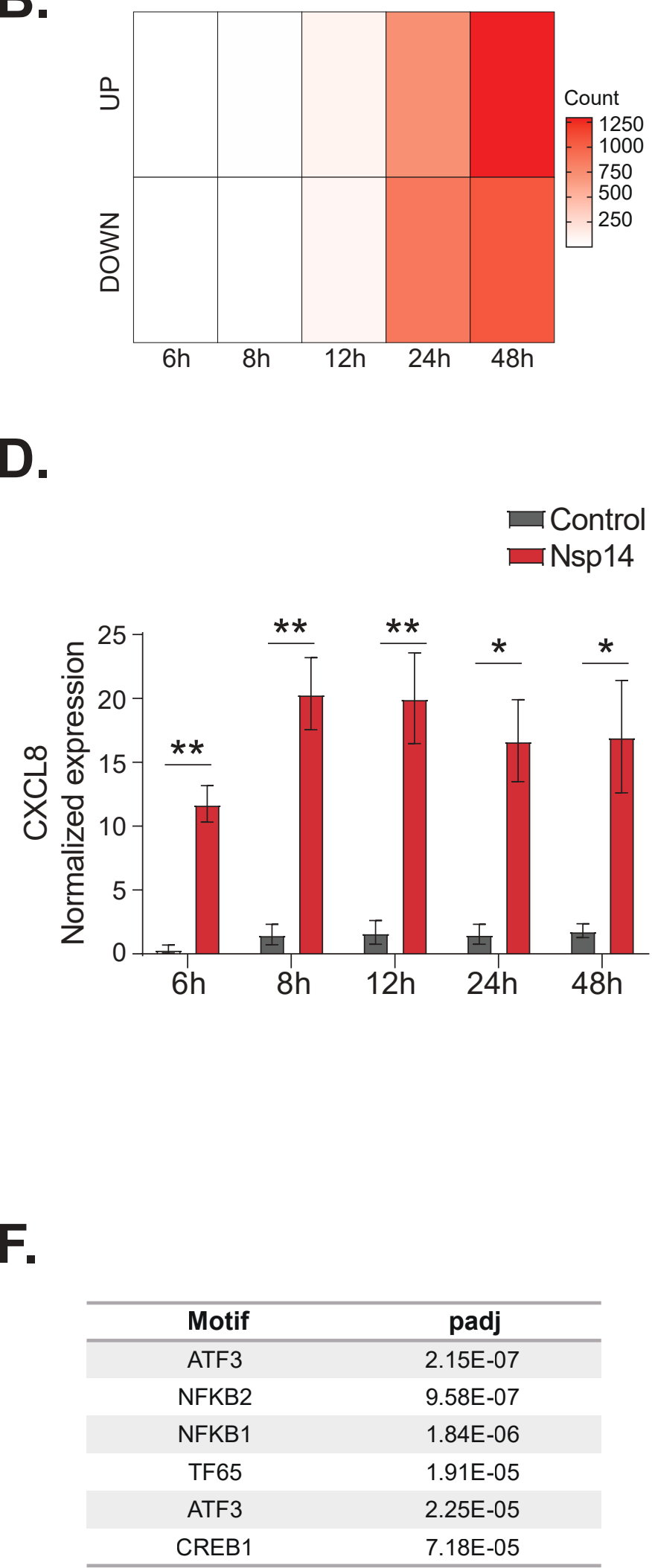
bioRxiv preprint doi: https://doi.org/10.1101/2021.07.02.450964; this version posted February 16,2022 . The copyright holder for this preprint (which was not certified by peer review) is the author/funder. All rights reserved. No reuse allowed without permission.
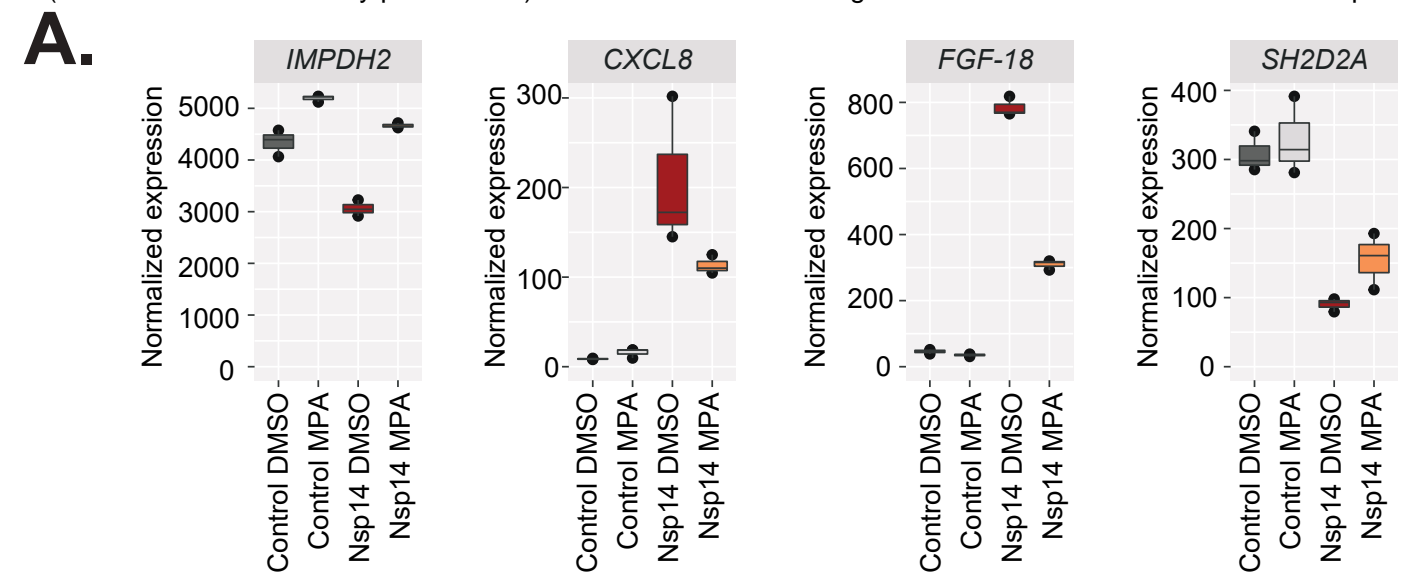

B.
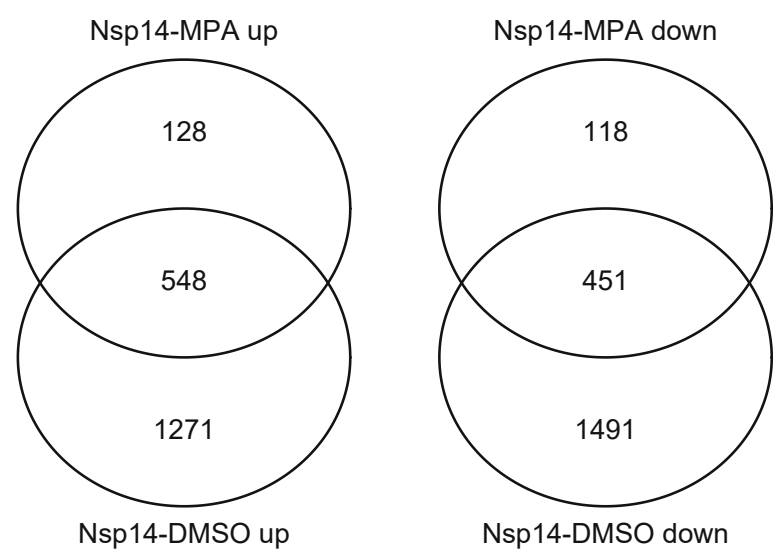

D.

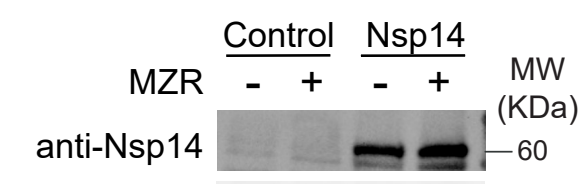

anti-IMPDH2

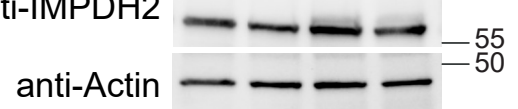

F.

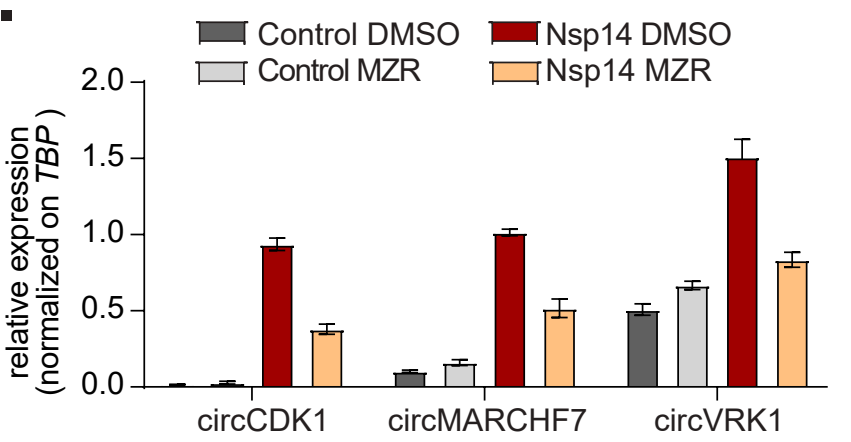

E.

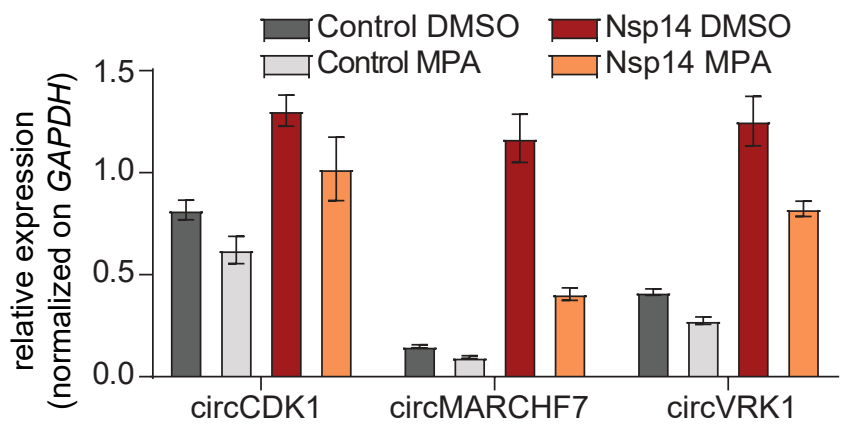

G.

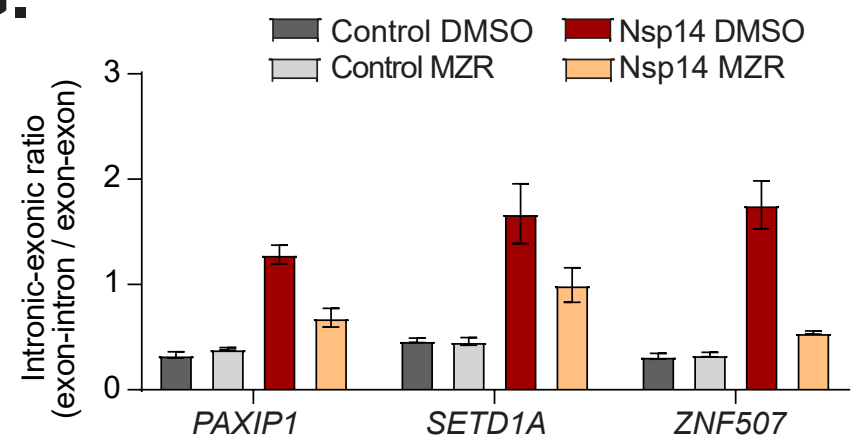


bioRxiv preprint doi: https://doi.org/10.1101/2021.07.02.450964; this version posted February 16,2022 . The copyright holder for this preprint (which was not certified by peer review) is the author/funder. All rights reserved. No reuse allowed without permission.

A.

\begin{tabular}{|c|c|}
\hline \multicolumn{2}{|c|}{$12 \mathrm{~h}$} \\
\hline Control & Nsp14 \\
\hline 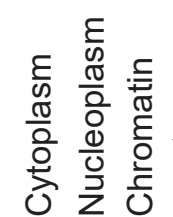 & 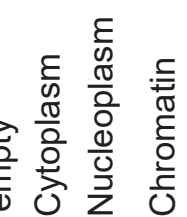 \\
\hline
\end{tabular}
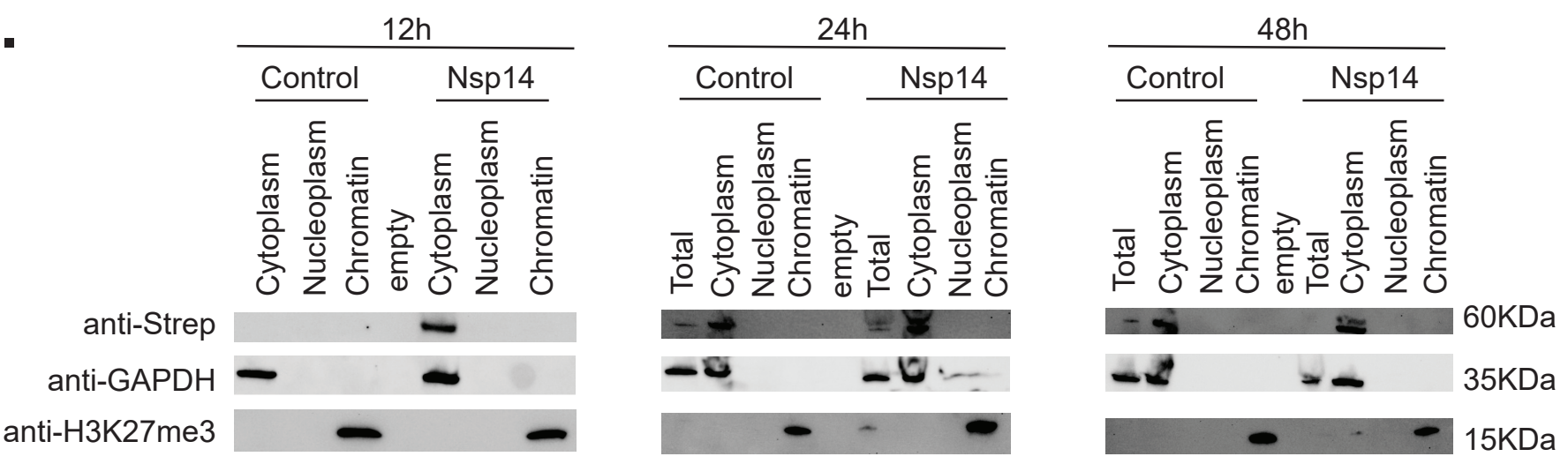

B.
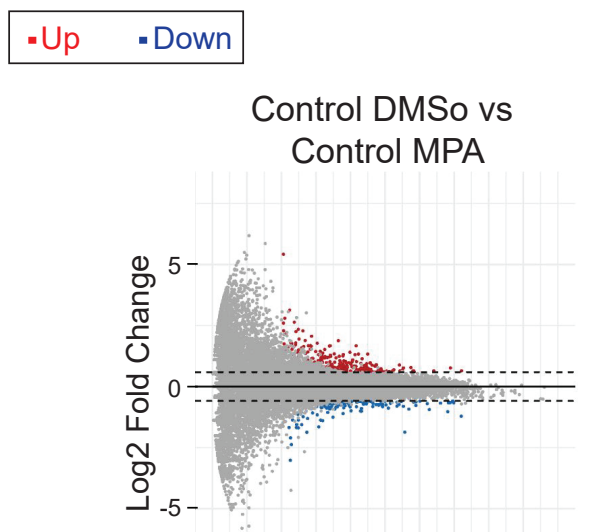

$\begin{array}{lllllllllll}1 & 1 & 1 & 1 & 1 & 1 & 1 & 1 & 1 & 1 & 1 \\ 0 & 2 & 4 & 6 & 7 & 8 & 10 & 12 & 14 & 16 & 18\end{array}$ Log2 mean expression

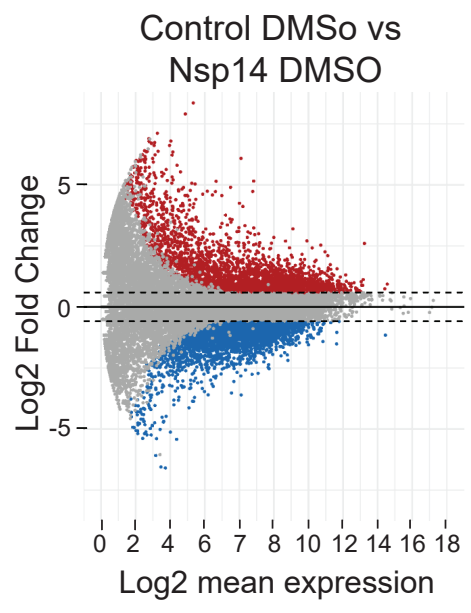

Nsp14 DMSo vs
Nsp14 MPA

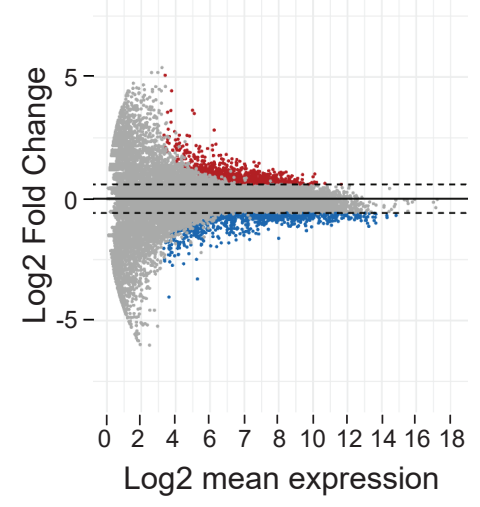

Control DMSo vs

Nsp14 MPA

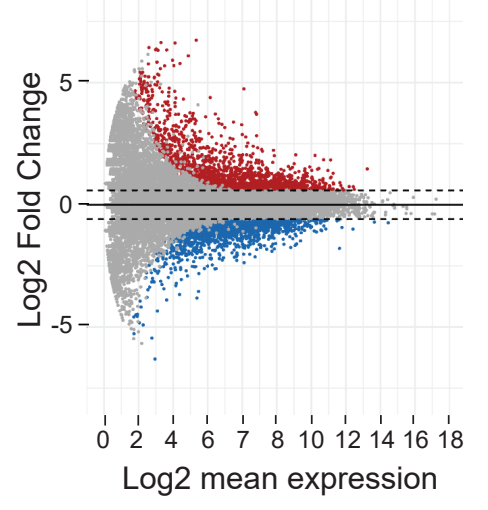


bioRxiv preprint doi: https://doi.org/10.1101/2021.07.02.450964; this version posted February 16, 2022. The copyright holder for this preprint (which was not certified by peer review) is the author/funder. All rights reserved. No reuse allowed without permission.

A.

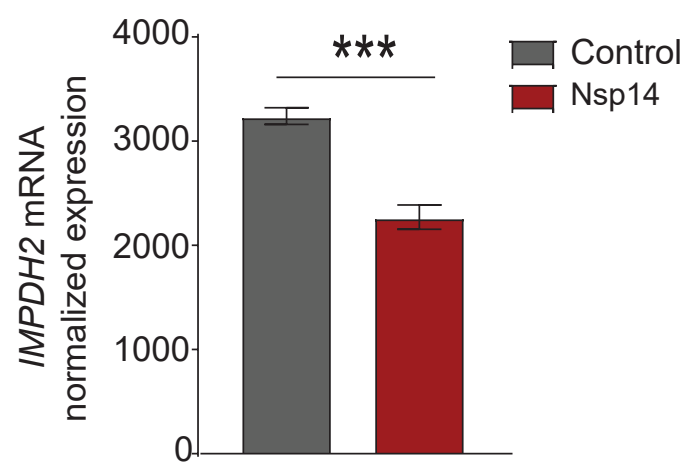

C.

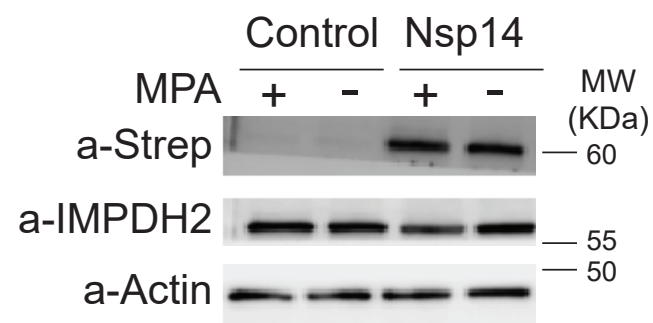

E.

\begin{tabular}{ccc}
\hline Comparison & $\begin{array}{c}\text { Number of } \\
\text { Up DEGs }\end{array}$ & $\begin{array}{c}\text { Number of } \\
\text { Down DEGs }\end{array}$ \\
\hline Nsp14-DMSO vs Control-DMSO & 1942 & 1819 \\
Nsp14-MPA vs Control-MPA & 569 & 676 \\
Control-MPA vs Control-DMSO & 27 & 88 \\
\hline
\end{tabular}

G.

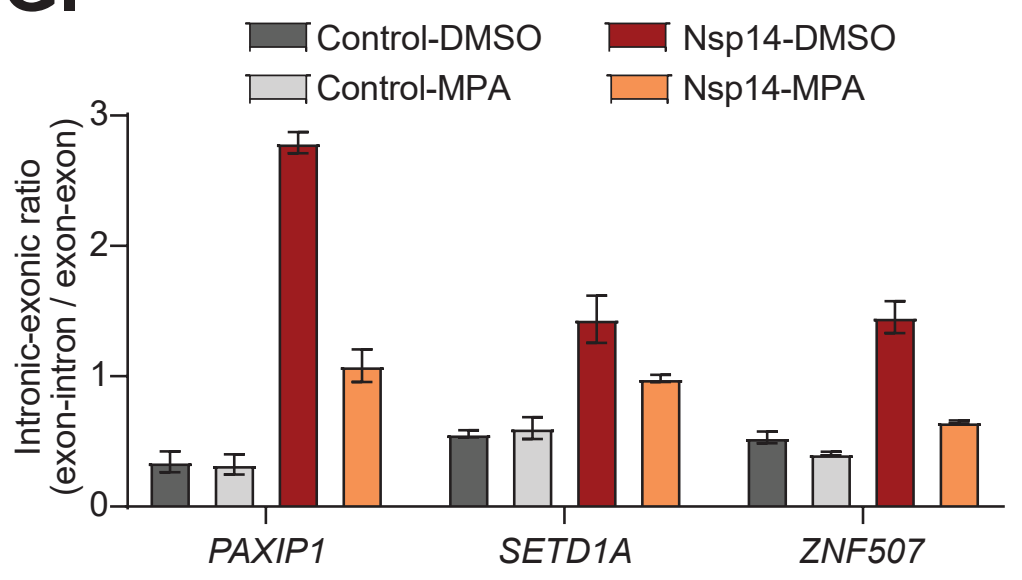

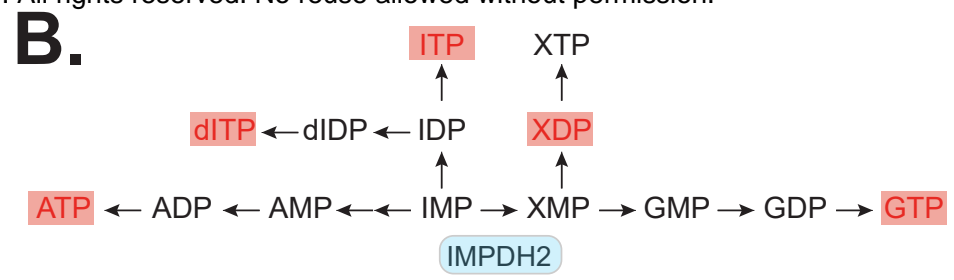

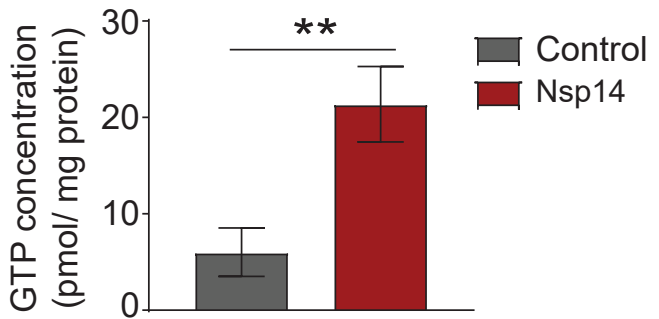

D.

Control-DMSO Nsp14-DMSO OControl-MPA ONsp14-MPA

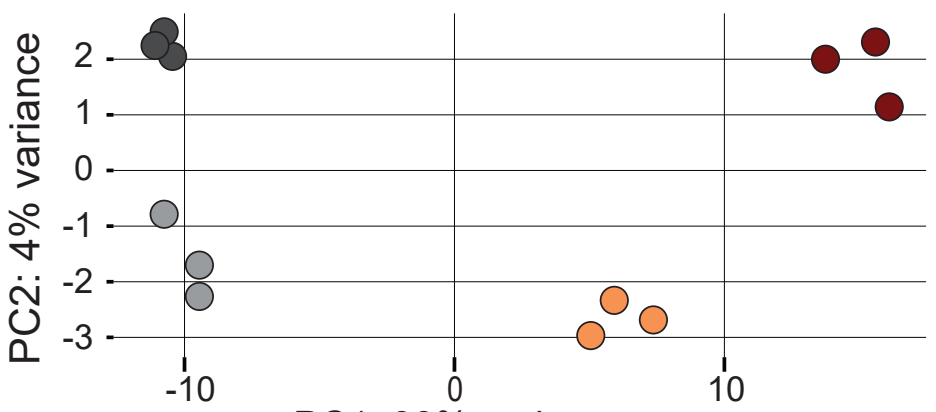

PC1: $90 \%$ variance
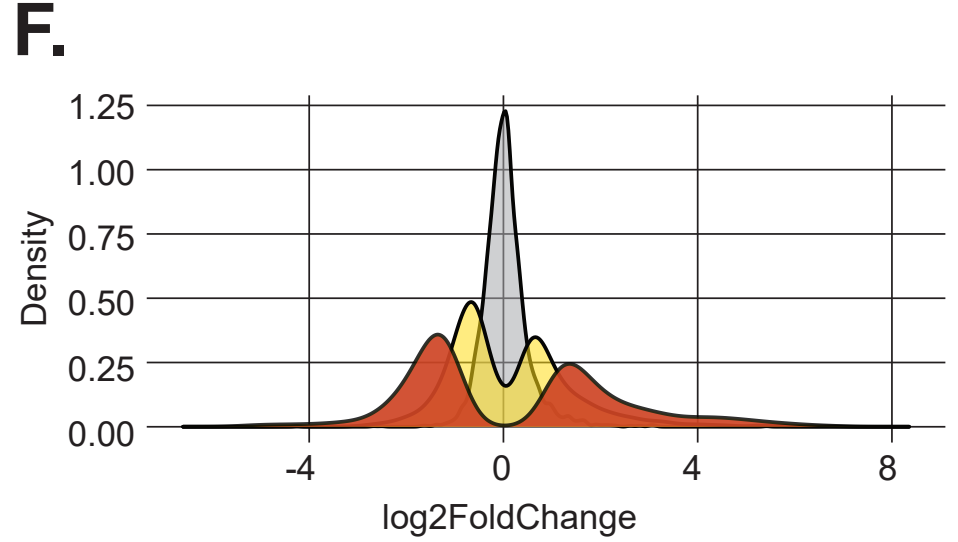

$\square$ Control DMSO vs Control MPA

$\square$ Nsp14 MPA vs Control MPA

Nsp14 DMSO vs Control DMSO 